\title{
Cu(II)-mediated Cross-Dehydrogenative Coupling of Indolines with Sulfonamides, Carboxamides and Amines
}

Mohit Kumar, ${ }^{\S}$ Raziullah, ${ }^{\dagger}$ Afsar Ali Khan, ${ }^{\S}$ Ashfaq Ahmad, ${ }^{\dagger}$ Himangsu Sekhar Dutta, ${ }^{\S}$ Ruchir Kant, ${ }^{\dagger}$ Dipankar Koley*,†,

${ }^{\dagger}$ Medicinal and Process Chemistry Division and ${ }^{\ddagger}$ Molecular and Structural Biology Division, CSIR-Central Drug Research Institute, Lucknow, 226031, India. ${ }^{\S}$ Academy of Scientific and Innovative Research, New Delhi, 110001, India 


\section{Index of Contents}

$\begin{array}{ll}\text { No. Contents } & \text { Page no }\end{array}$

$\begin{array}{llr}\text { I Crystal structures of 3ah } & \text { SI- } 3\end{array}$

II Copies of ${ }^{1} \mathrm{H}$ and ${ }^{13} \mathrm{C}$ NMR spectra of products 


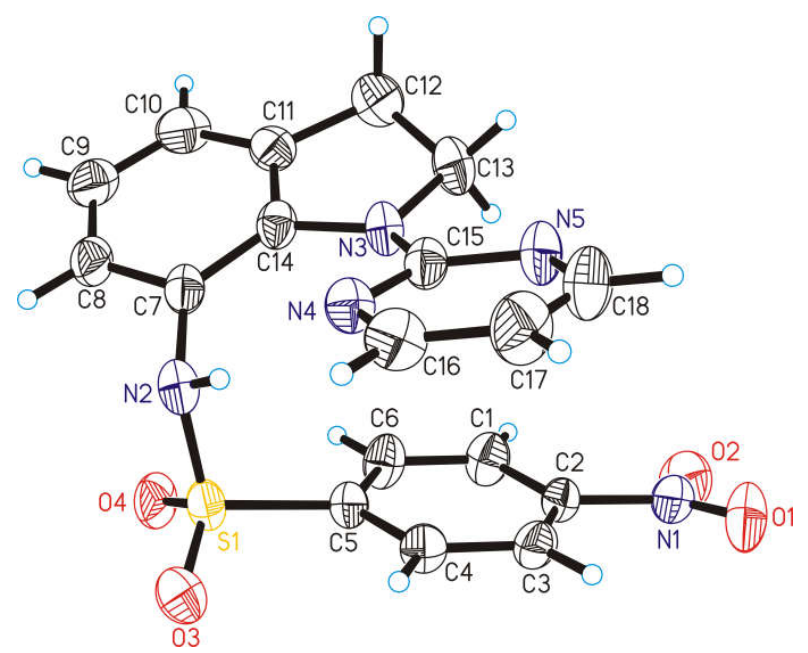

Figure S1: ORTEP diagram drawn with 30\% ellipsoid probability for non-H atoms of the crystal structure of compound 3ah determined at $293 \mathrm{~K}$.

Crystallization: Crystals of compound 3ah were grown from the solvent 30\% (Ethylacetate/Hexane) by slow evaporation method.

\section{X-Ray Data Collection and Structure Refinement Details:}

A good quality single crystal of size $0.53 \times 0.35 \times 0.35 \mathrm{~mm}$, was selected under a polarizing microscope and was mounted on a glass fiber for data collection. Single crystal X-ray data for compound 3ah were collected on the Rigaku Kappa 3 circle diffractometer equipped with the AFC12 goniometer and enhanced sensitivity (HG) Saturn724+ CCD detector in the 4x4 bin mode using the monochromated Mo-K $\alpha$ radiation generated from the microfocus sealed tube MicroMax-003 X-ray generator equipped with specially designed confocal multilayer optics. Data collection was performed using $\omega$-scans of $0.5^{\circ}$ steps at 293(2) K. Cell determination, data collection and data reduction was performed using the Rigaku CrystalClear-SM Expert 2.1 b24 software. Structure solution and refinement were performed by using SHELXTL-NT ${ }^{5}$. Refinement of coordinates and anisotropic thermal parameters of non-hydrogen atoms were carried out by the full-matrix least-squares method. The hydrogen atoms attached to carbon atoms were generated with idealized geometries and isotropically refined using a riding model. 
Table S1: Crystal data and structure refinement details for $\mathbf{3 a h}$

\begin{tabular}{c|c}
\hline Compound & 3ah \\
\hline Empirical formula & $\mathrm{C}_{18} \mathrm{H}_{15} \mathrm{~N}_{5} \mathrm{O}_{4} \mathrm{~S}$ \\
Formula weight & 397.41 \\
Crystal System & Monoclinic \\
Space group & $P 21 / \mathrm{c}$ \\
$a(\AA)$ & $14.950(7)$ \\
$b(\AA)$ & $12.555(5)$ \\
$c(\AA)$ & $10.281(5)$ \\
$\alpha\left(^{\circ}\right)$ & 90.00 \\
$\beta\left(^{\circ}\right)$ & $108.760(7)$ \\
$\gamma\left(^{\circ}\right)$ & 90.00 \\
$V\left(\AA^{3}\right)$ & $1827.2(14)$ \\
$Z$ & 4 \\
$\mathrm{D}_{\mathrm{c}}\left(\mathrm{g} / \mathrm{cm}^{3}\right)$ & 1.445 \\
$F_{000}$ & 824 \\
$\mu\left(\mathrm{mm}^{-1}\right)$ & 0.214 \\
$\theta_{\text {max }}\left({ }^{\circ}\right)$ & 25.39 \\
Total reflections & 11690 \\
Unique reflections & 3322 \\
Reflections $[I>2 \sigma(I)]$ & 2160 \\
Parameters & 257 \\
$R_{\text {int }}$ & 0.0598 \\
Goodness-of-fit & 0.871 \\
$R\left[F^{2}>2 \sigma\left(F^{2}\right)\right]$ & 0.0419 \\
$w R\left(F^{2}\right.$, all data $)$ & 0.1078 \\
$\mathrm{CCDC} \mathrm{No}$. & 1917173 \\
\hline
\end{tabular}

\section{References:}

1. CrystalClear 2.1, Rigaku Corporation, Tokyo, Japan

2. Sheldrick, G. M. Acta Crystallogr., Sect. A 2008, 64, 112-122. 


\section{${ }^{1}$ H NMR and ${ }^{13}$ C NMR Spectra}

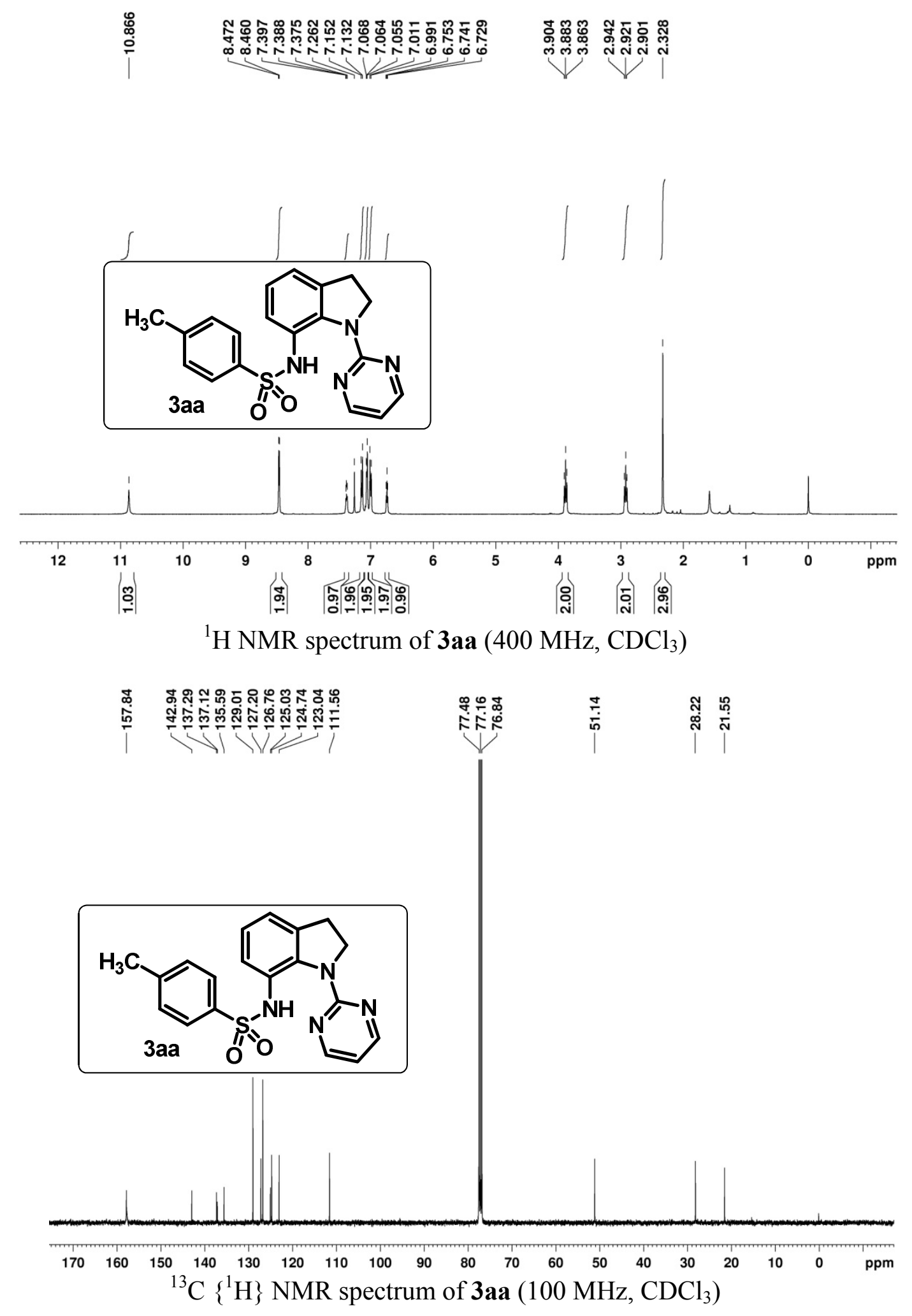




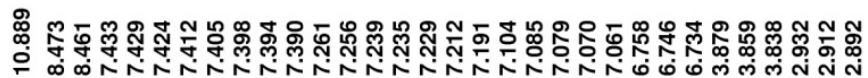

管
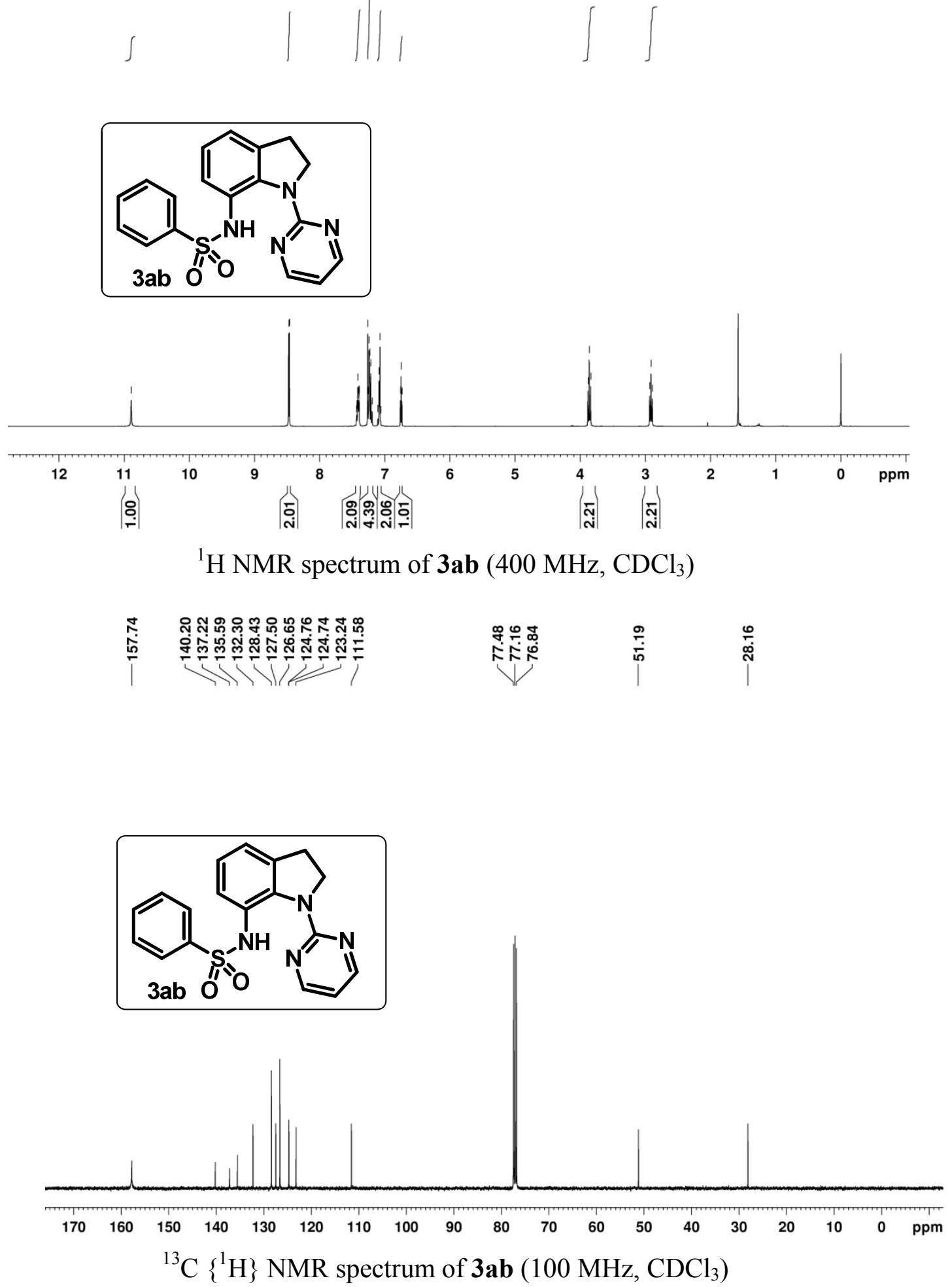

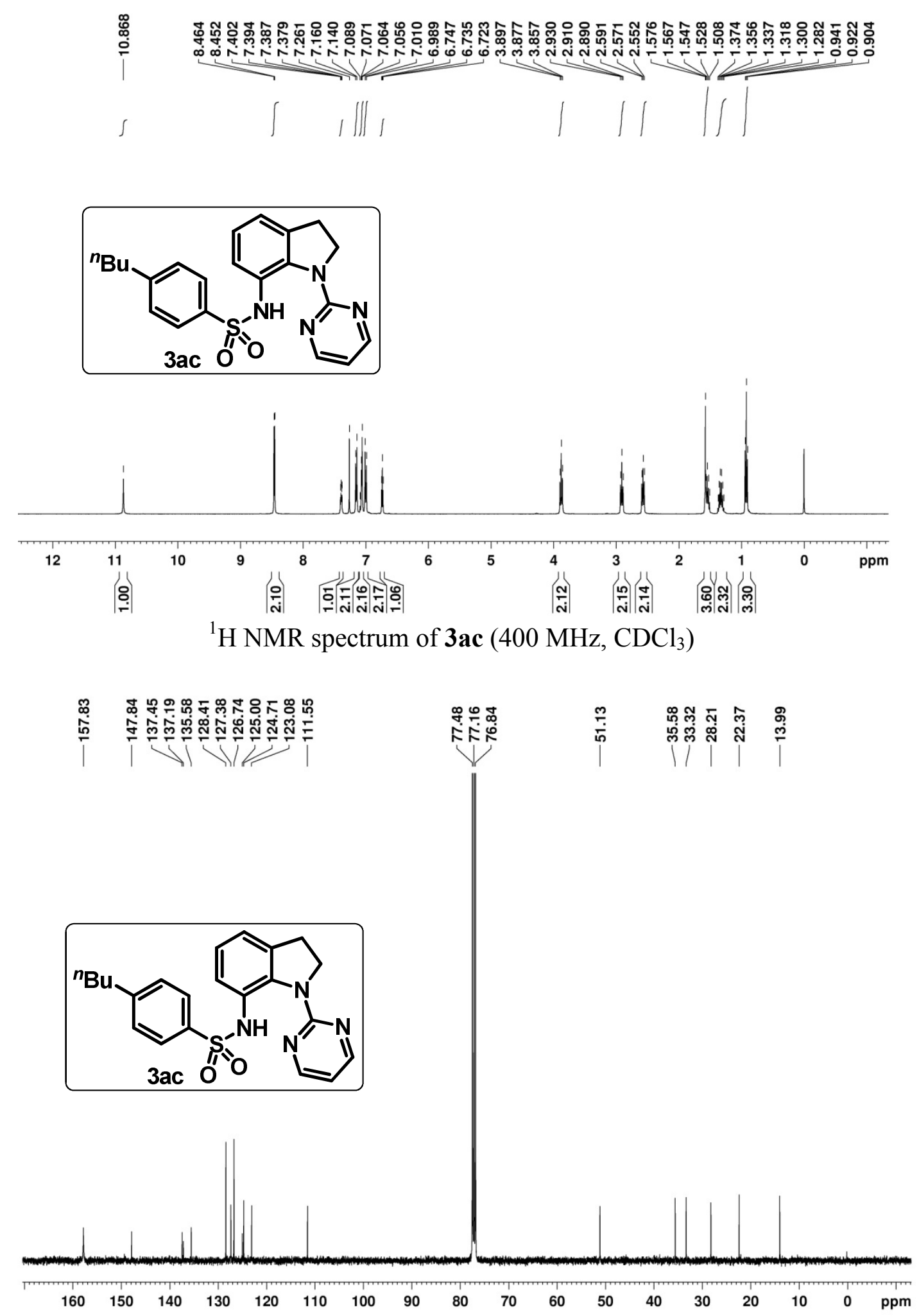

${ }^{13} \mathrm{C}\left\{{ }^{1} \mathrm{H}\right\}$ NMR spectrum of $\mathbf{3 a c}\left(100 \mathrm{MHz}, \mathrm{CDCl}_{3}\right)$ 
|
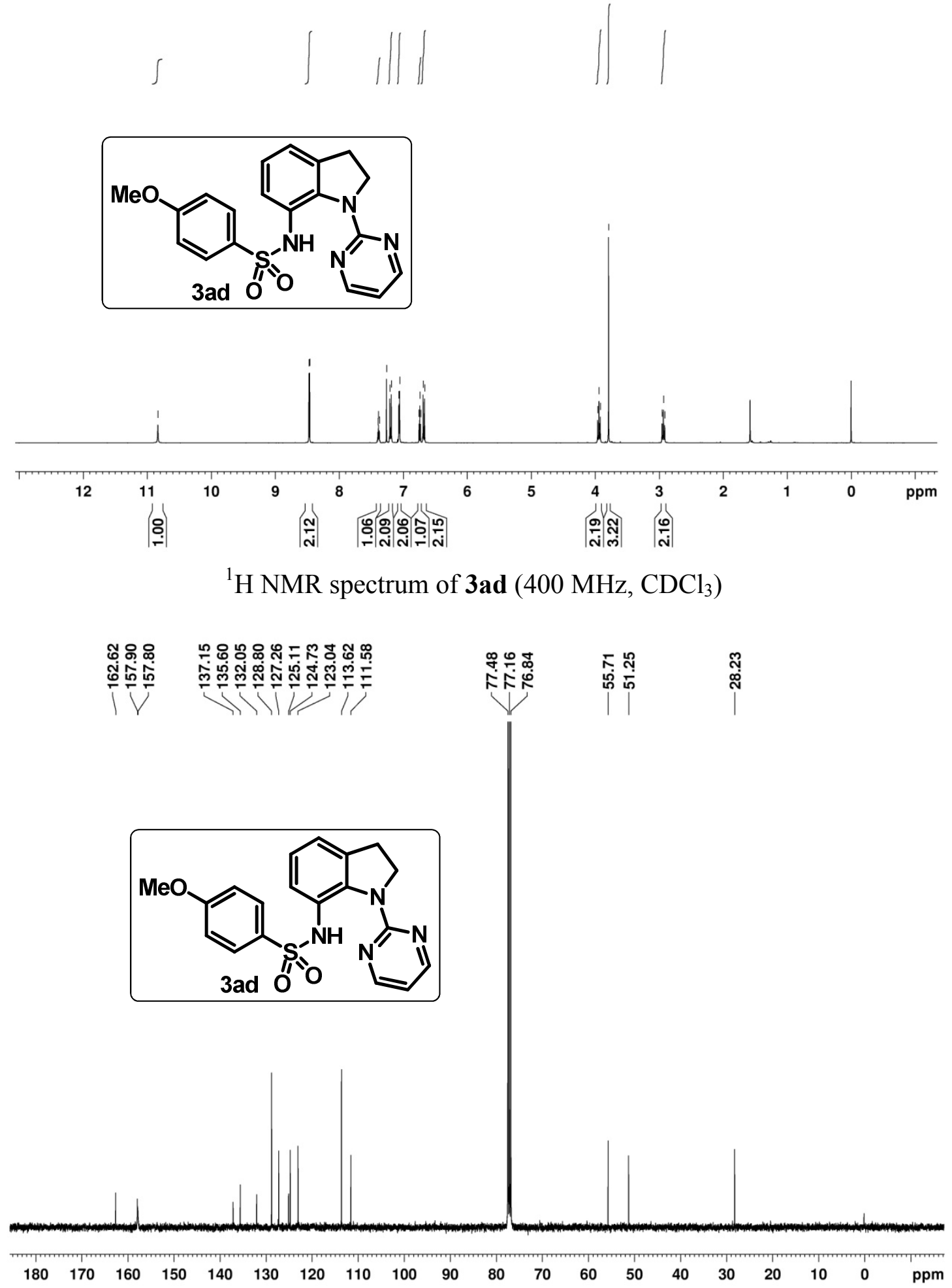

${ }^{13} \mathrm{C}\left\{{ }^{1} \mathrm{H}\right\}$ NMR spectrum of $\mathbf{3 a d}\left(100 \mathrm{MHz}, \mathrm{CDCl}_{3}\right)$ 


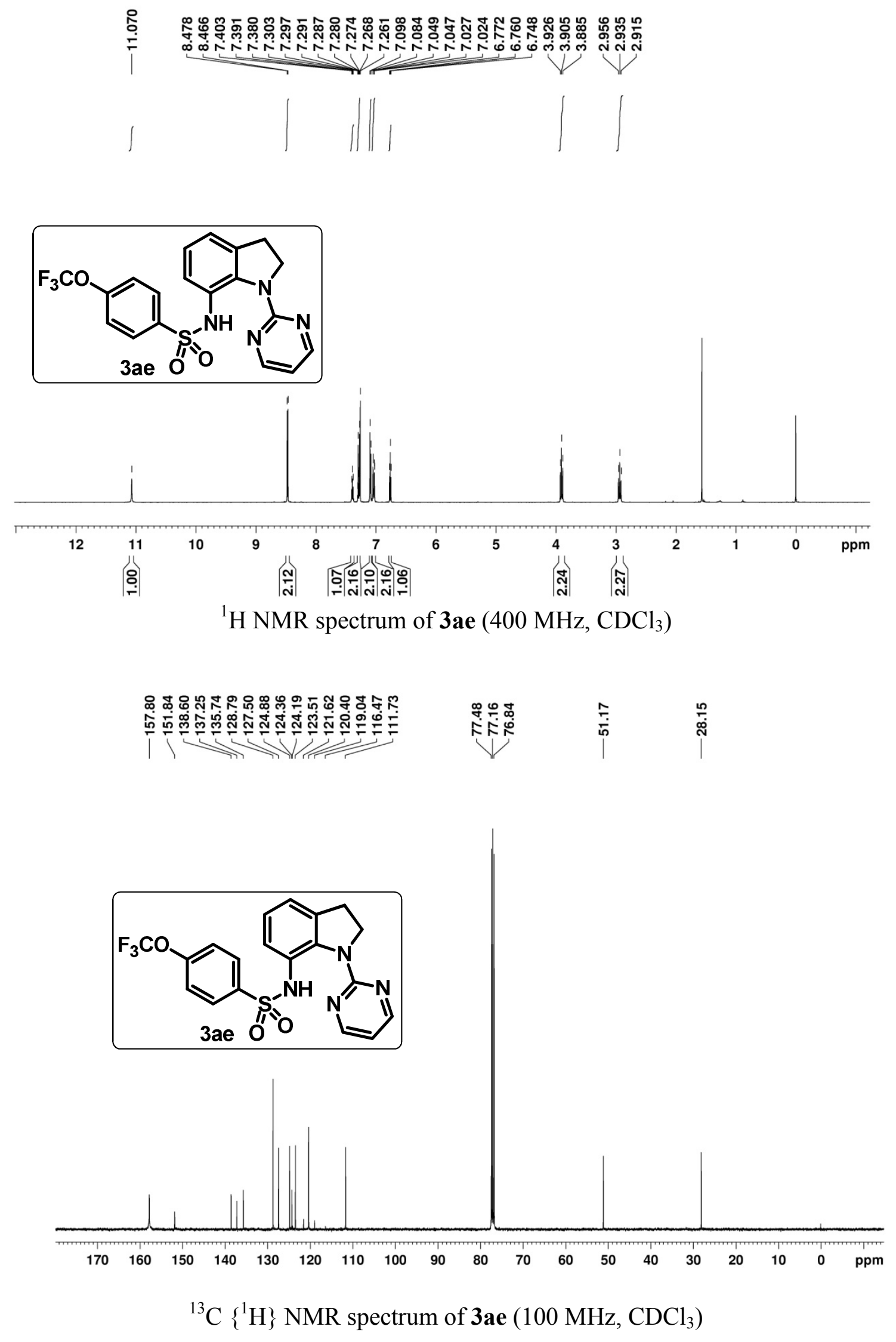




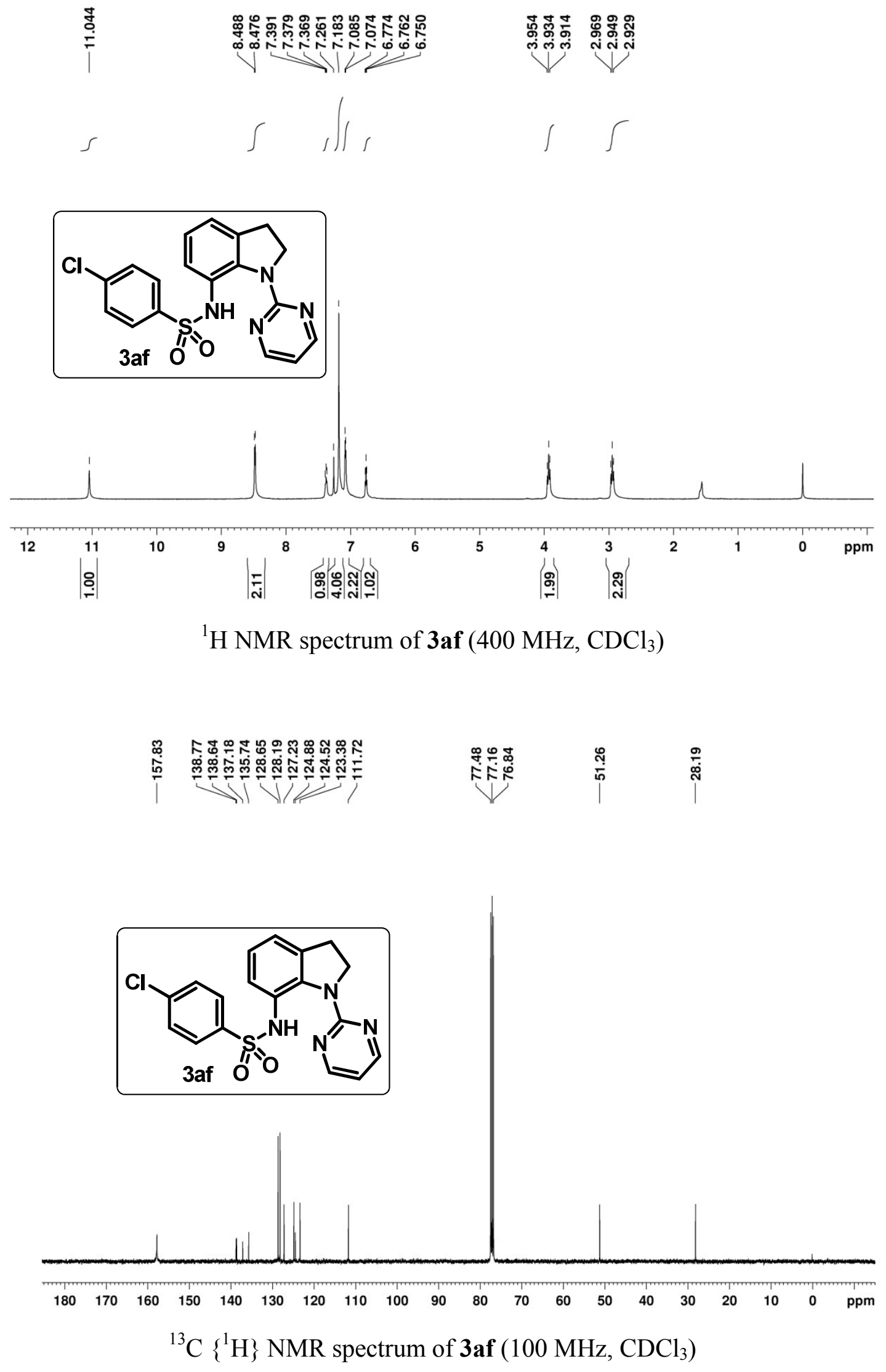



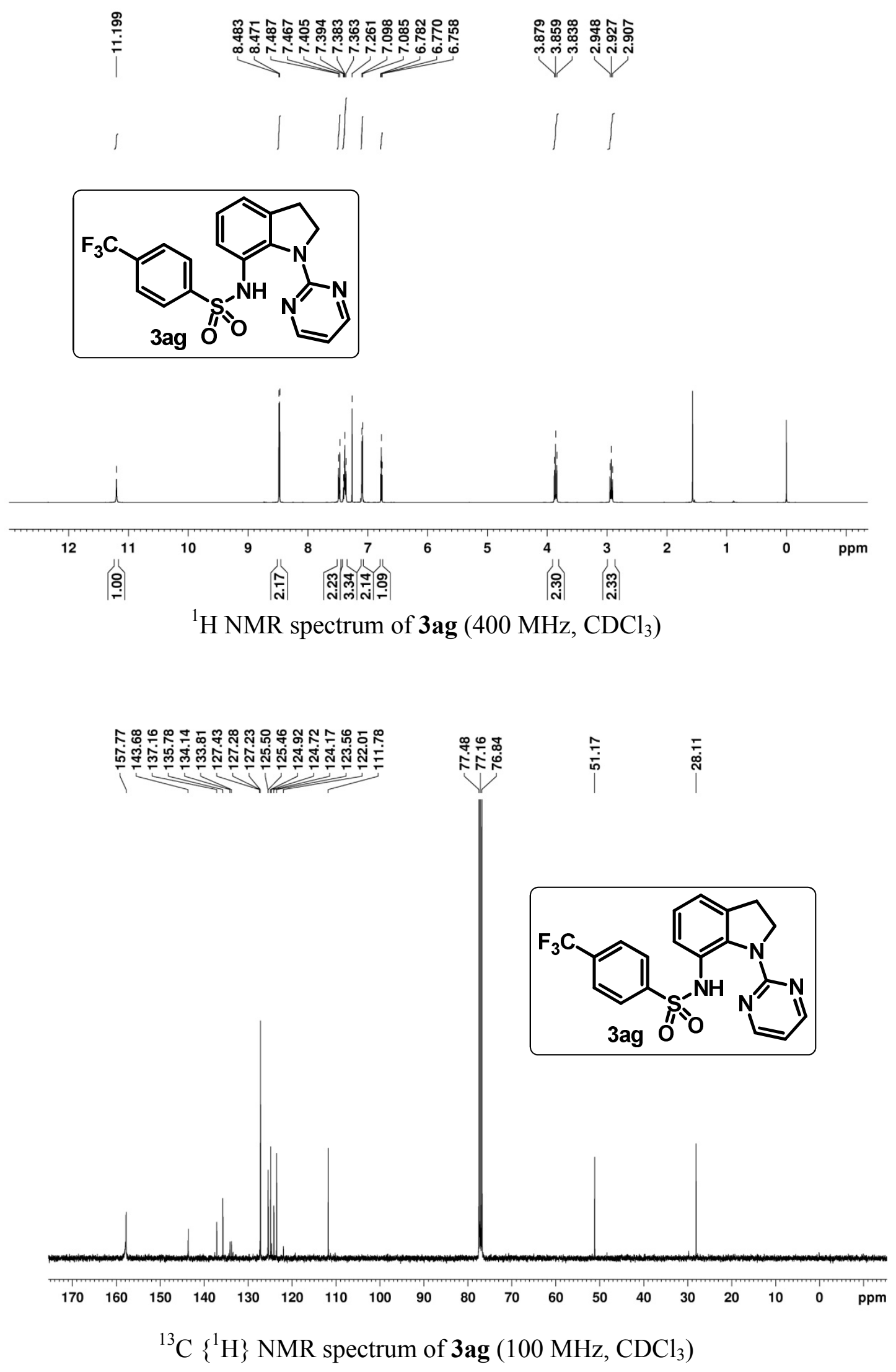

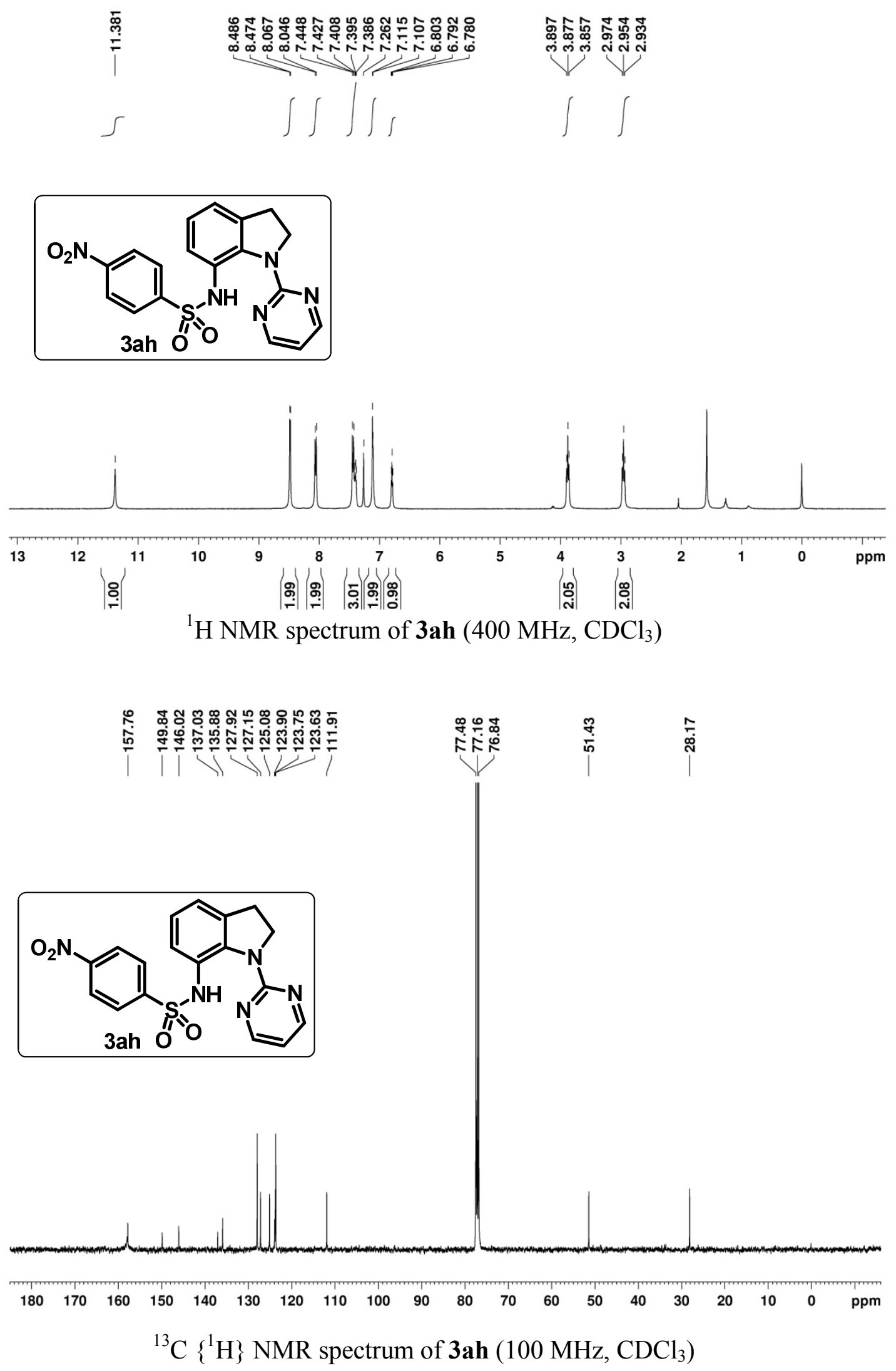

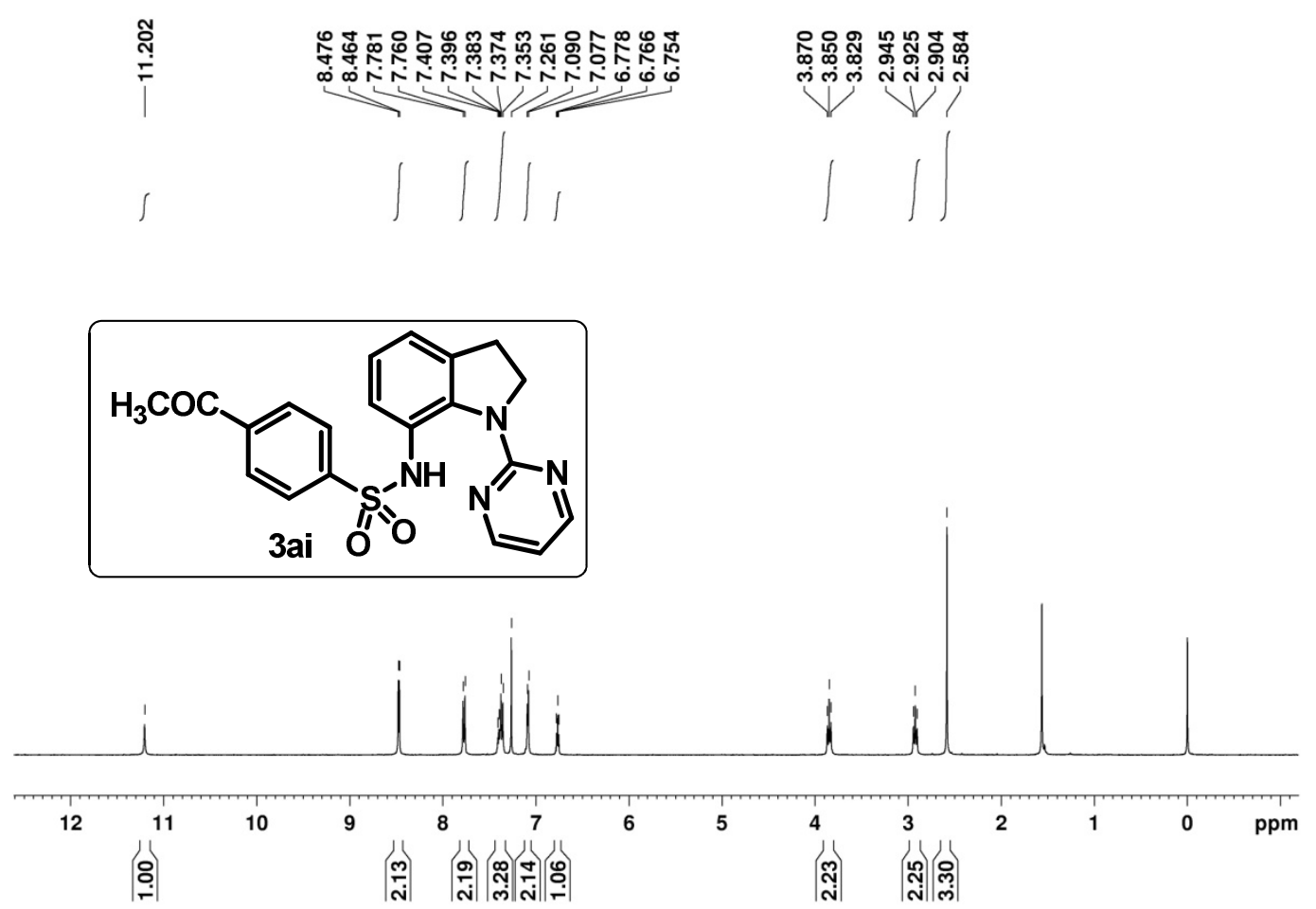

${ }^{1} \mathrm{H}$ NMR spectrum of 3 ai (400 MHz, $\mathrm{CDCl}_{3}$ )
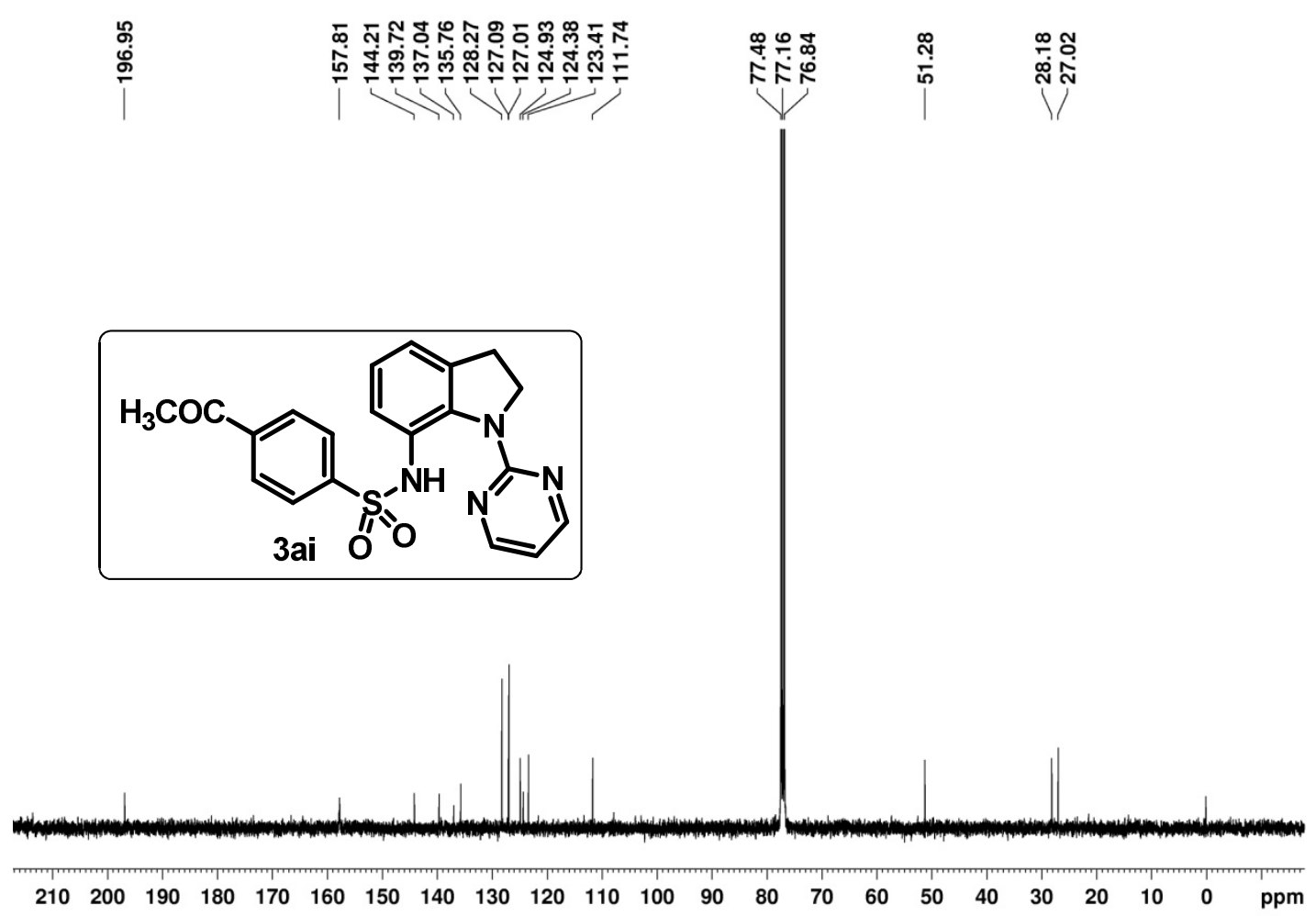

${ }^{13} \mathrm{C}\left\{{ }^{1} \mathrm{H}\right\}$ NMR spectrum of 3ai $\left(100 \mathrm{MHz}, \mathrm{CDCl}_{3}\right)$ 


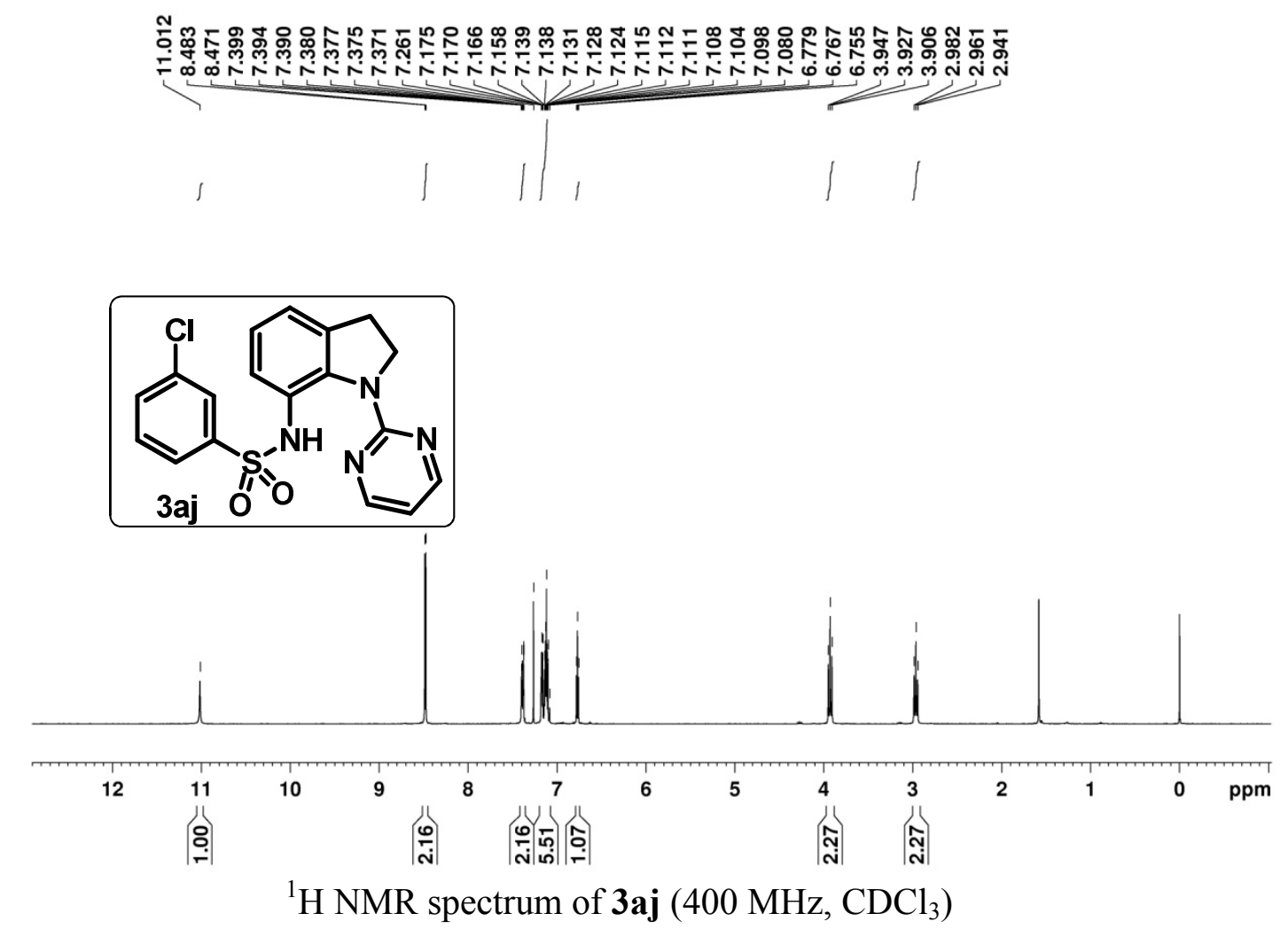

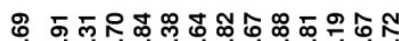

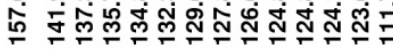

似/
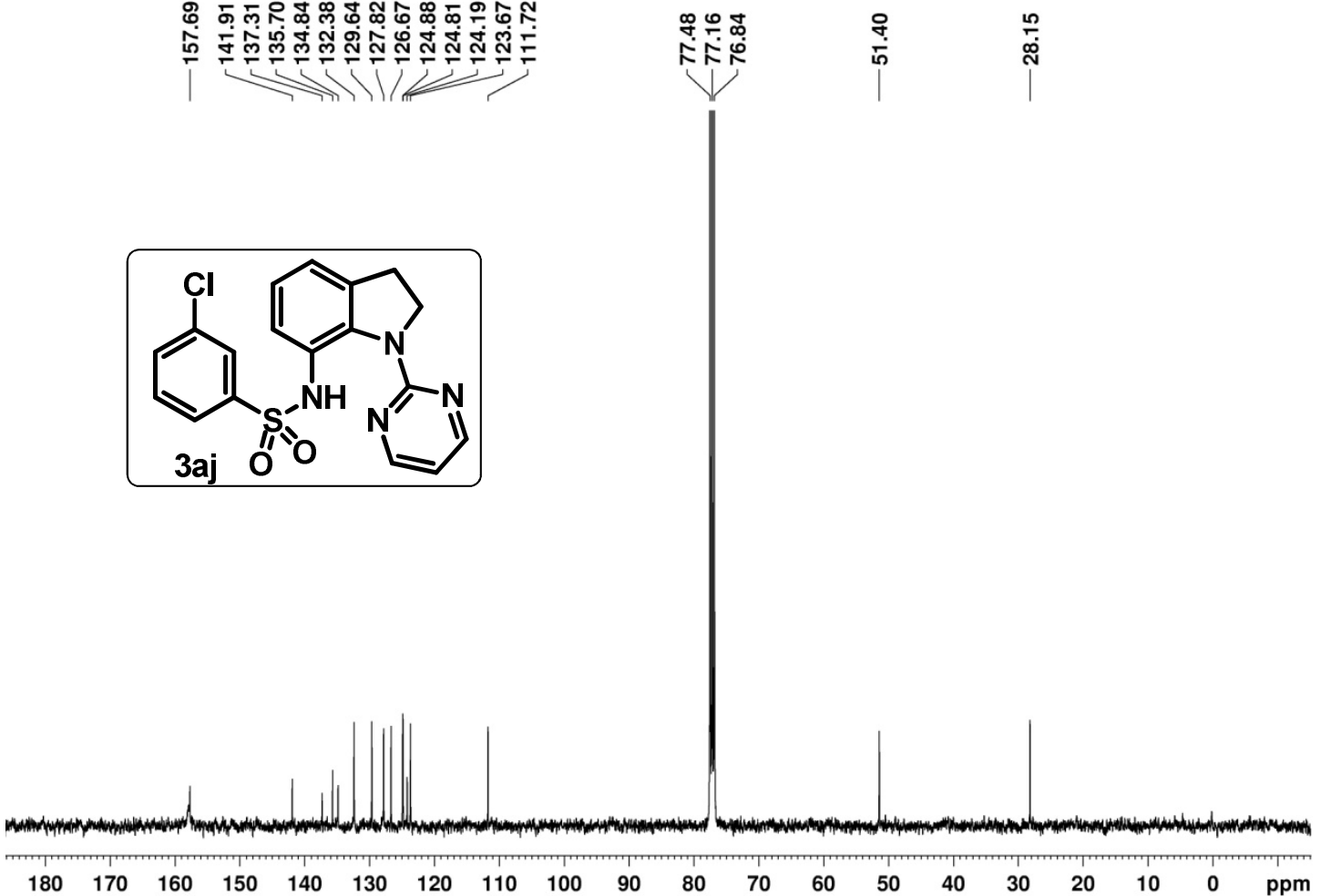

${ }^{13} \mathrm{C}\left\{{ }^{1} \mathrm{H}\right\}$ NMR spectrum of $\mathbf{3 a j}\left(100 \mathrm{MHz}, \mathrm{CDCl}_{3}\right)$ 


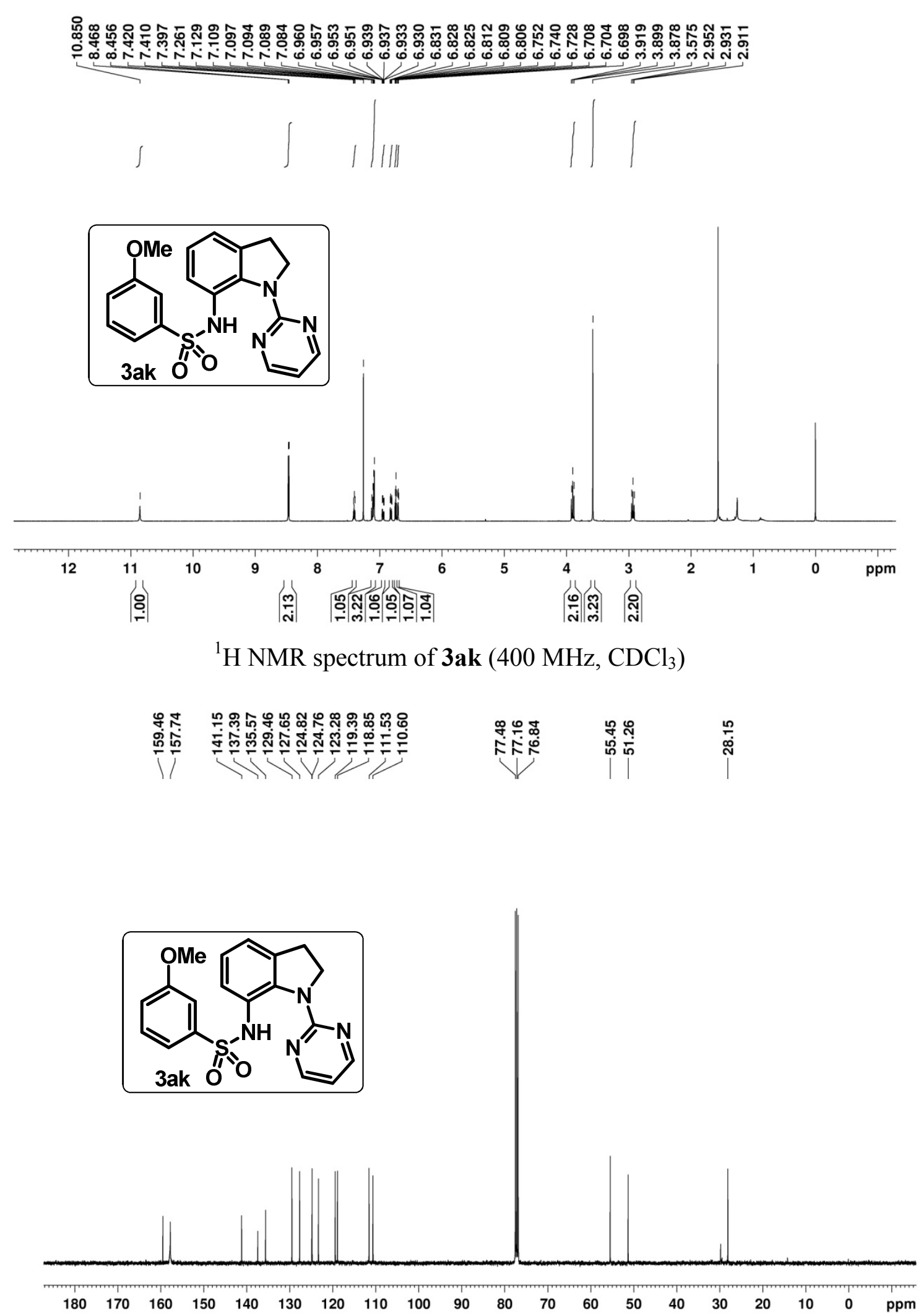

${ }^{13} \mathrm{C}\left\{{ }^{1} \mathrm{H}\right\}$ NMR spectrum of $\mathbf{3 a k}\left(100 \mathrm{MHz}, \mathrm{CDCl}_{3}\right)$ 


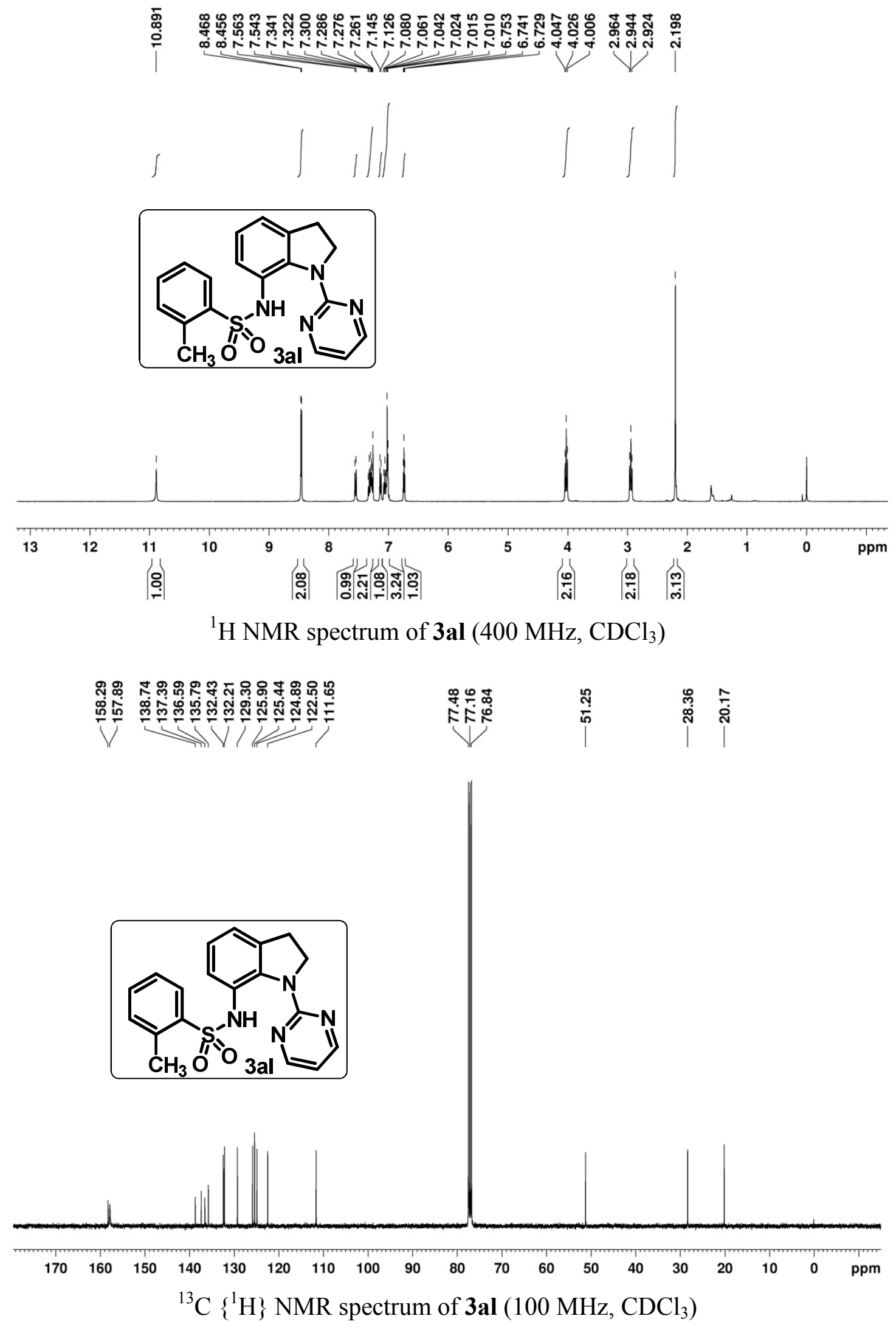



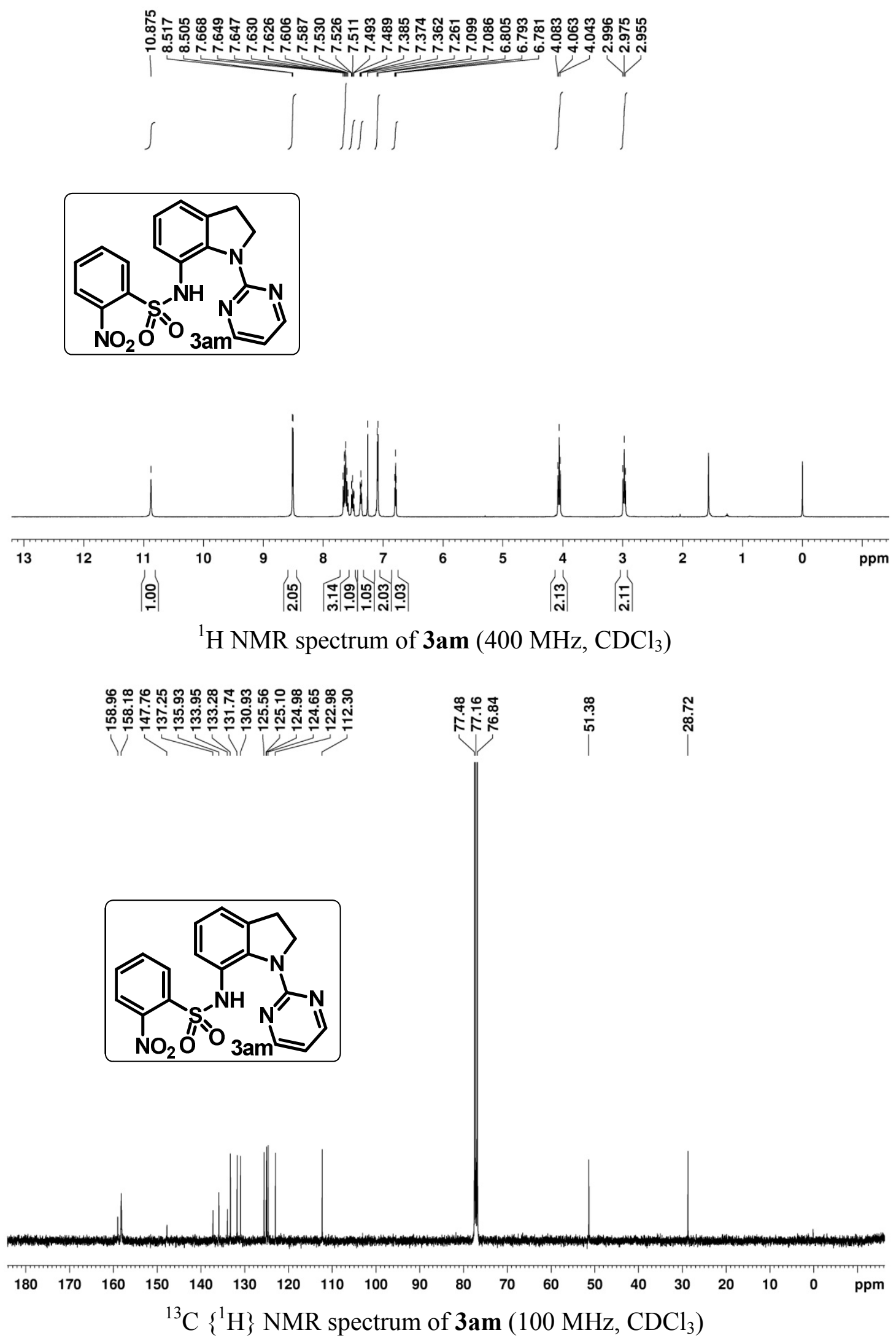

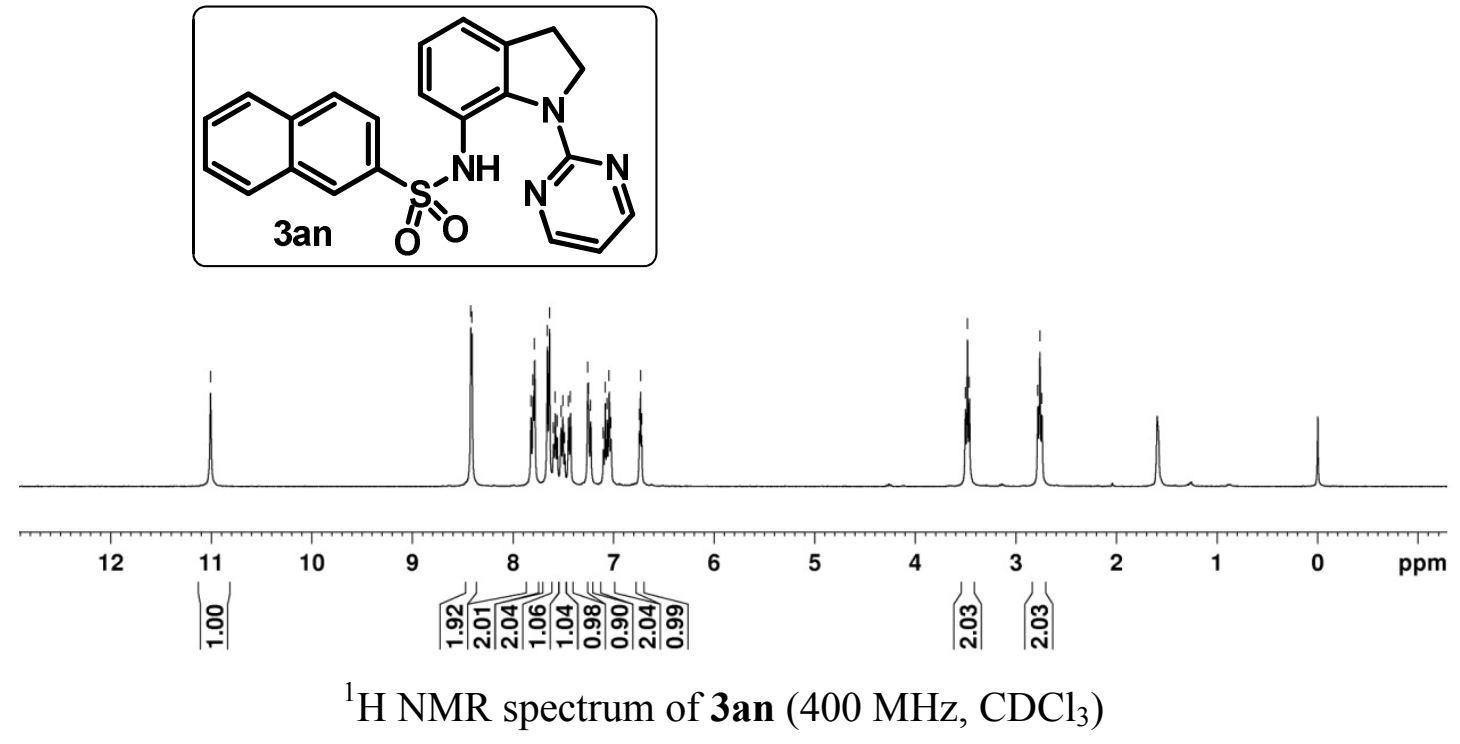

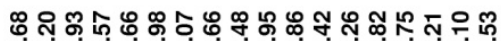

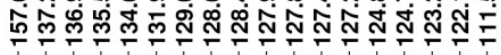

学㲾递

ஸ ஹั่
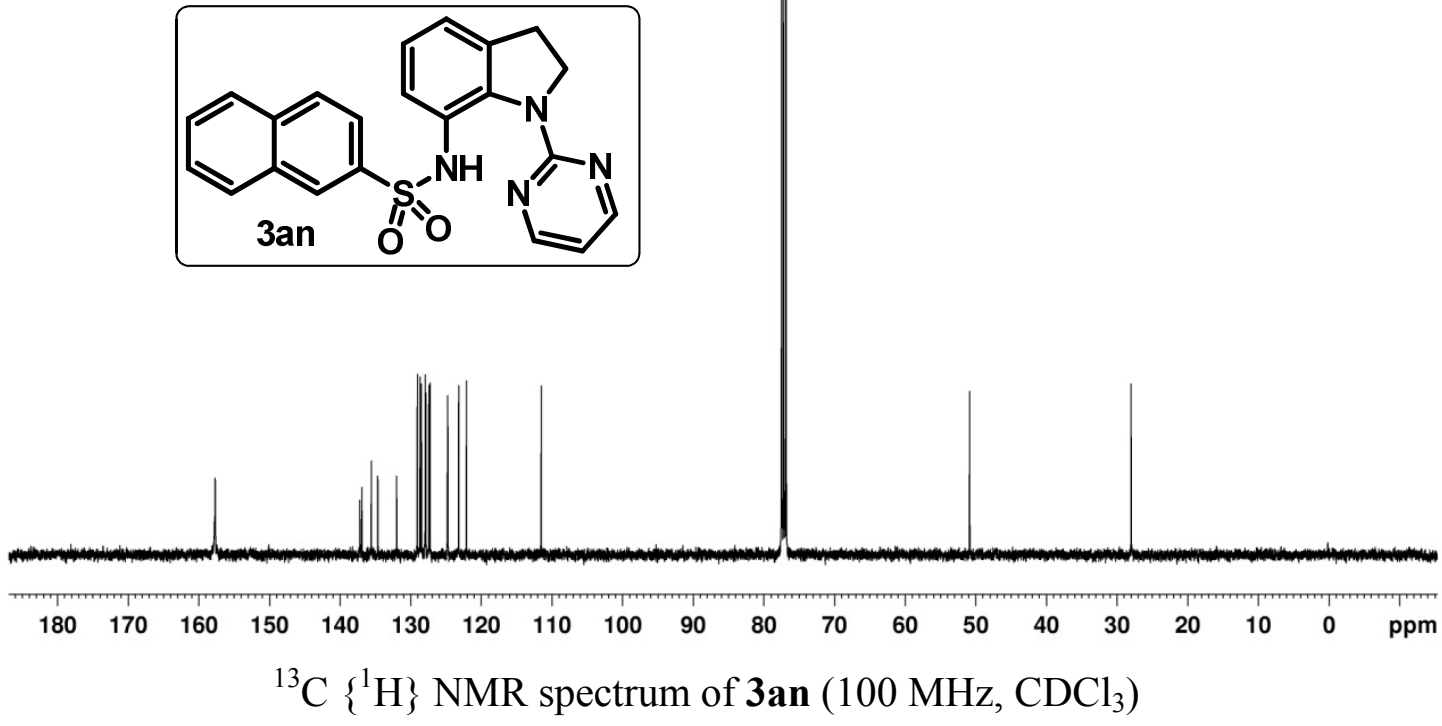


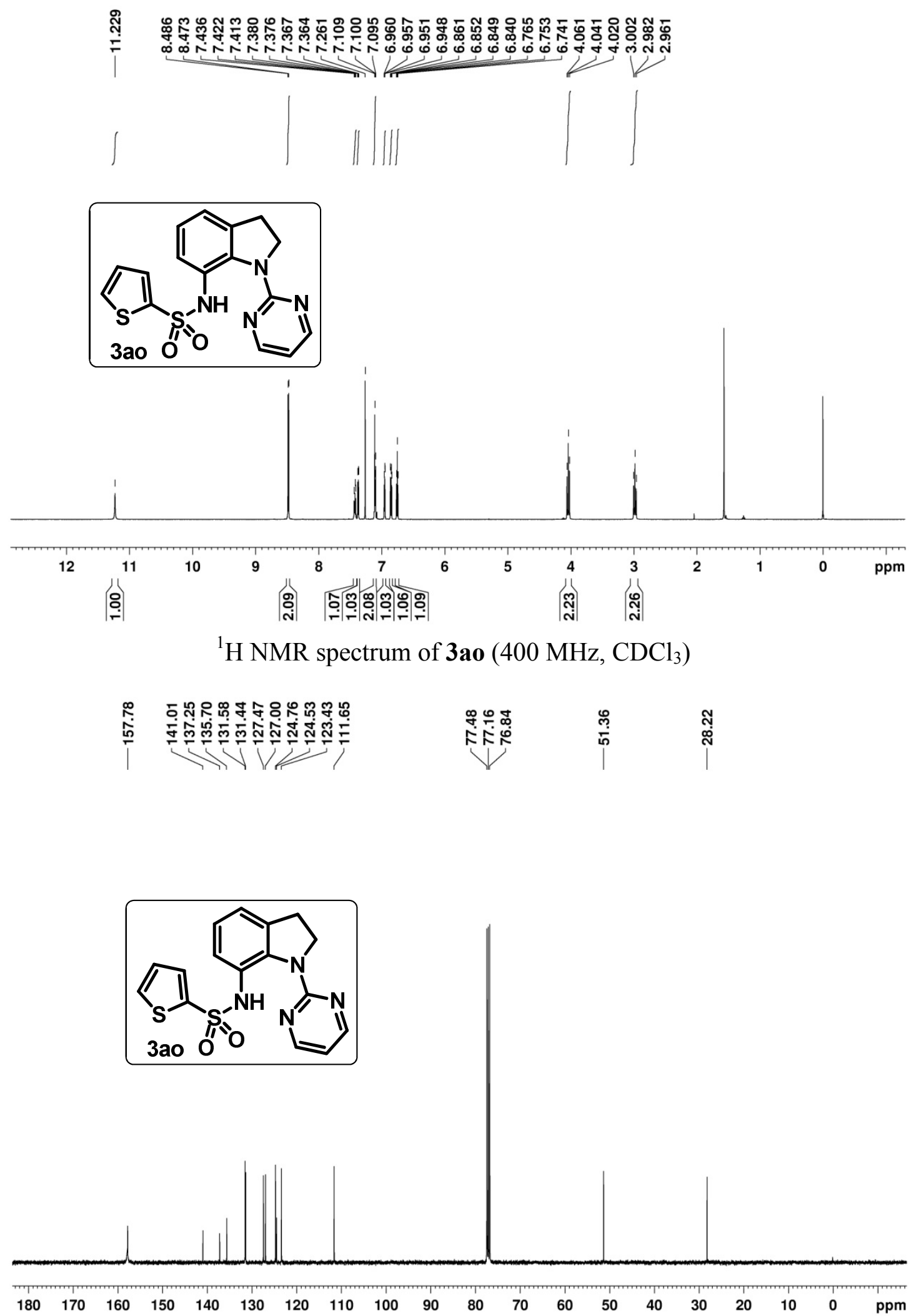

${ }^{13} \mathrm{C}\left\{{ }^{1} \mathrm{H}\right\}$ NMR spectrum of 3 ao $\left(100 \mathrm{MHz}, \mathrm{CDCl}_{3}\right)$ 

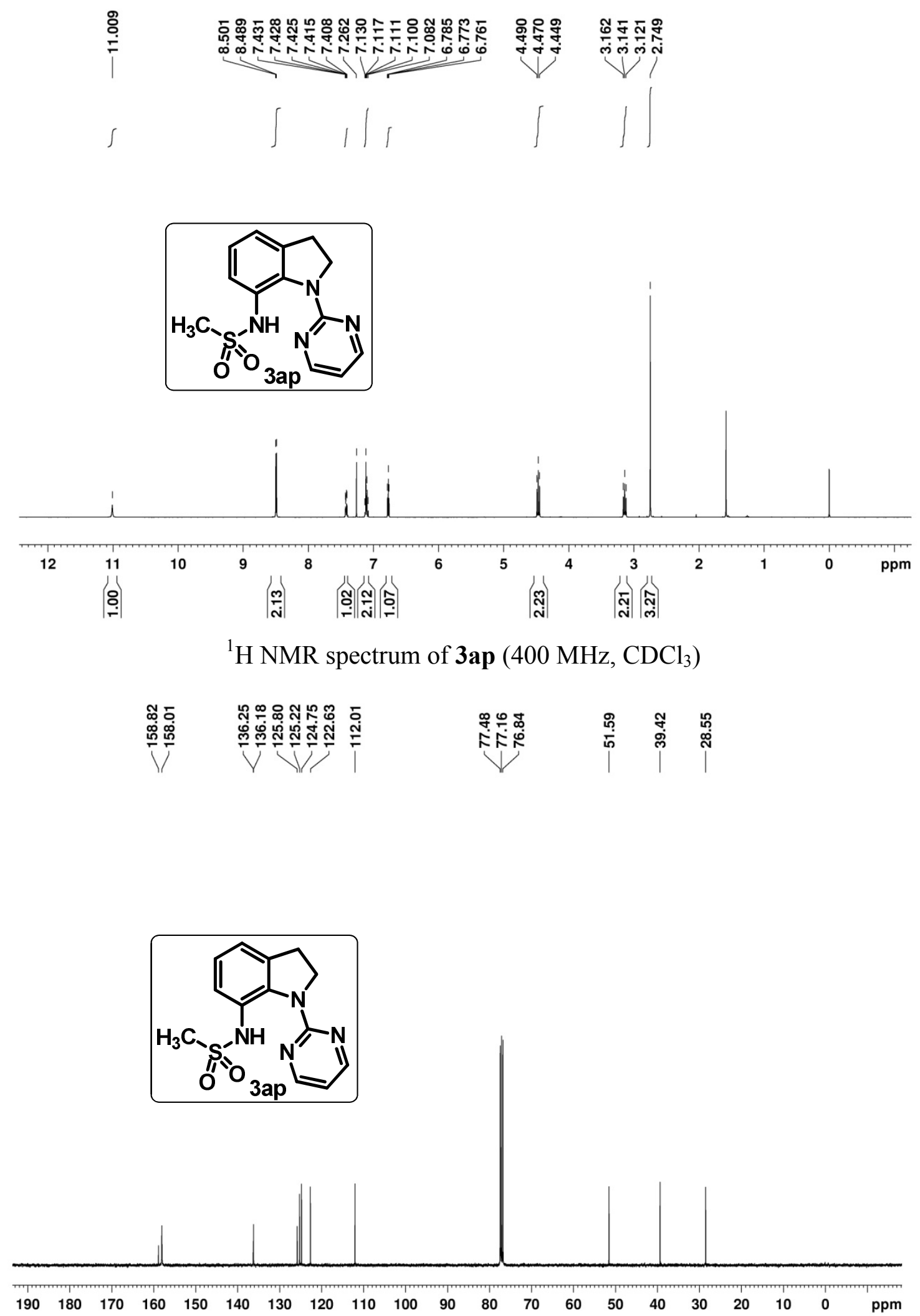

${ }^{13} \mathrm{C}\left\{{ }^{1} \mathrm{H}\right\}$ NMR spectrum of $\mathbf{3 a p}\left(100 \mathrm{MHz}, \mathrm{CDCl}_{3}\right)$ 

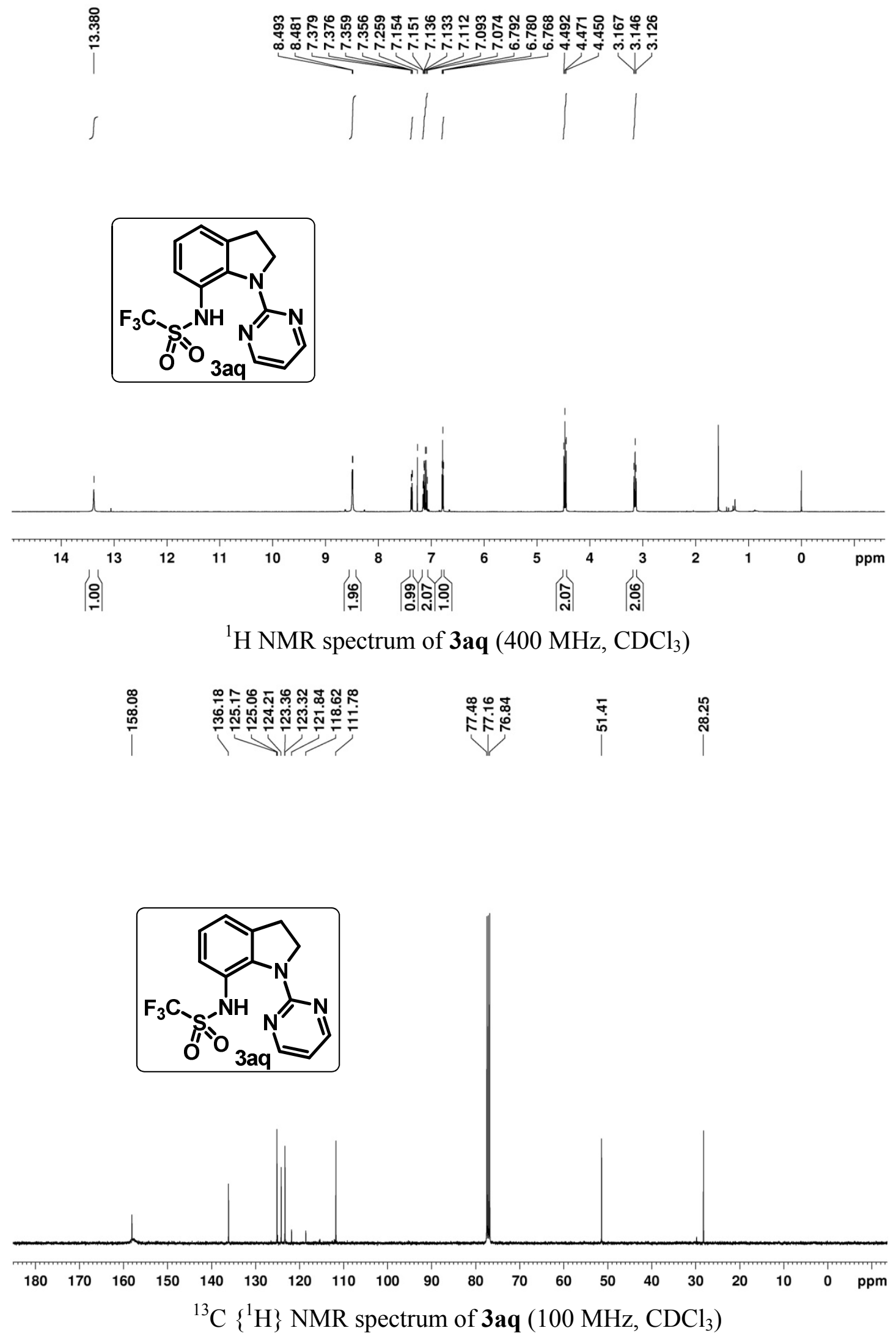

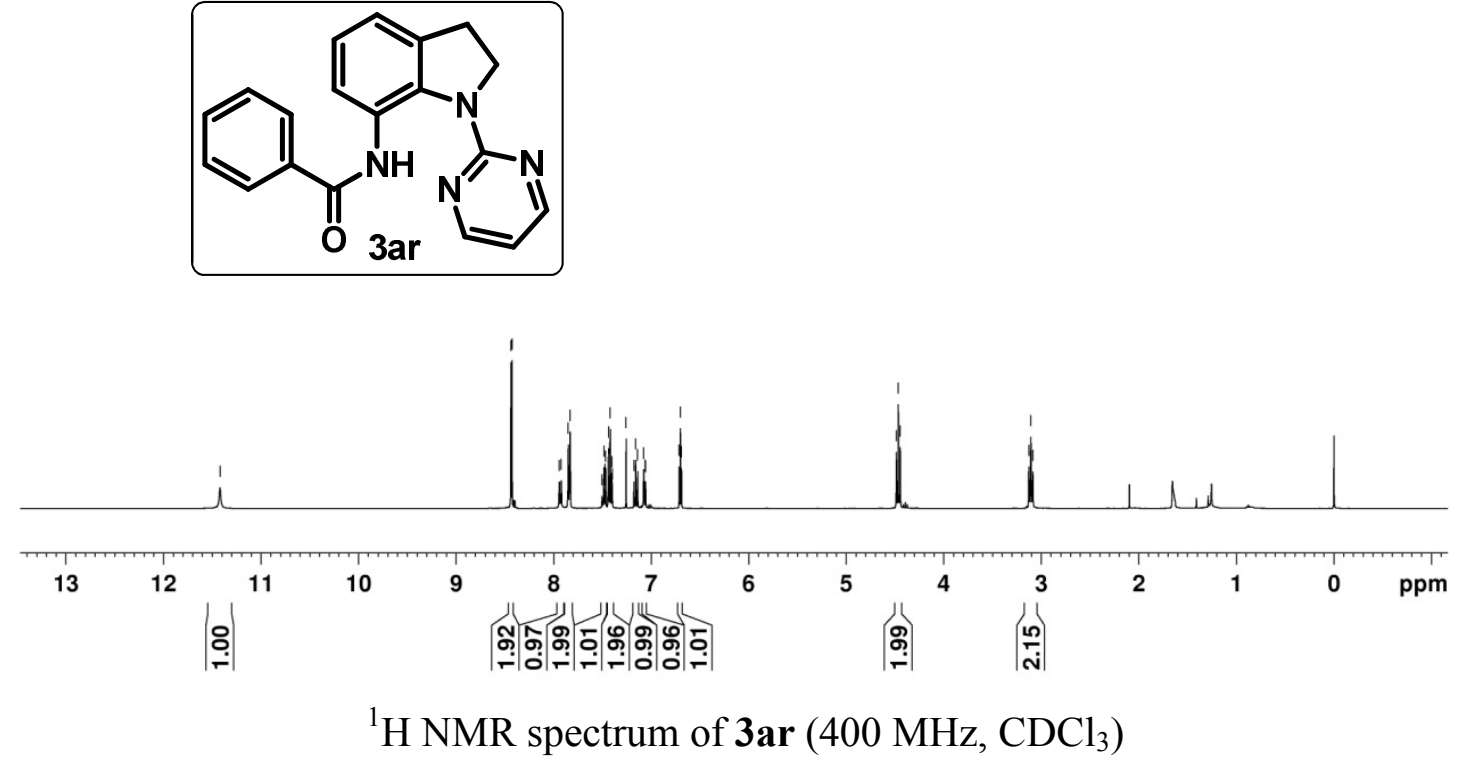

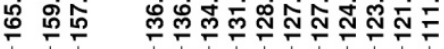
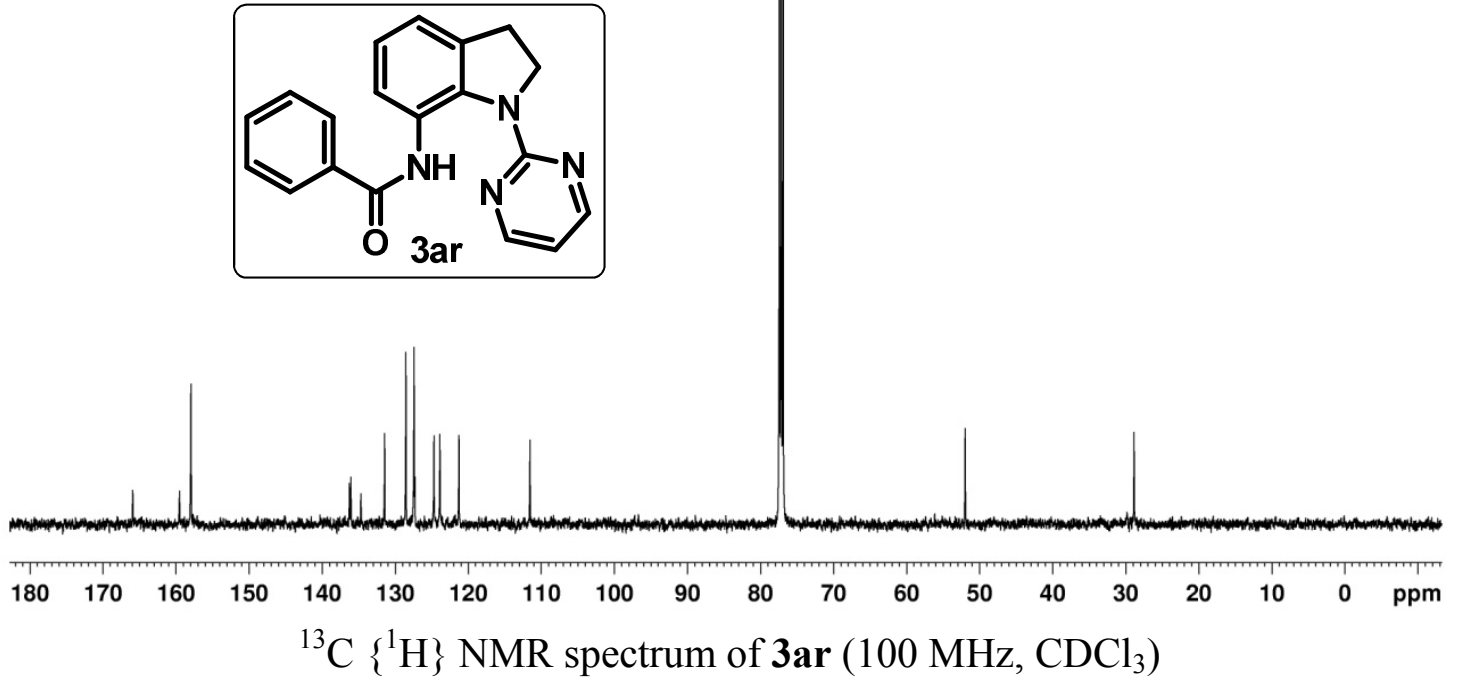


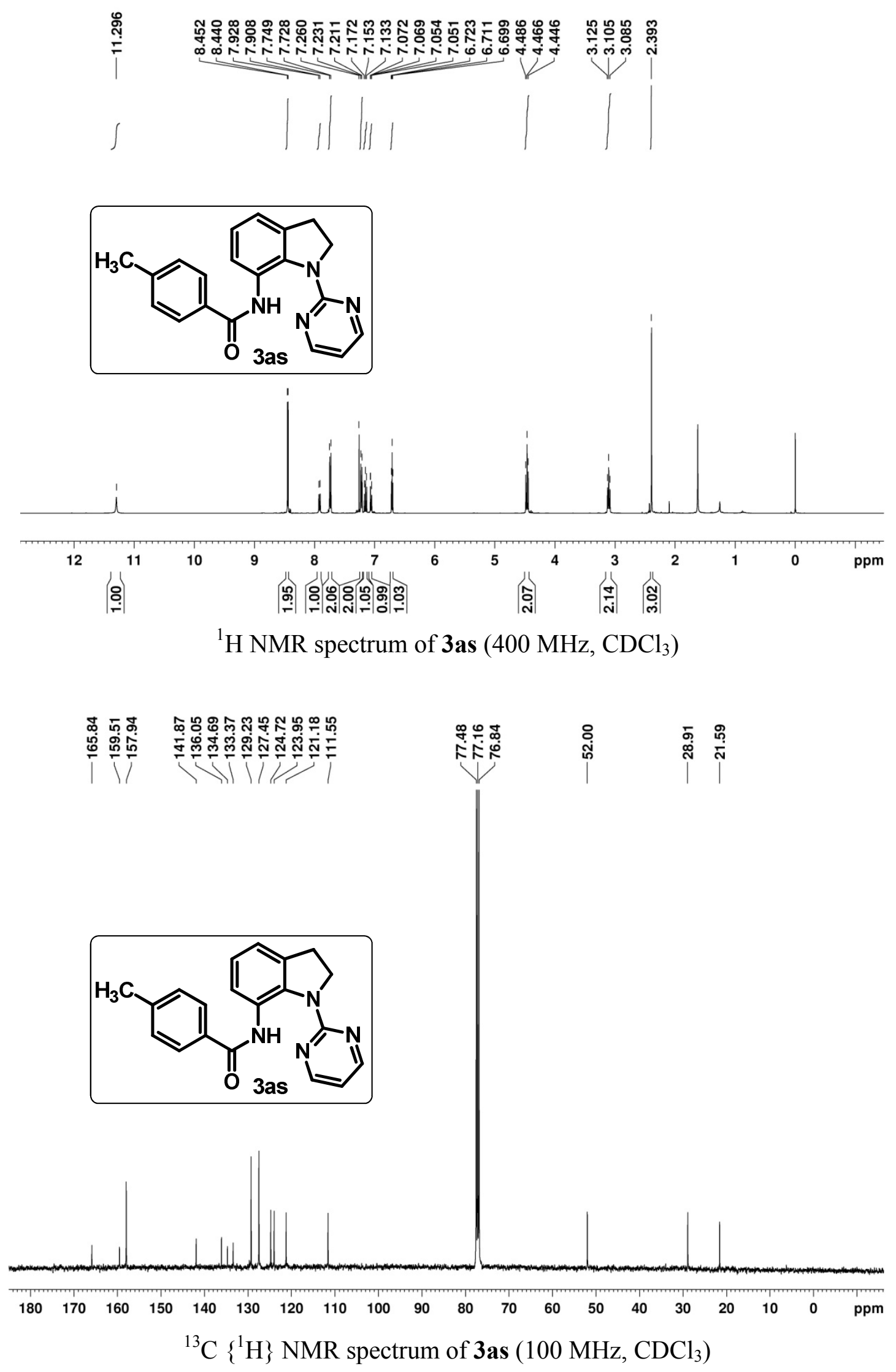




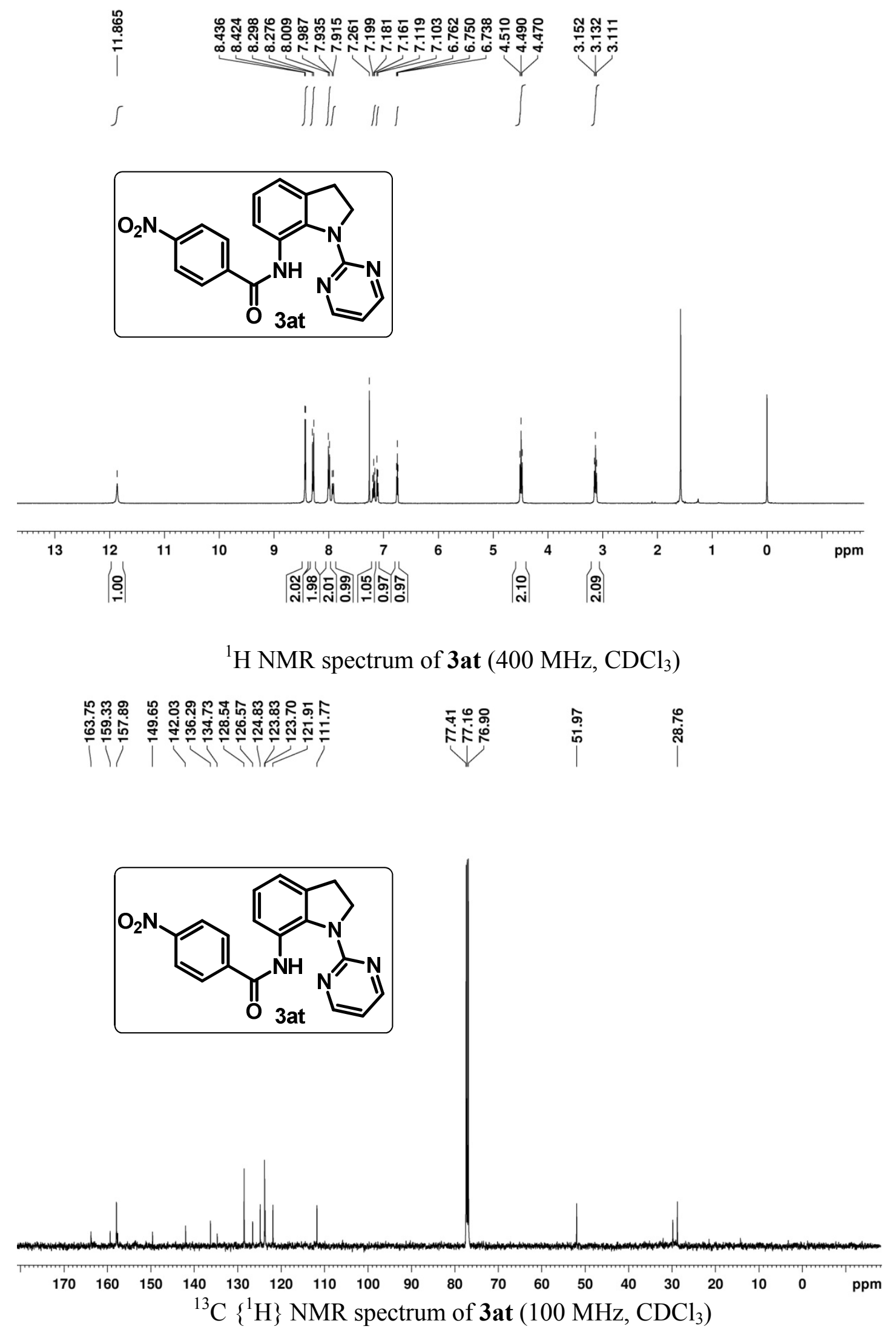




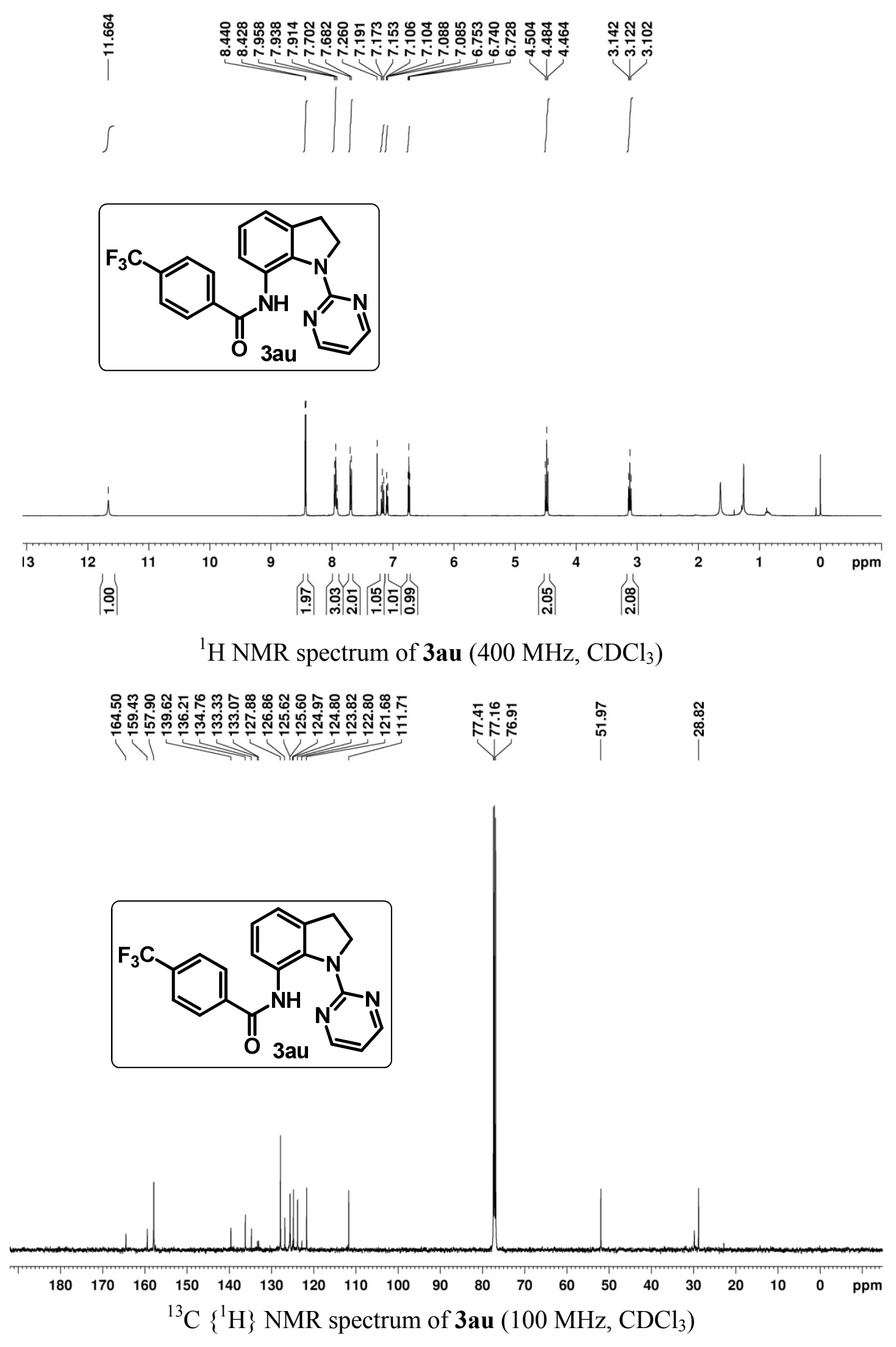




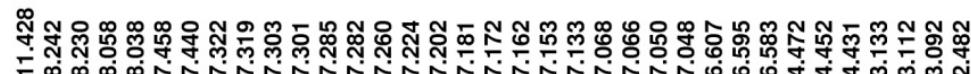

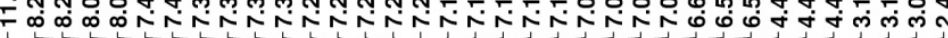

$\left.\iint 1 \| 11\right) \int$
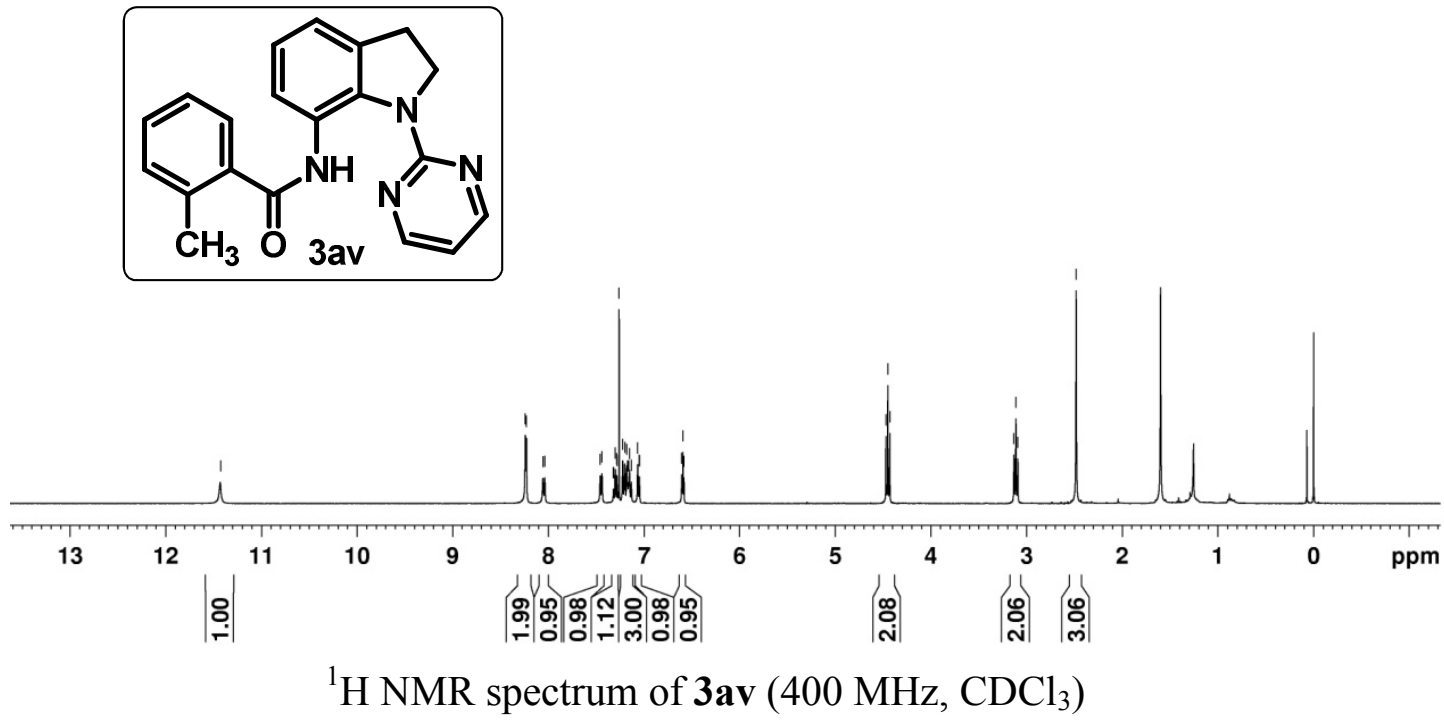

œ

○
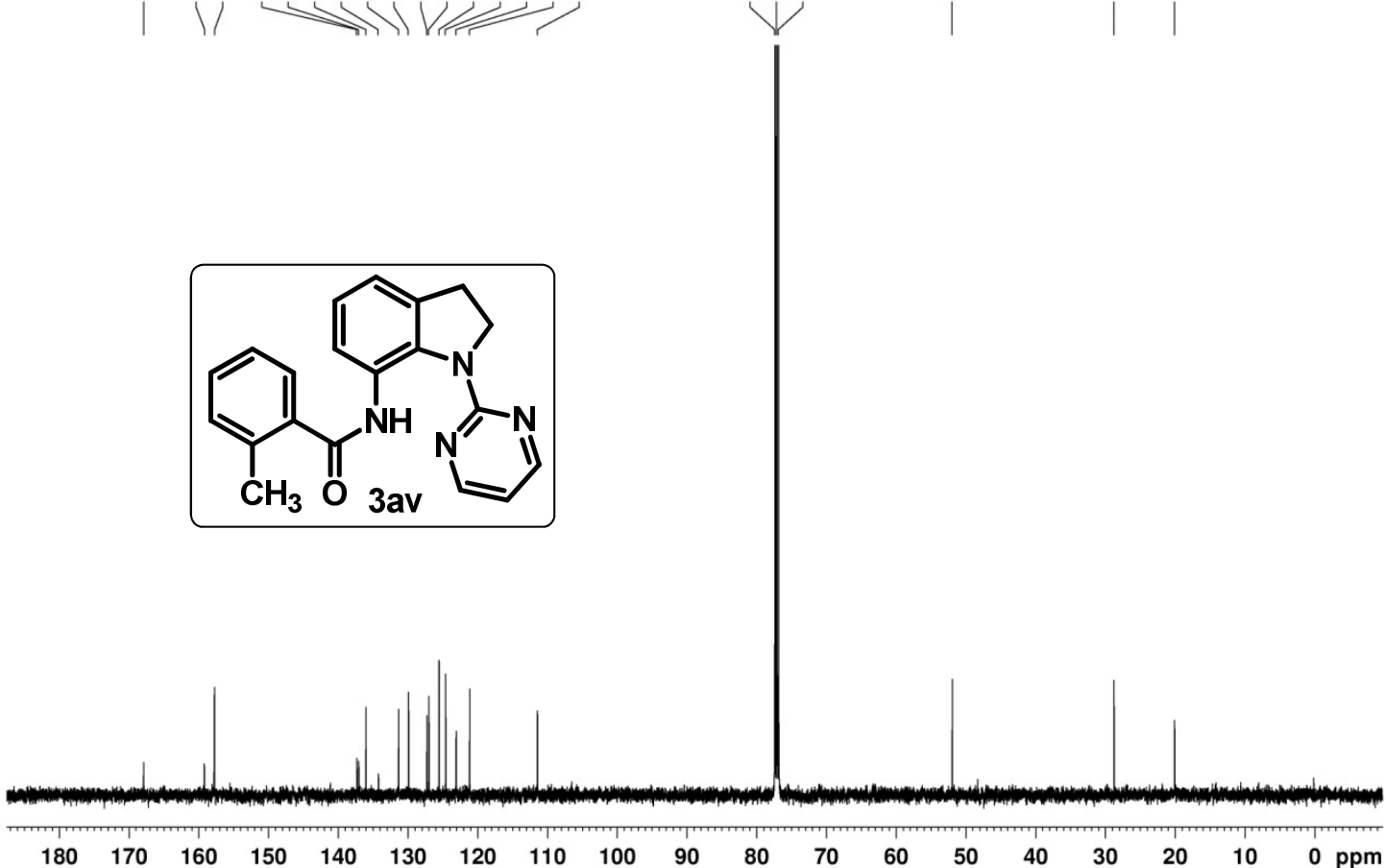

${ }^{13} \mathrm{C}\left\{{ }^{1} \mathrm{H}\right\}$ NMR spectrum of $\mathbf{3 a v}\left(100 \mathrm{MHz}, \mathrm{CDCl}_{3}\right)$ 


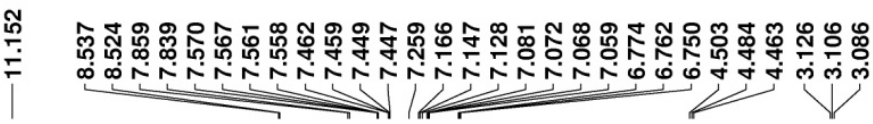
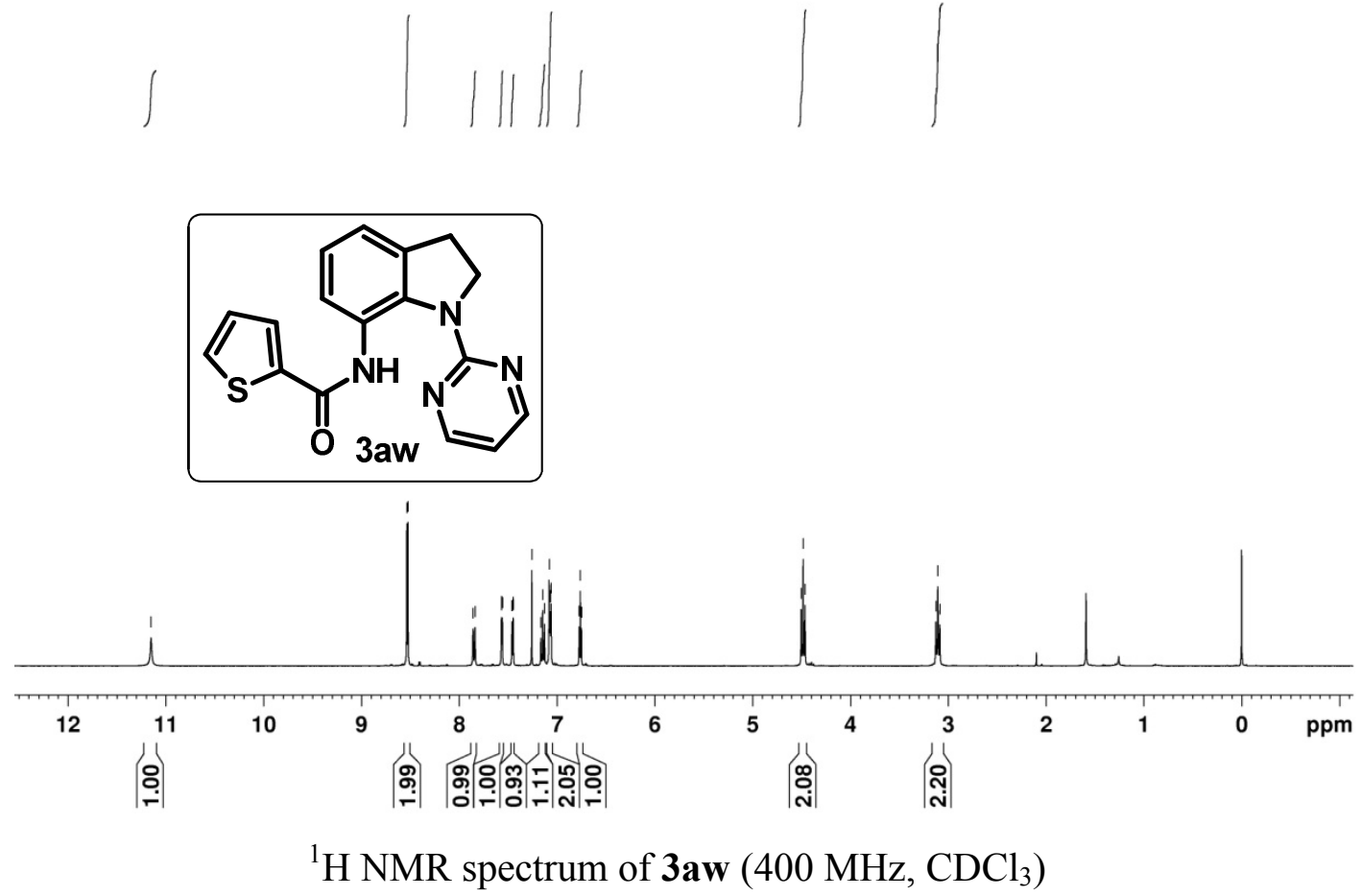

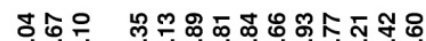

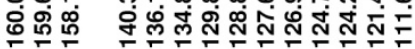

药

突ำำ

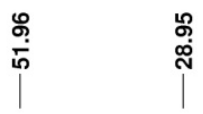
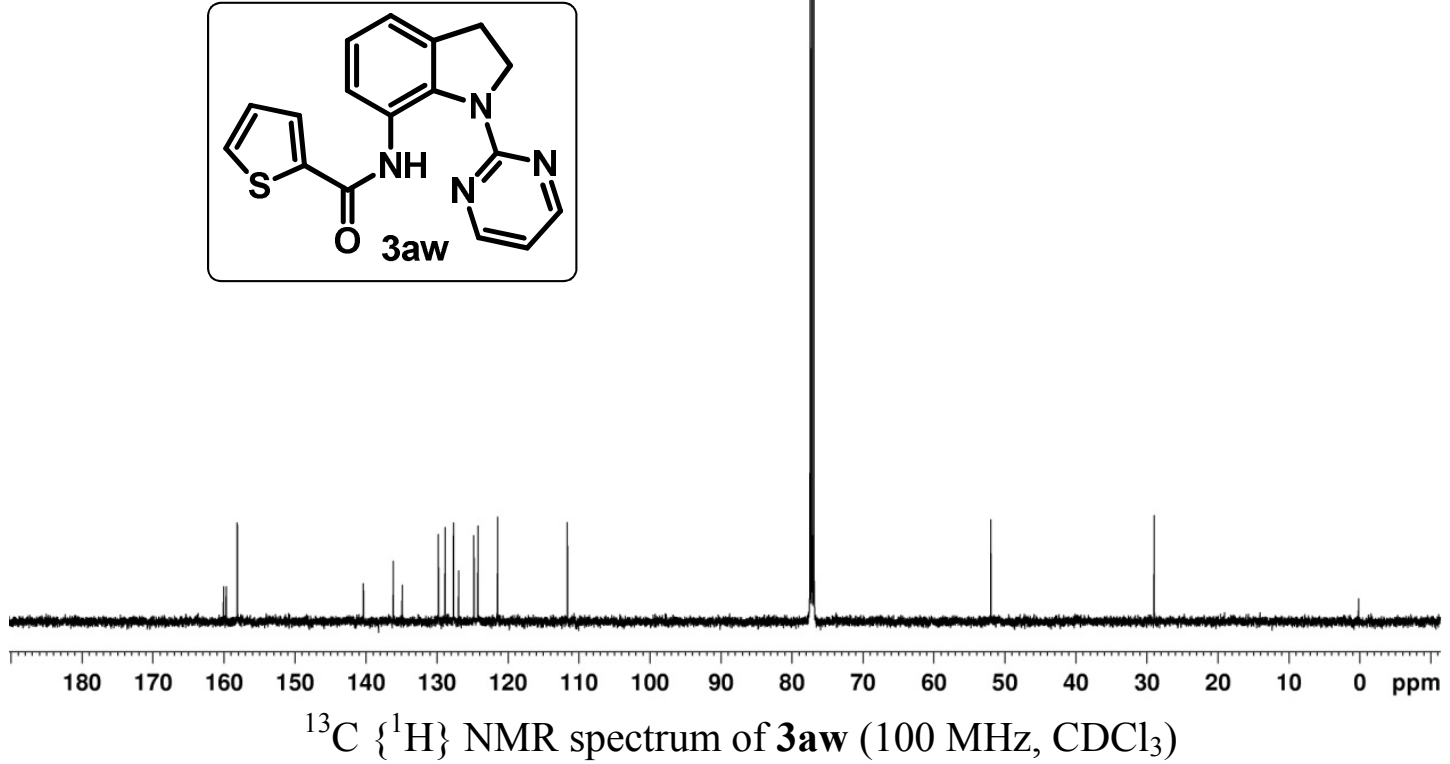

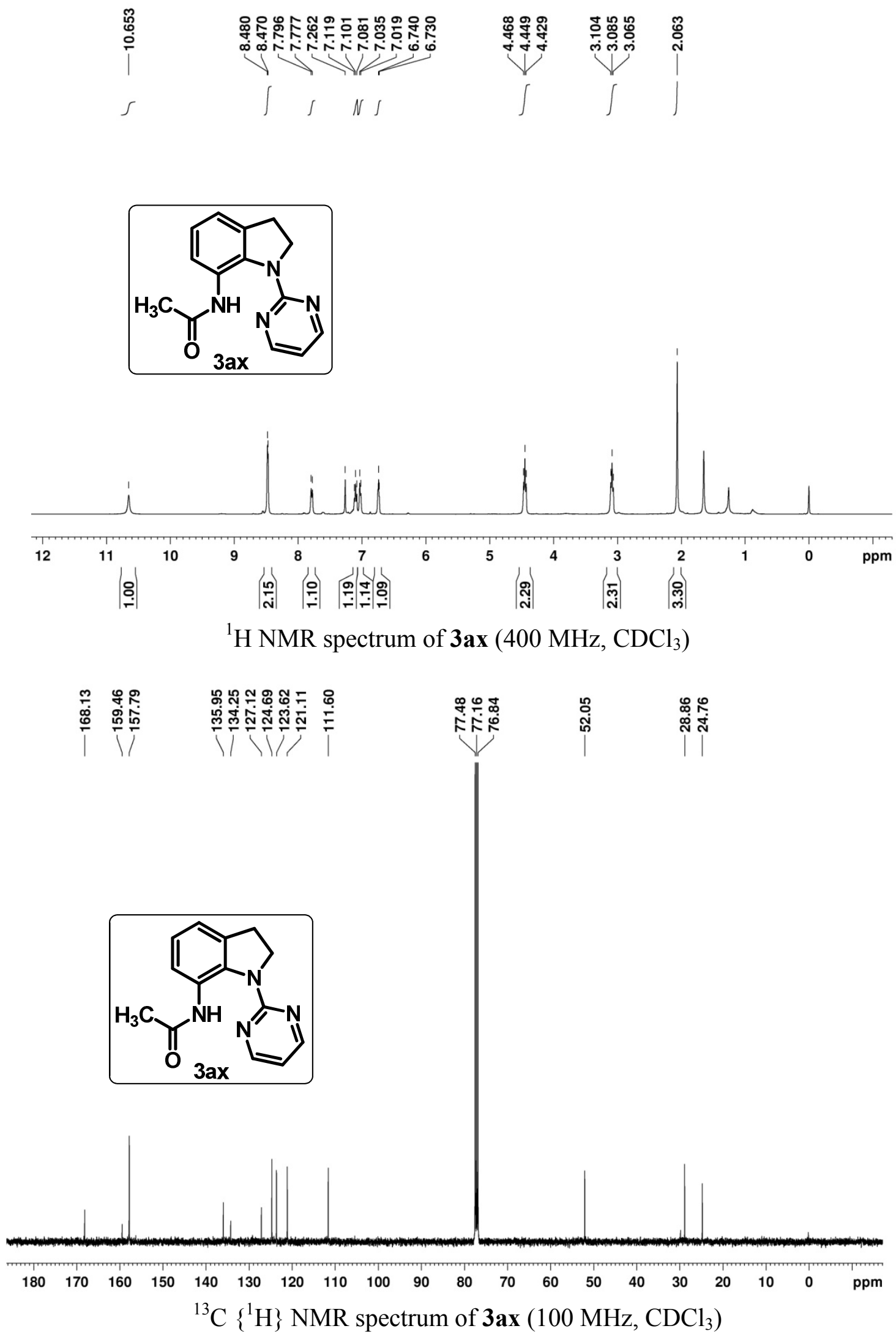


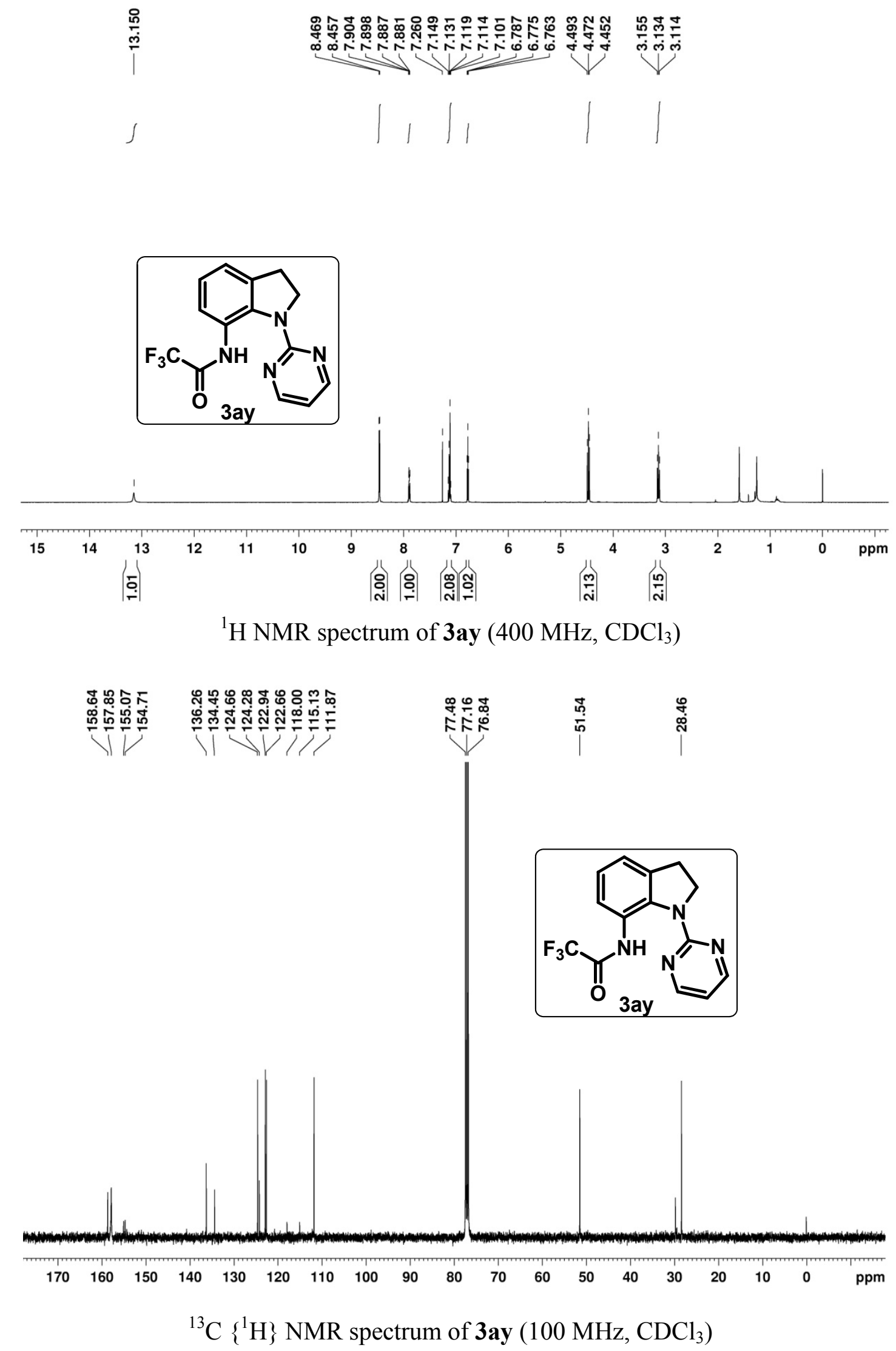



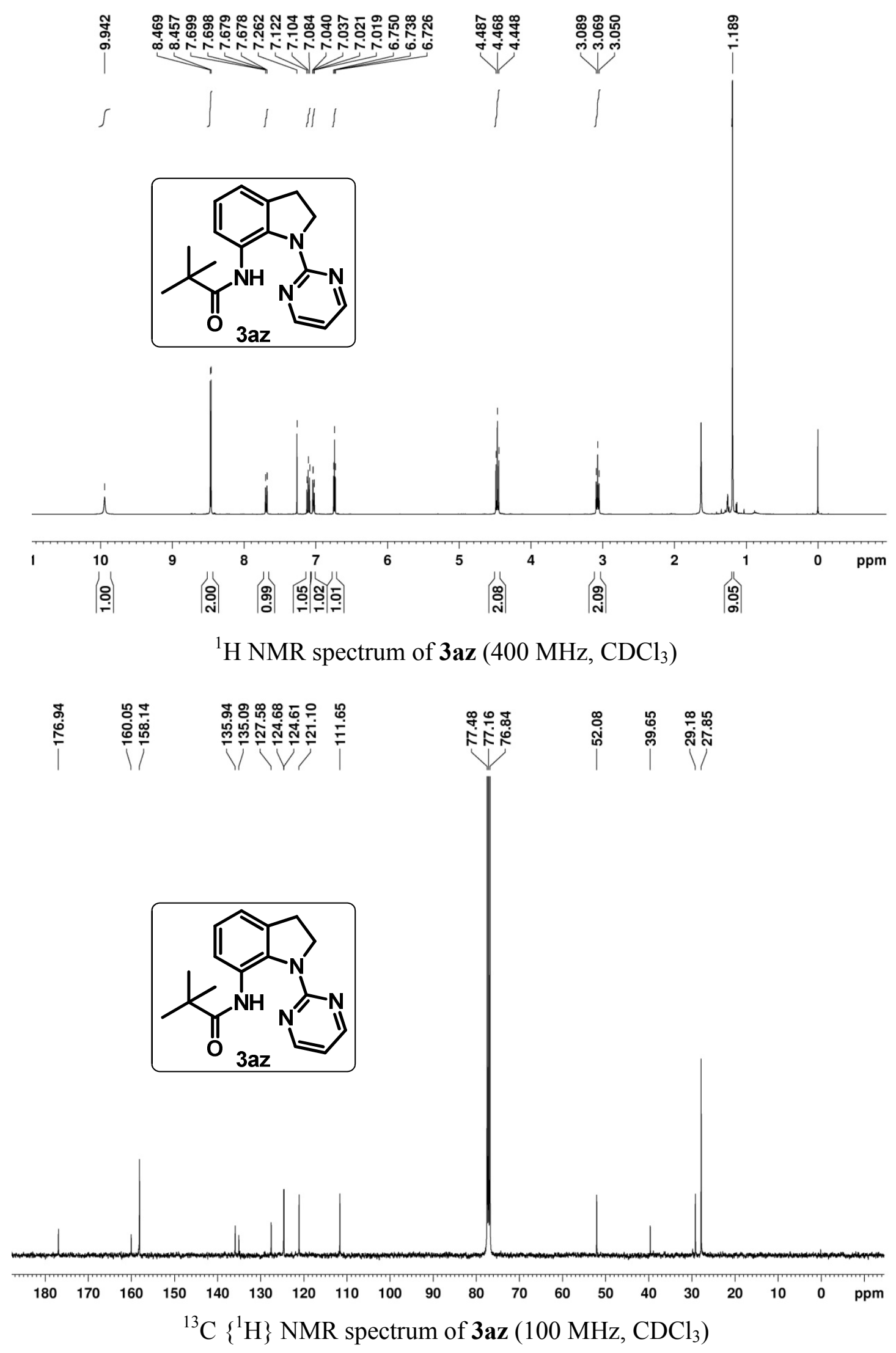

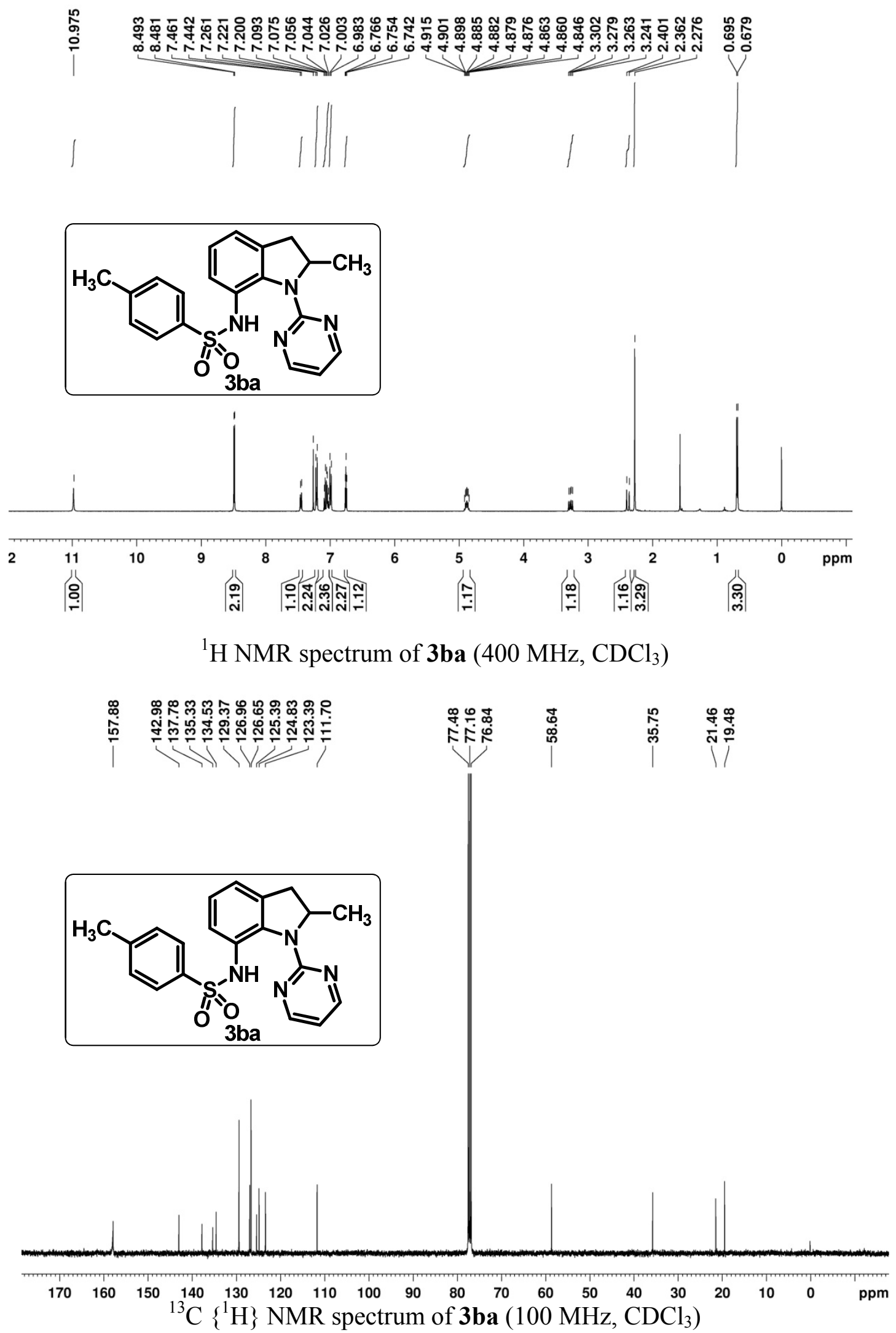

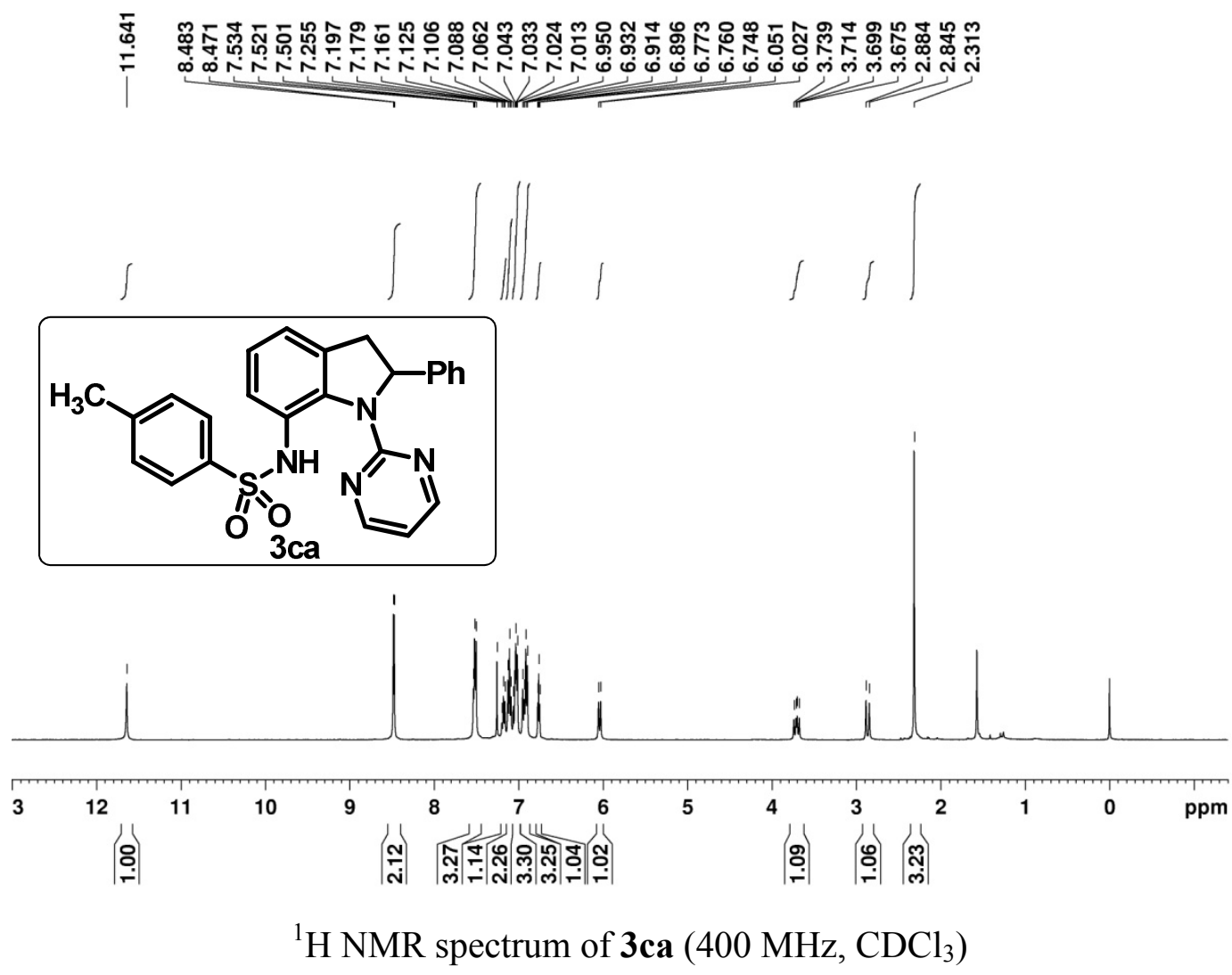

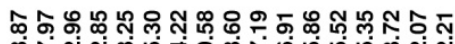

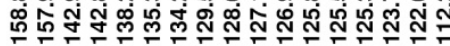
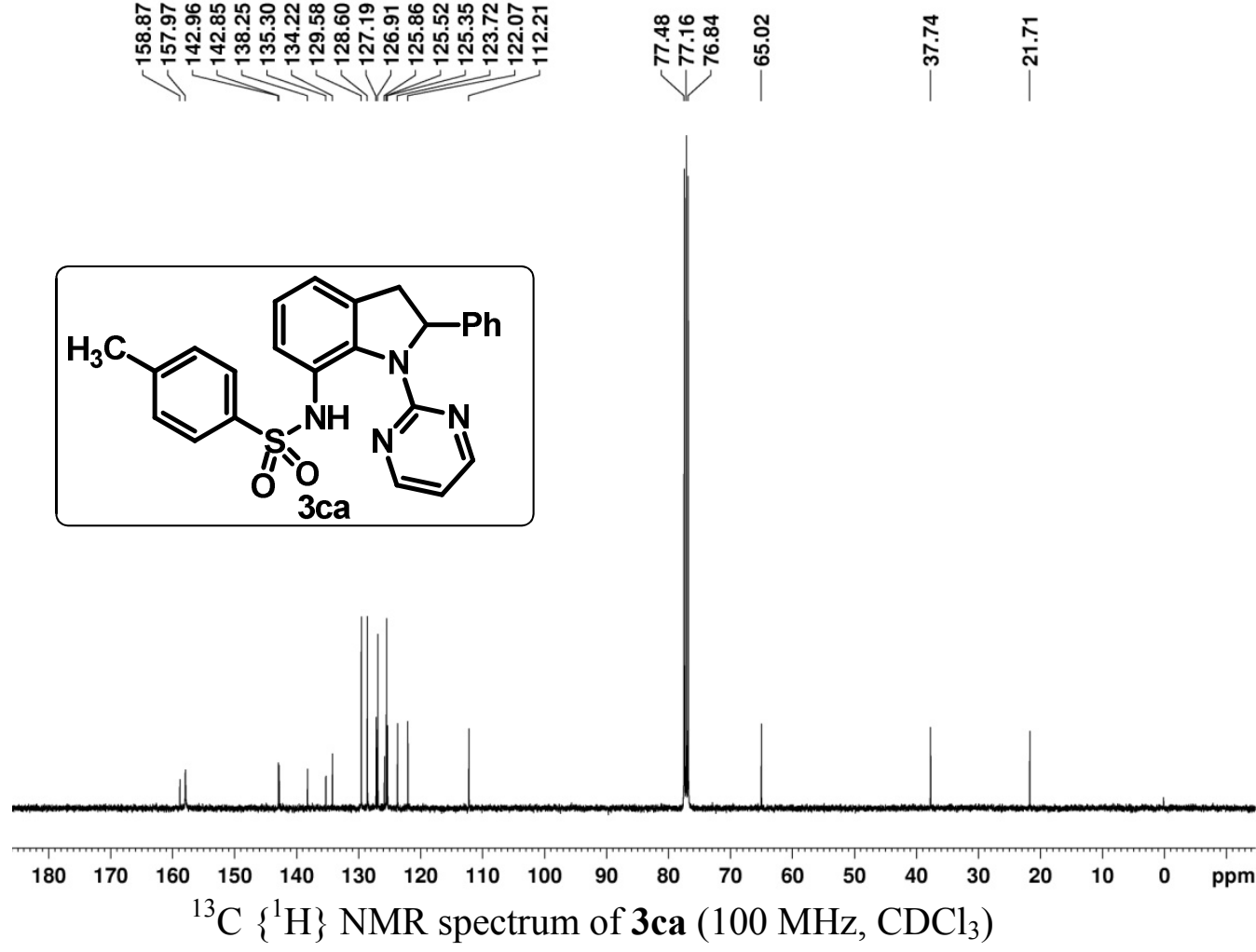

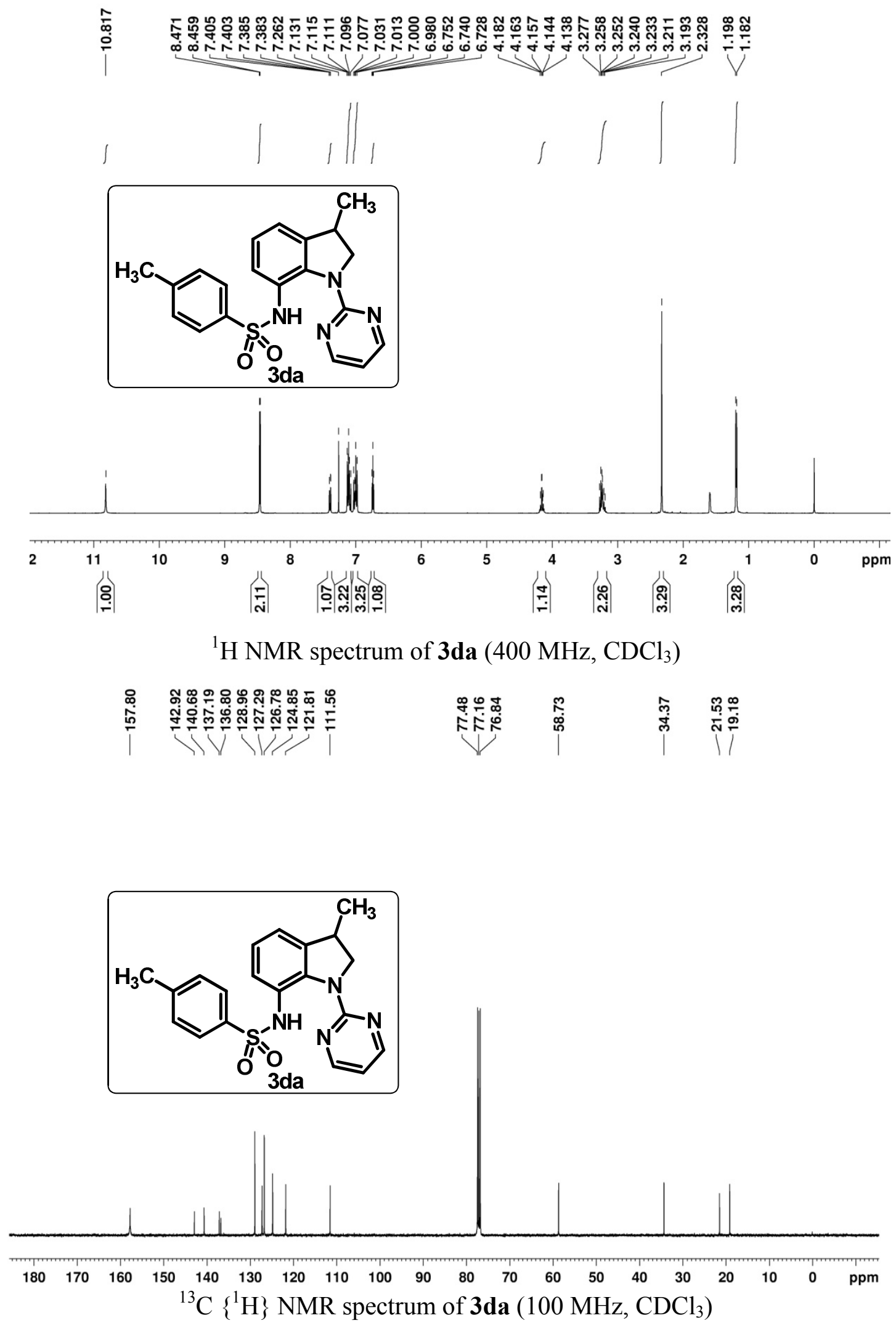

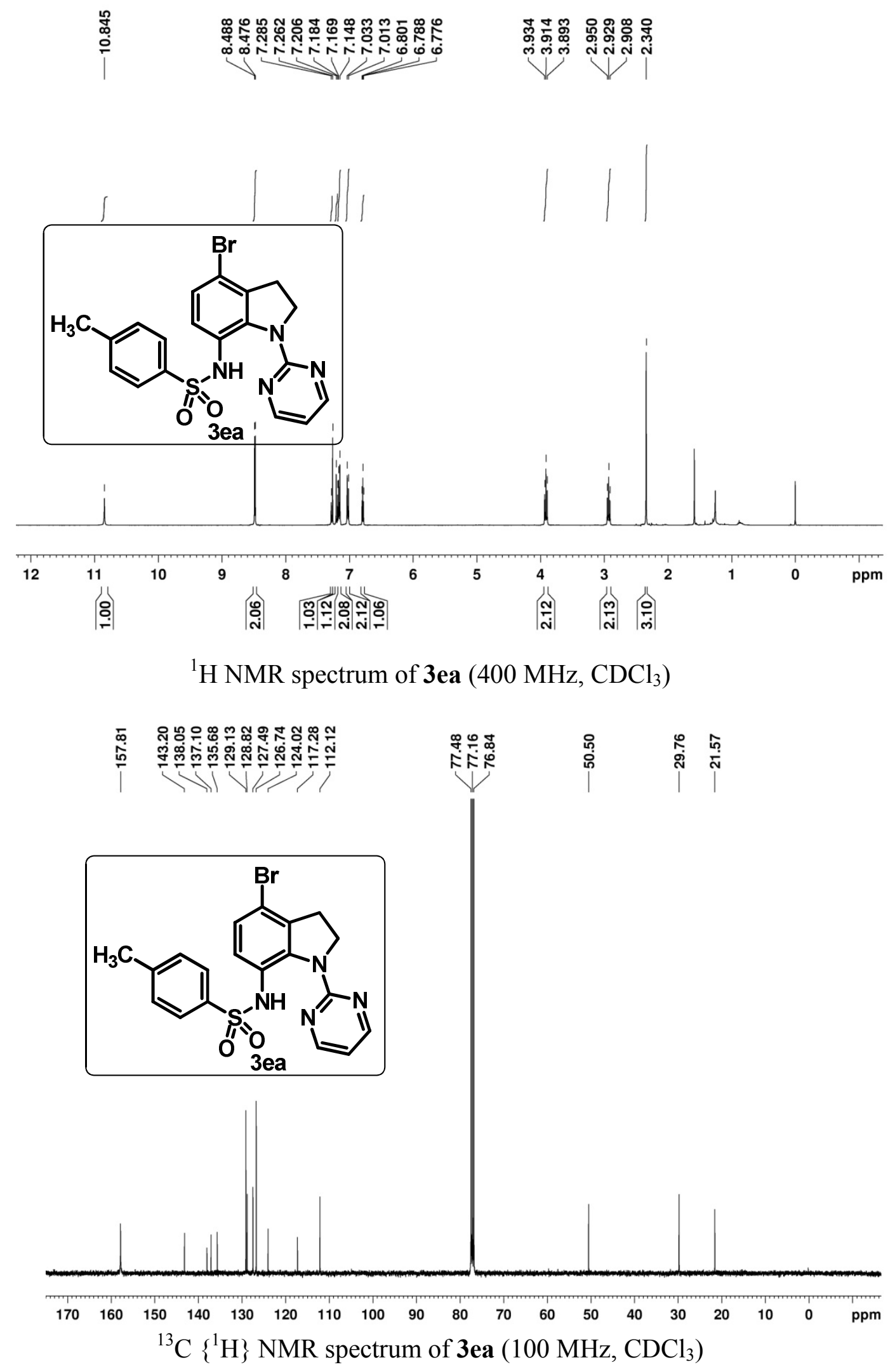

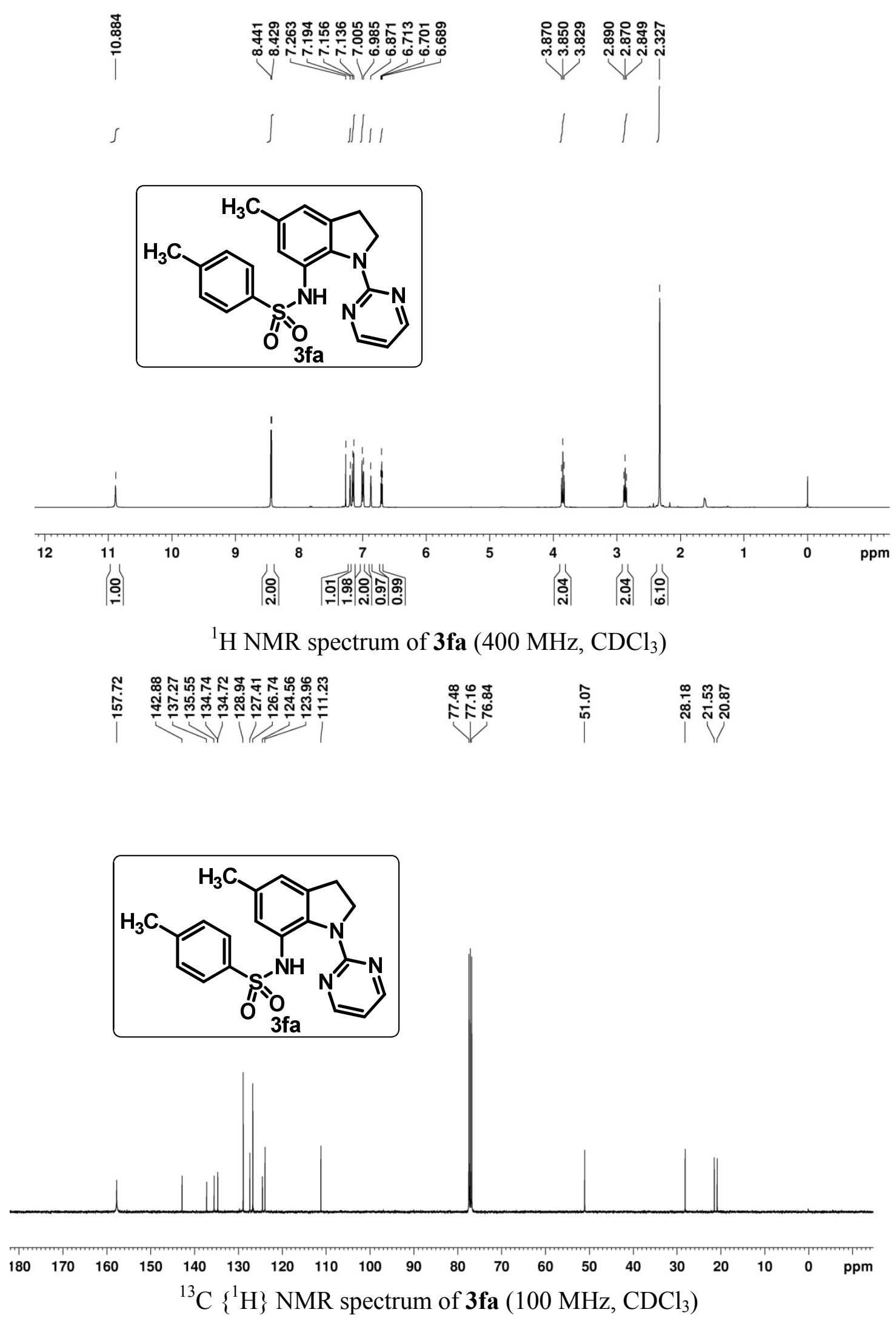


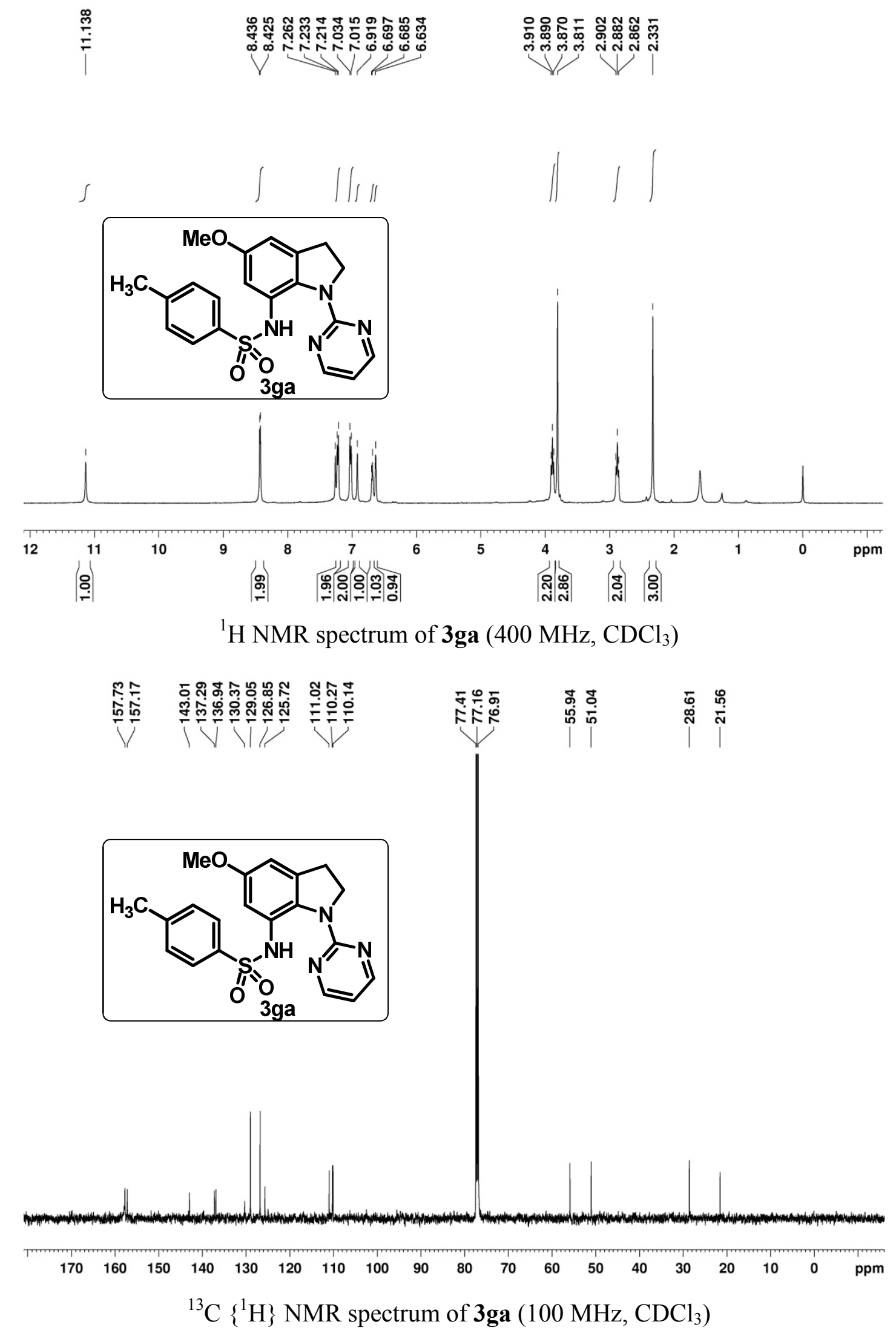



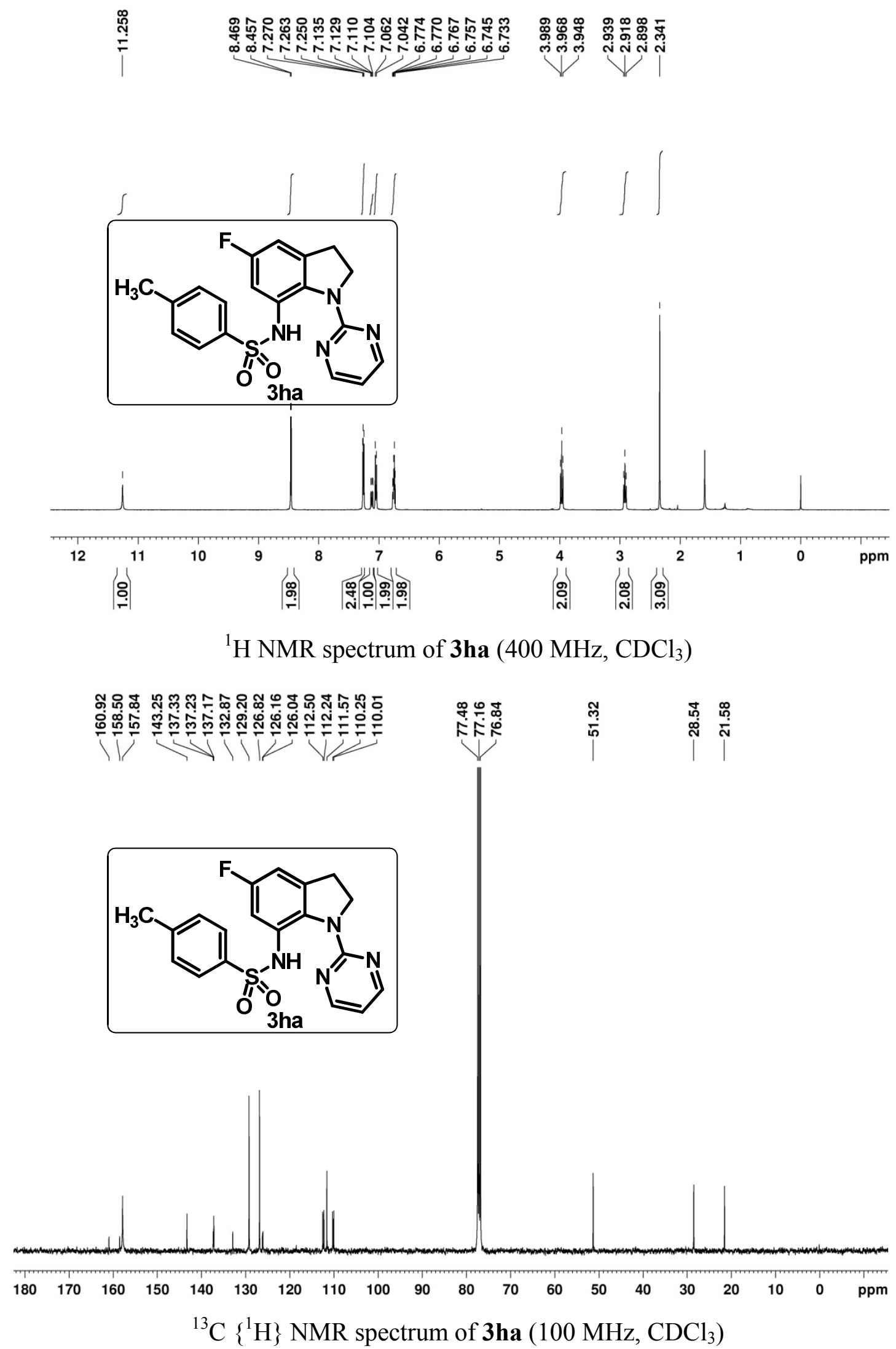


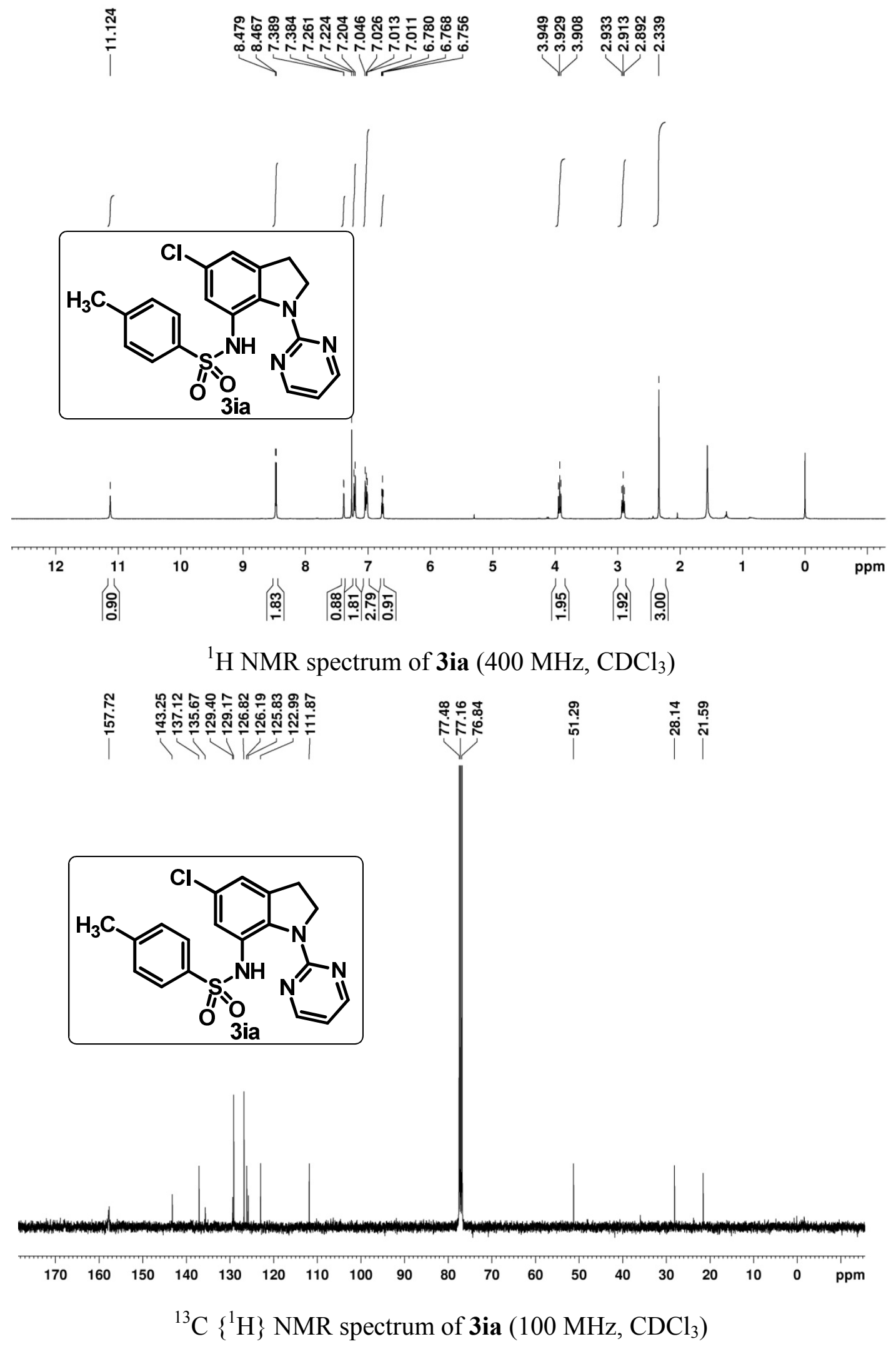



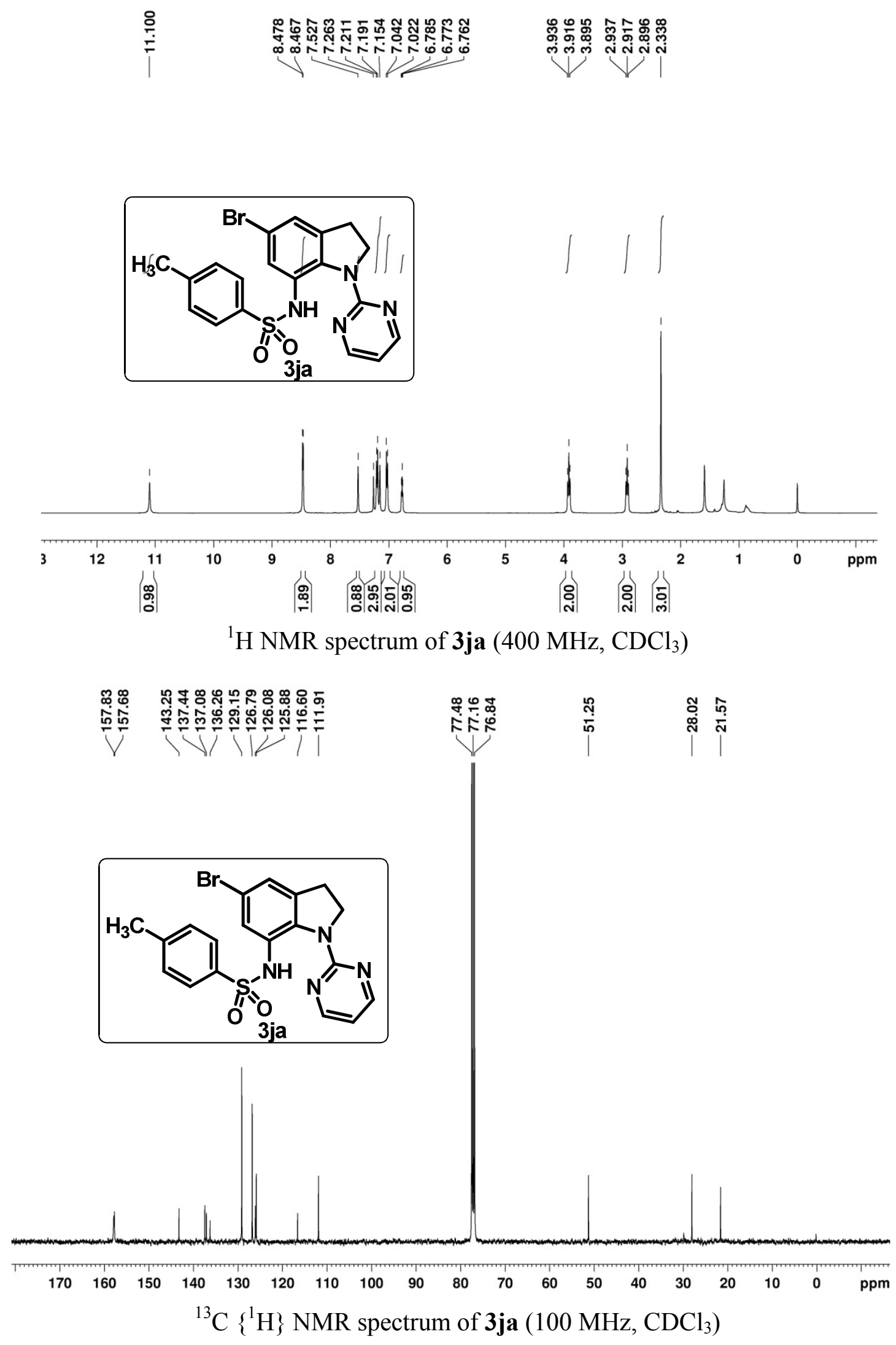

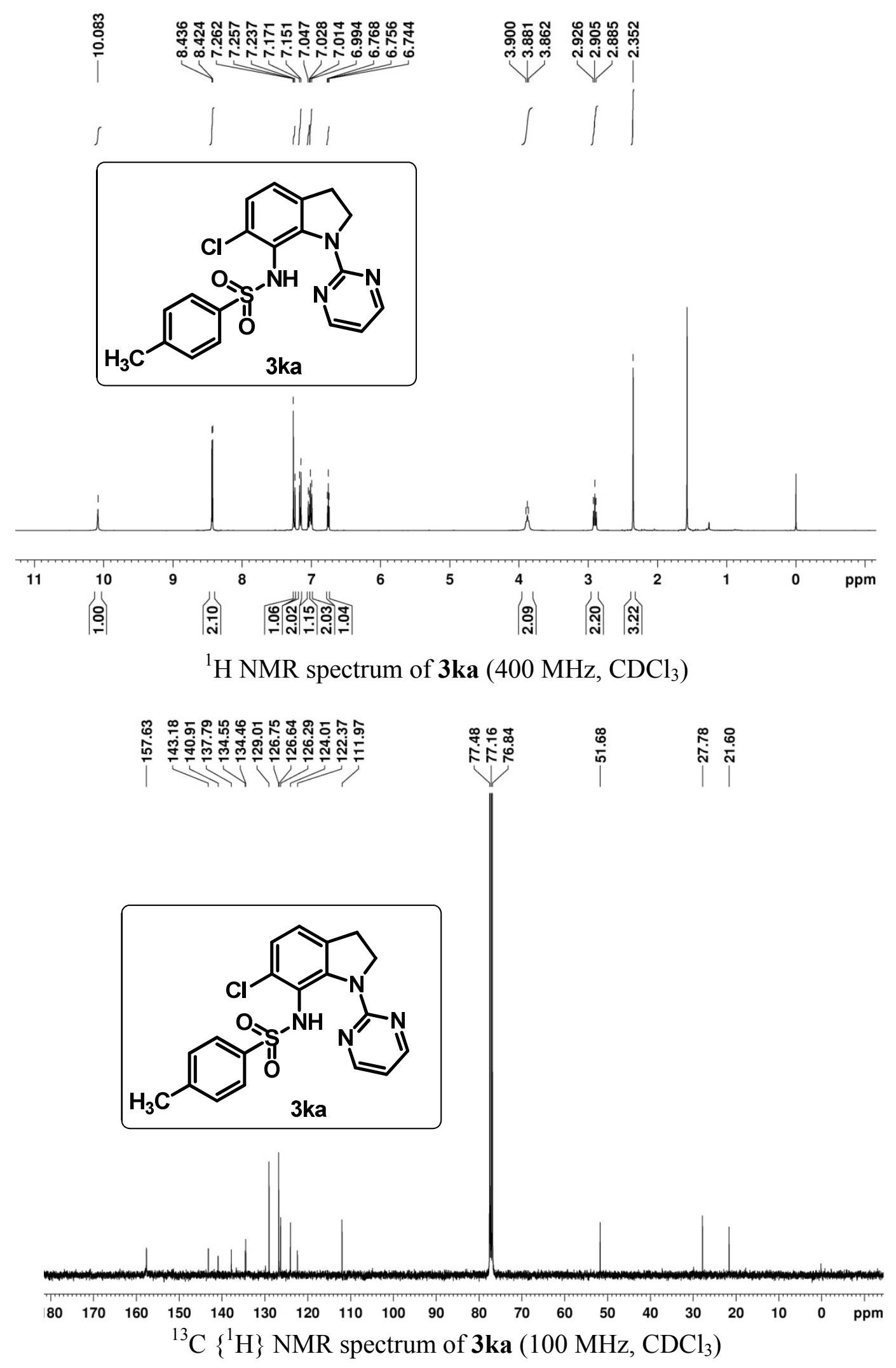


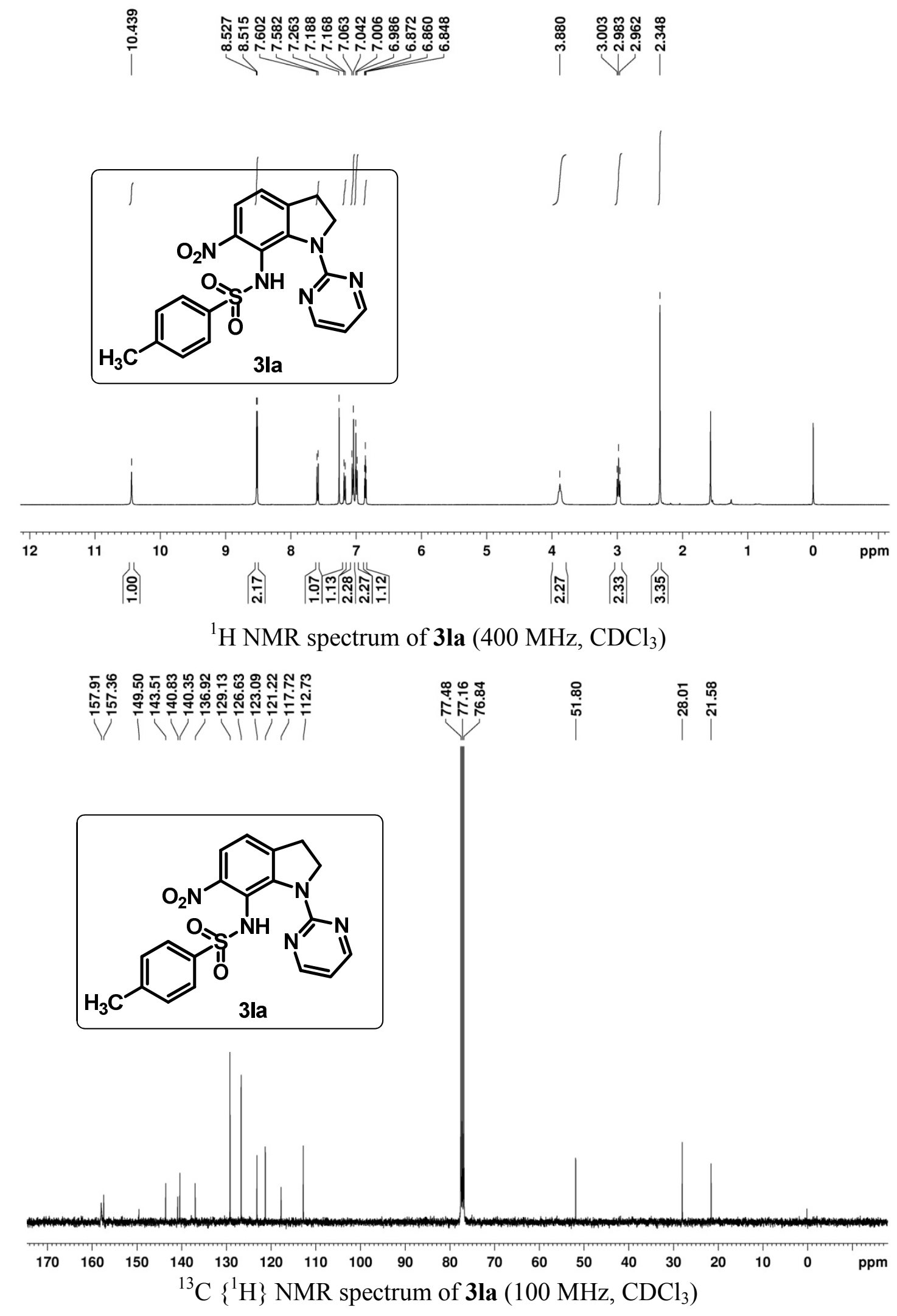




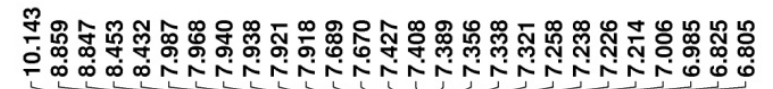

$\frac{8}{4}$
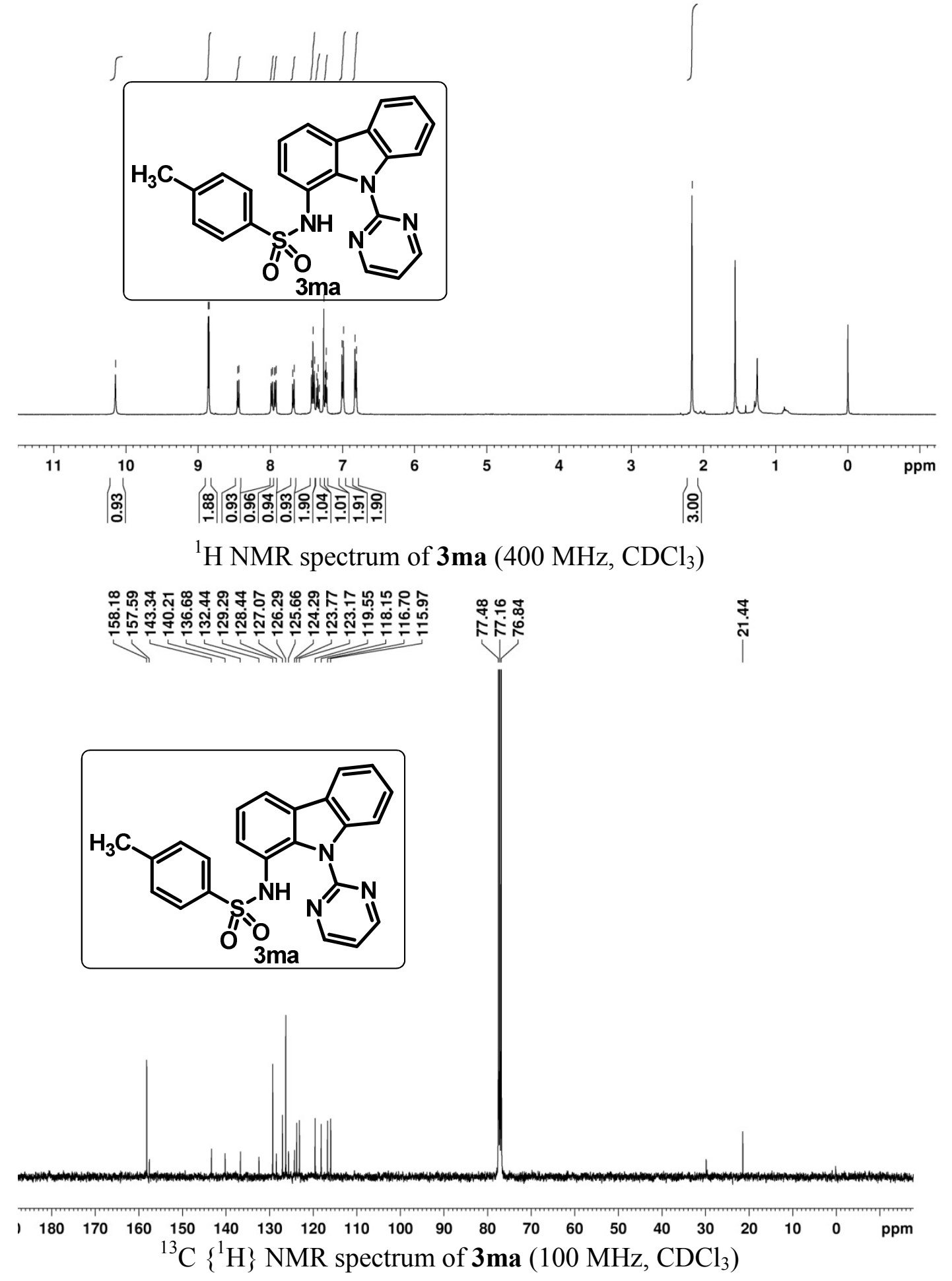

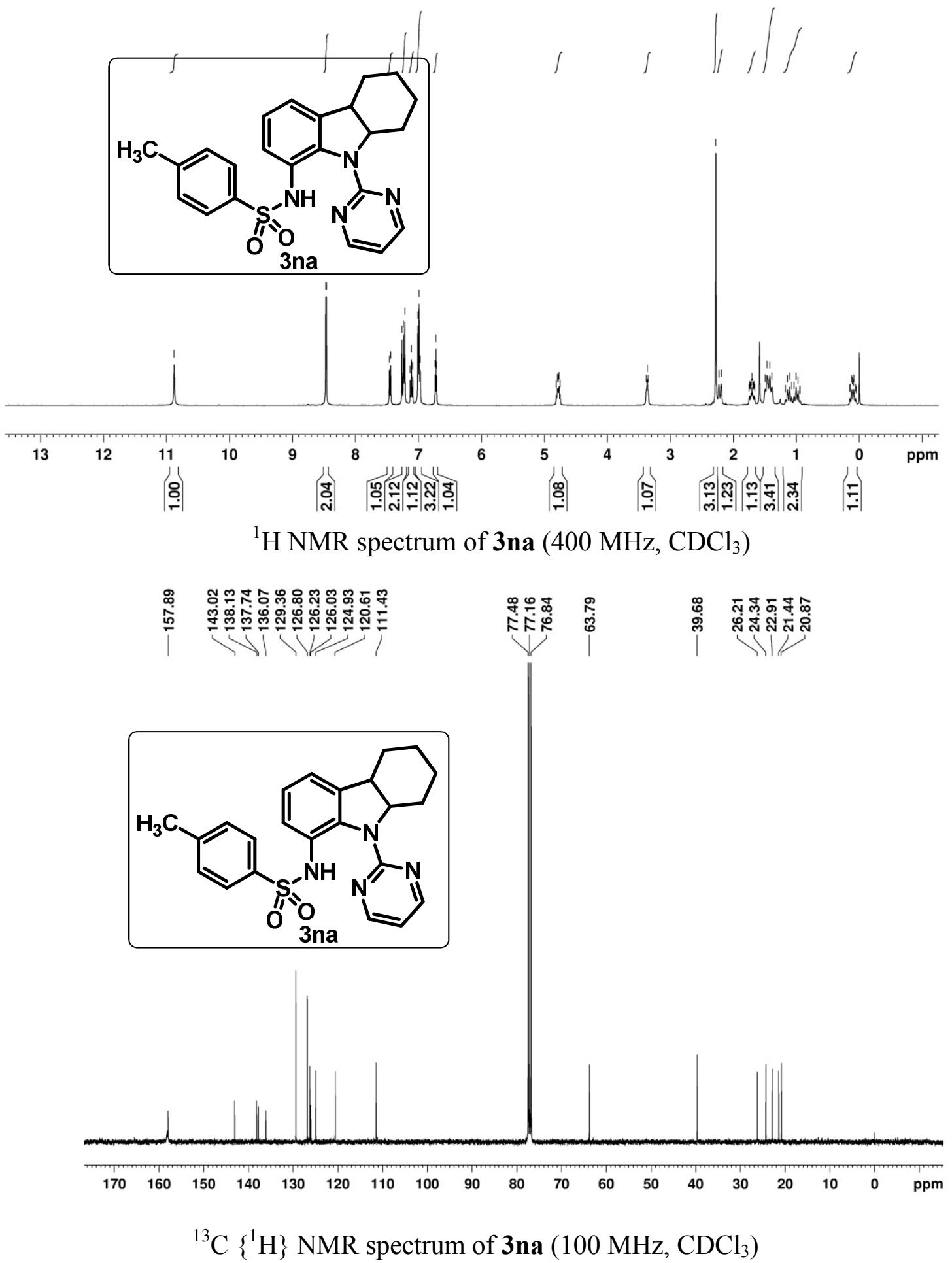


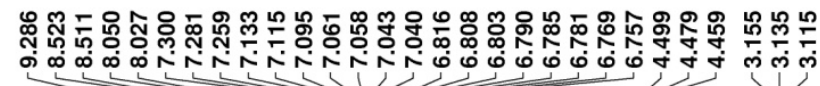
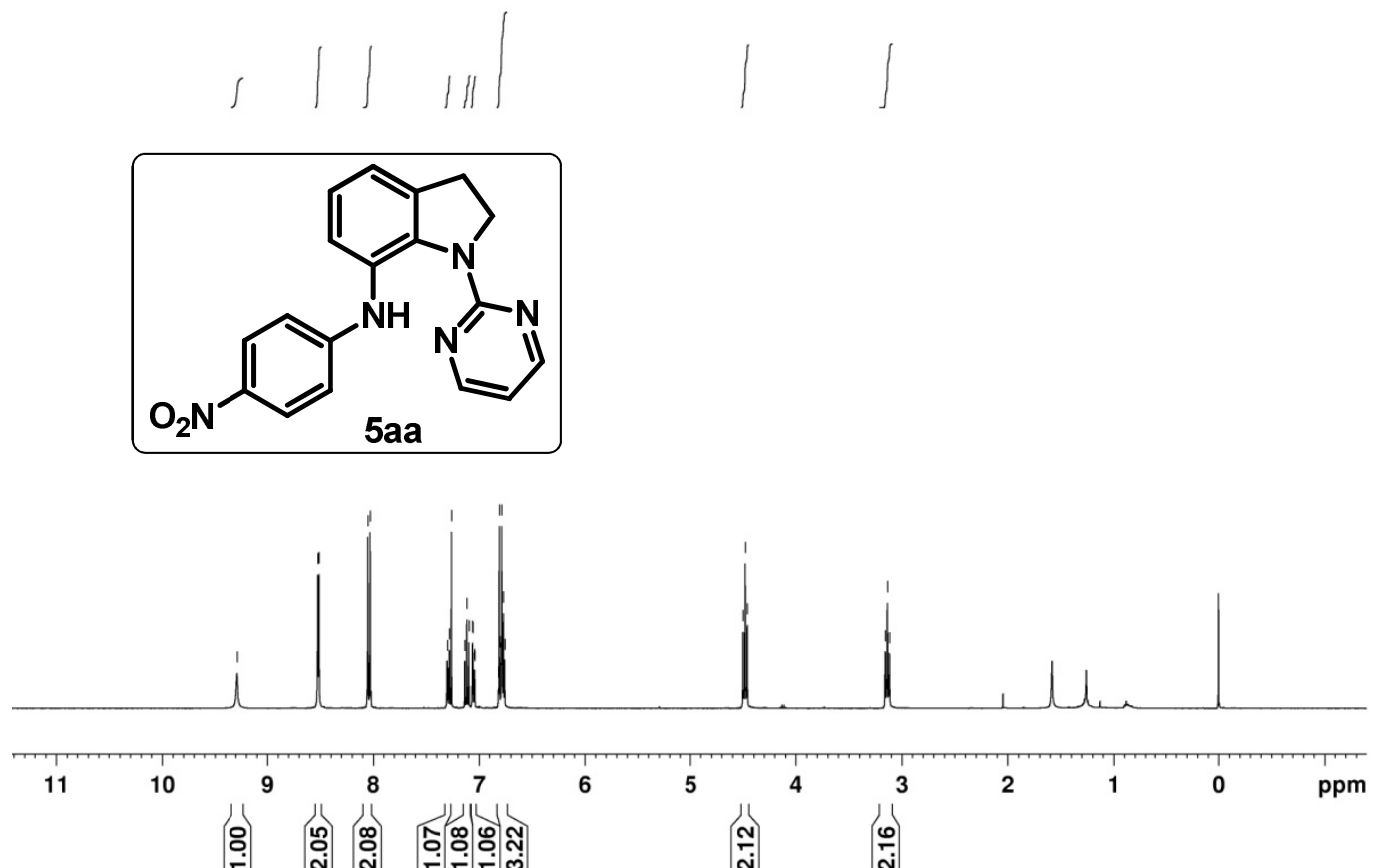

${ }^{1} \mathrm{H}$ NMR spectrum of $\mathbf{5 a a}\left(100 \mathrm{MHz}, \mathrm{CDCl}_{3}\right)$

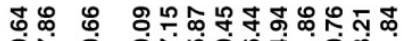

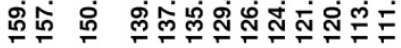

TT YTIT

约
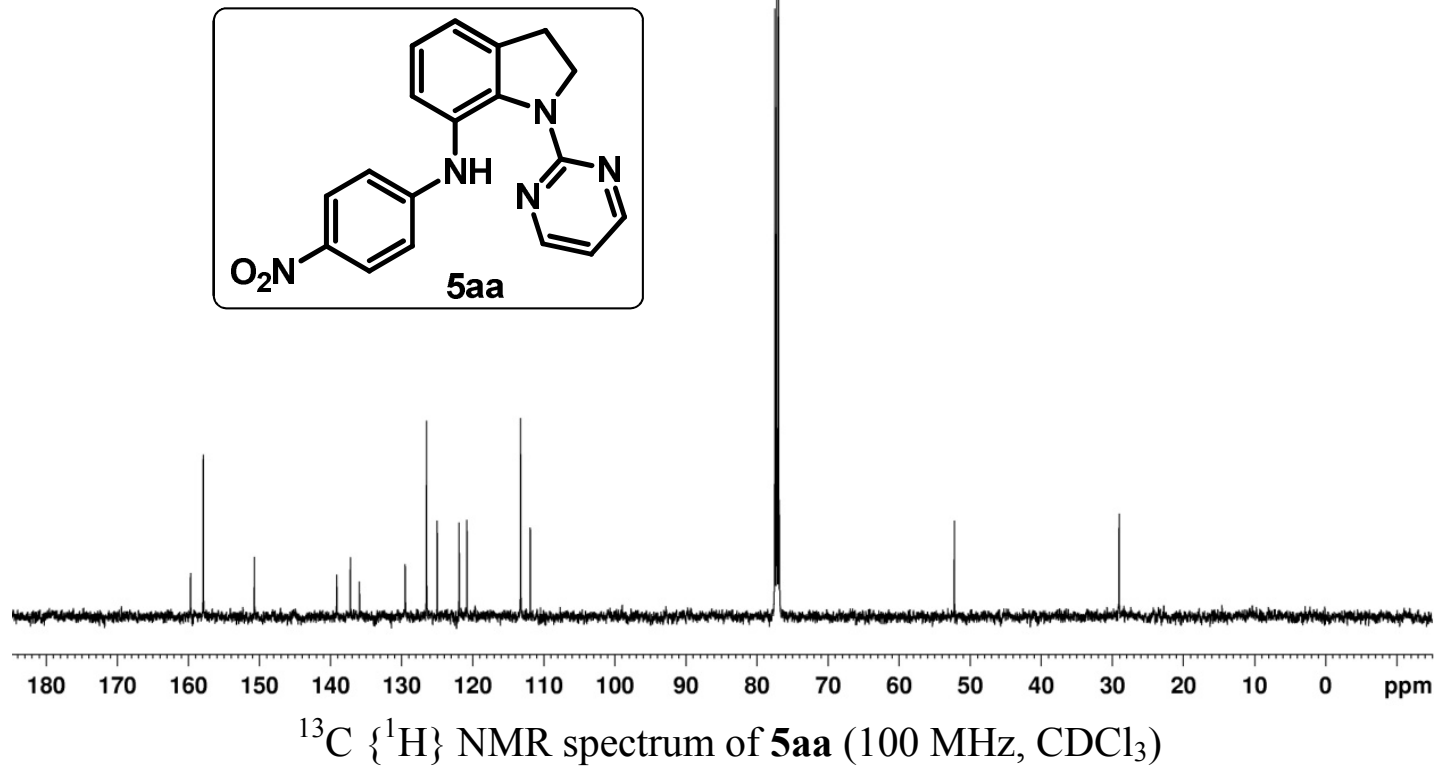


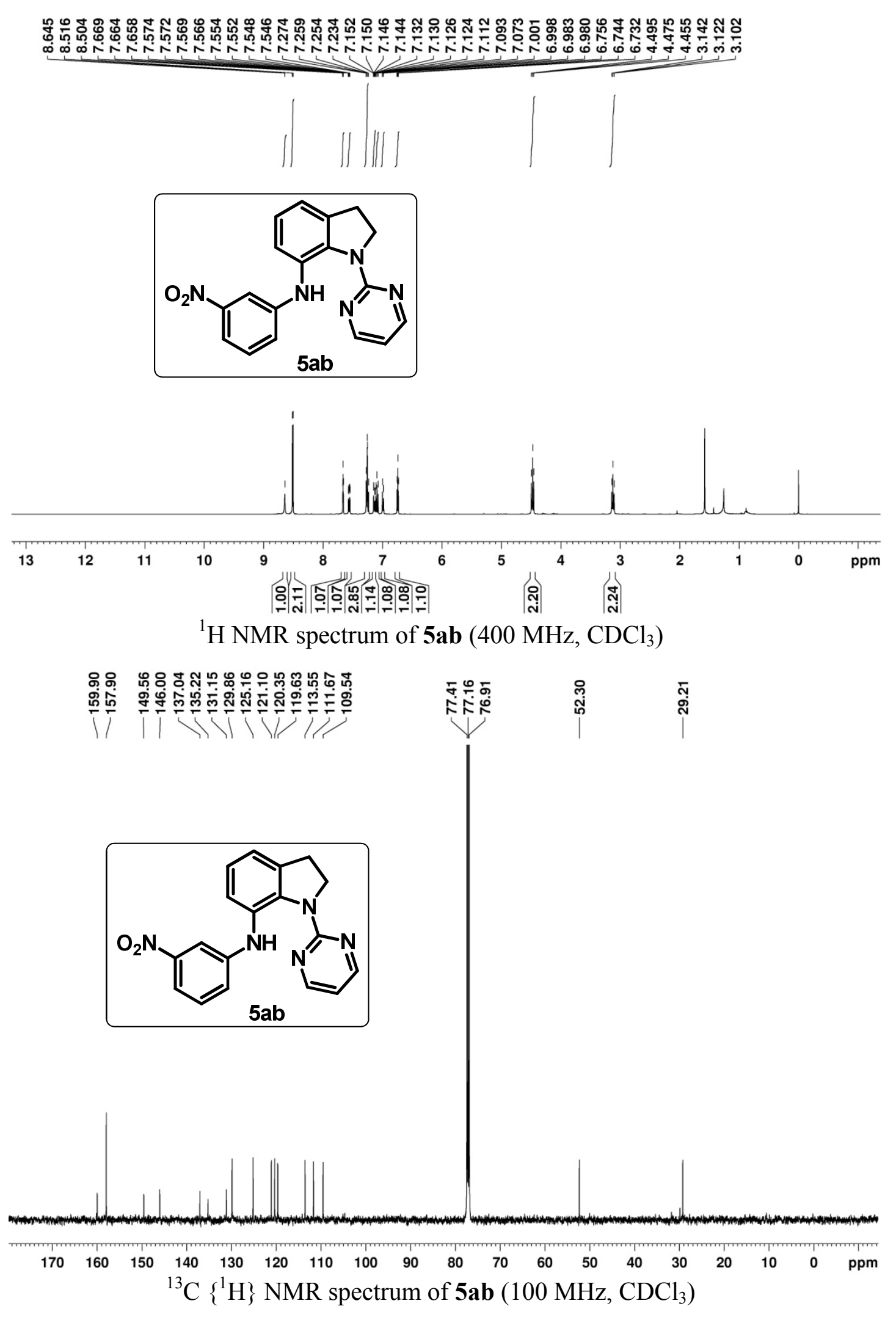




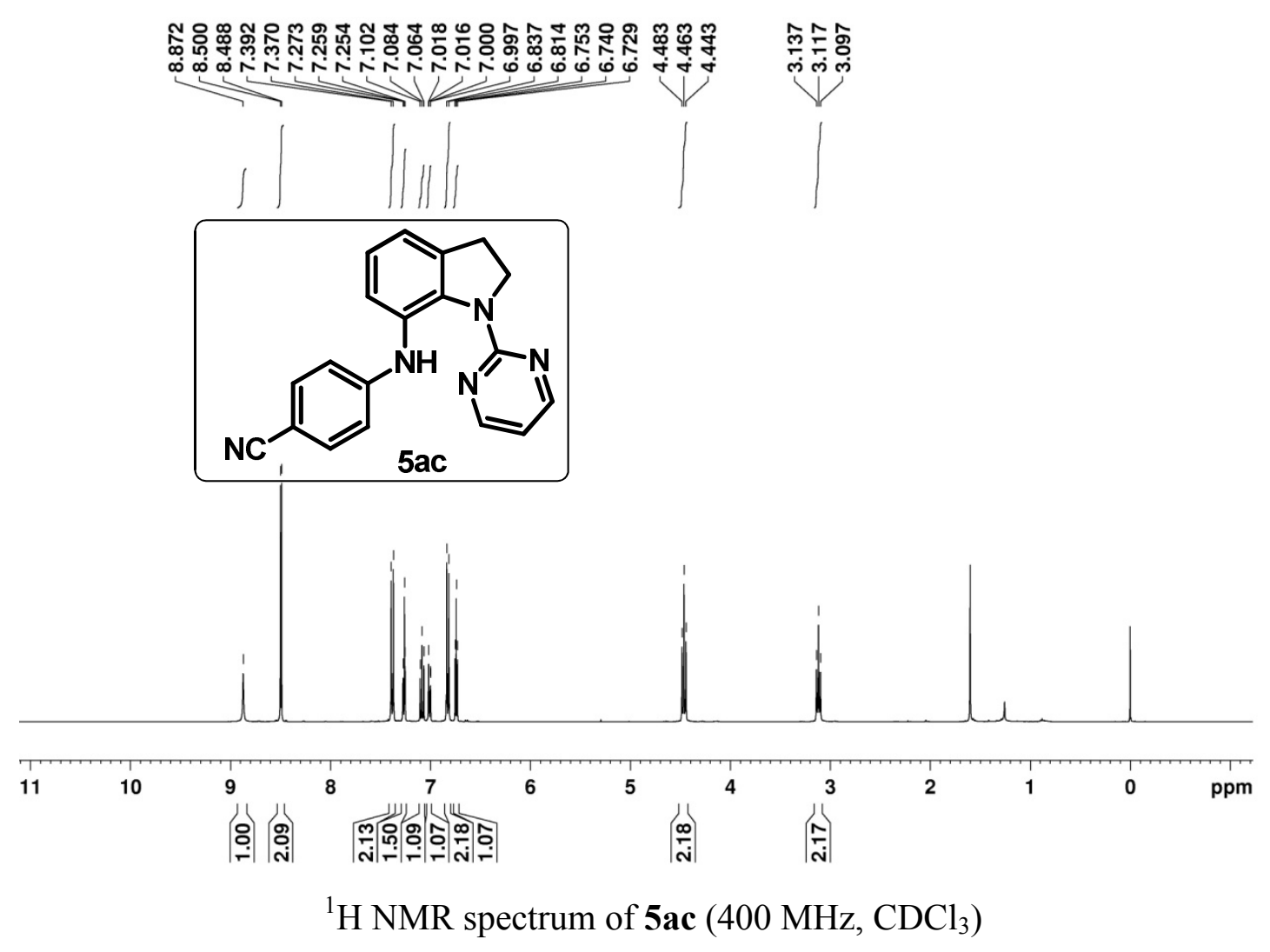

ำ

ชิ

仿

ণับู
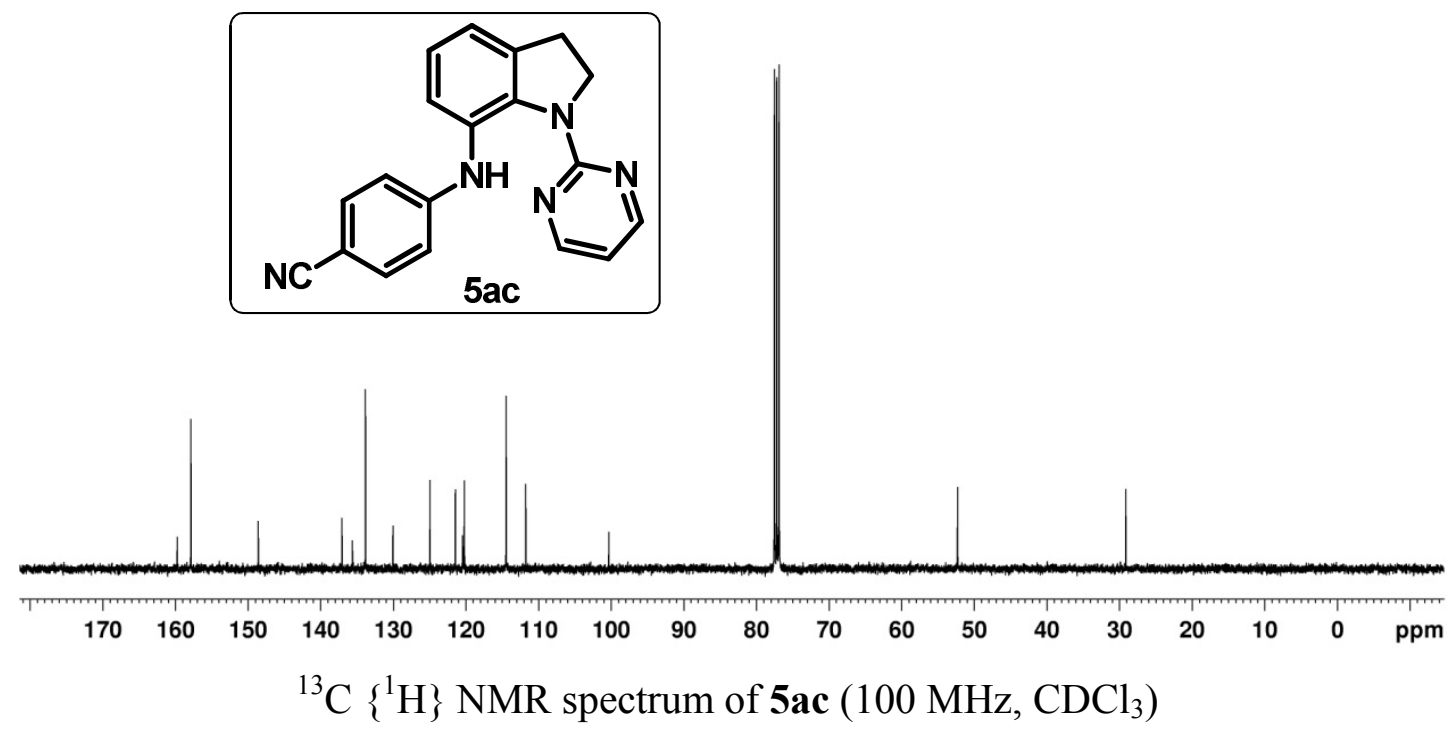


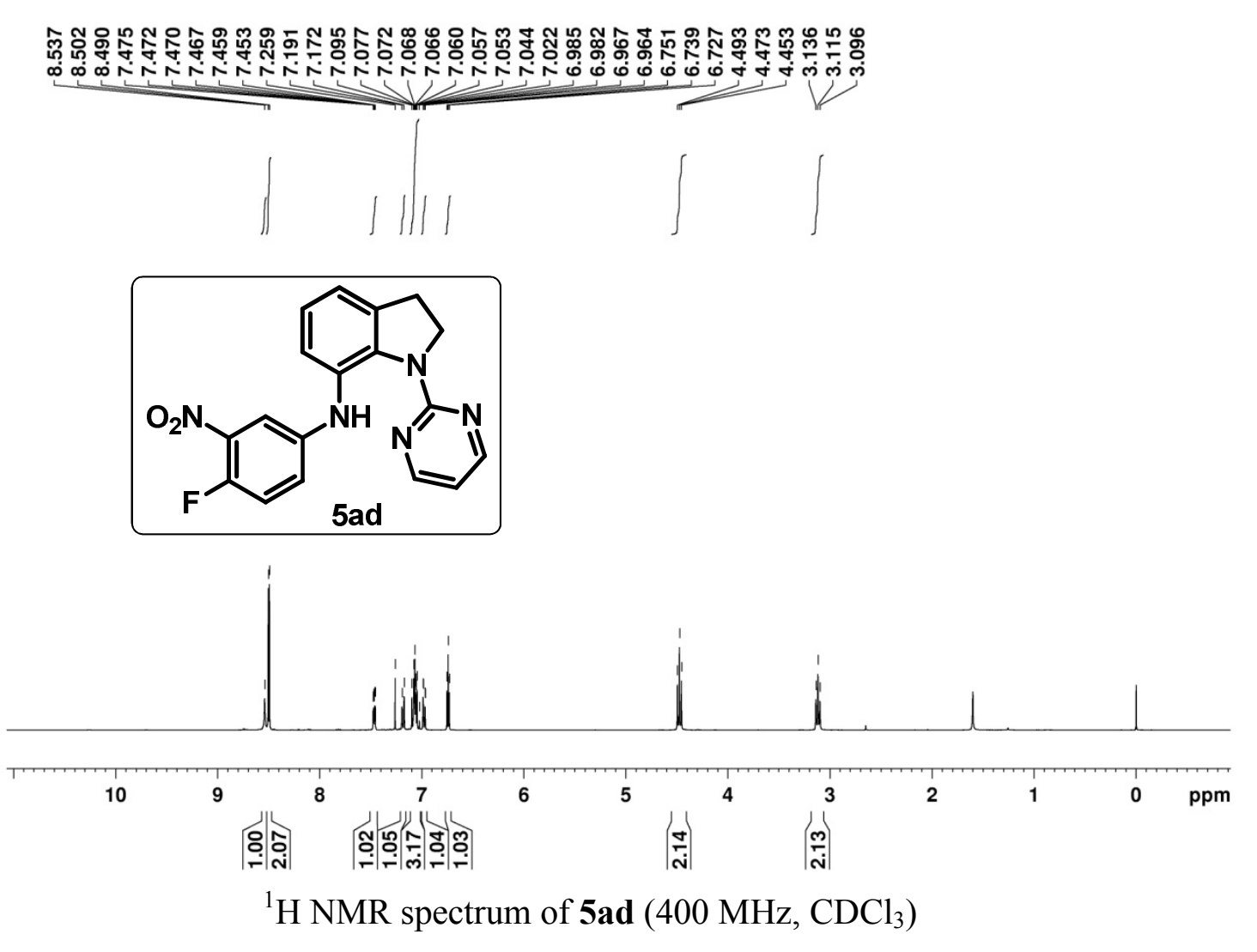

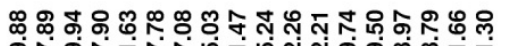

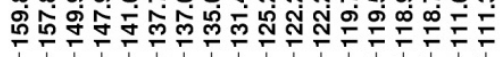

\र

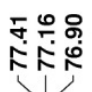

กิ่
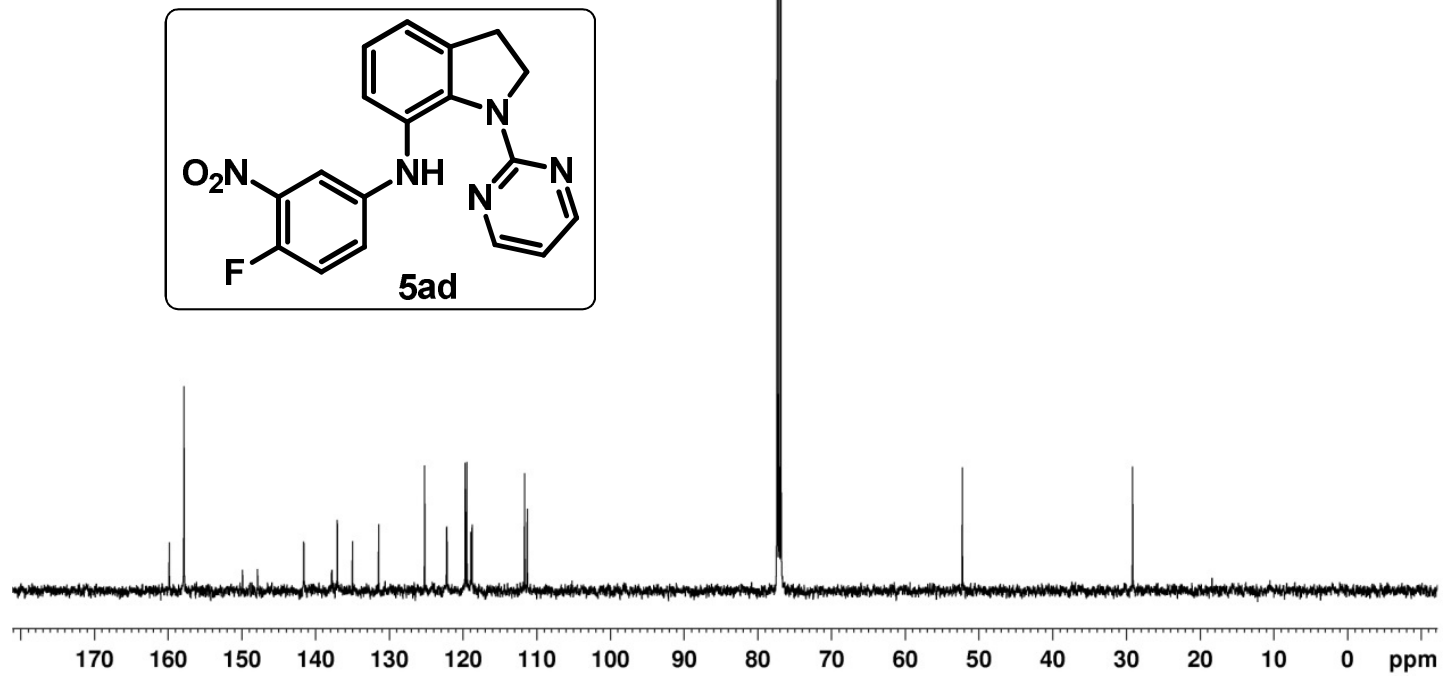

${ }^{13} \mathrm{C}\left\{{ }^{1} \mathrm{H}\right\}$ NMR spectrum of $\mathbf{5 a d}\left(100 \mathrm{MHz}, \mathrm{CDCl}_{3}\right)$ 

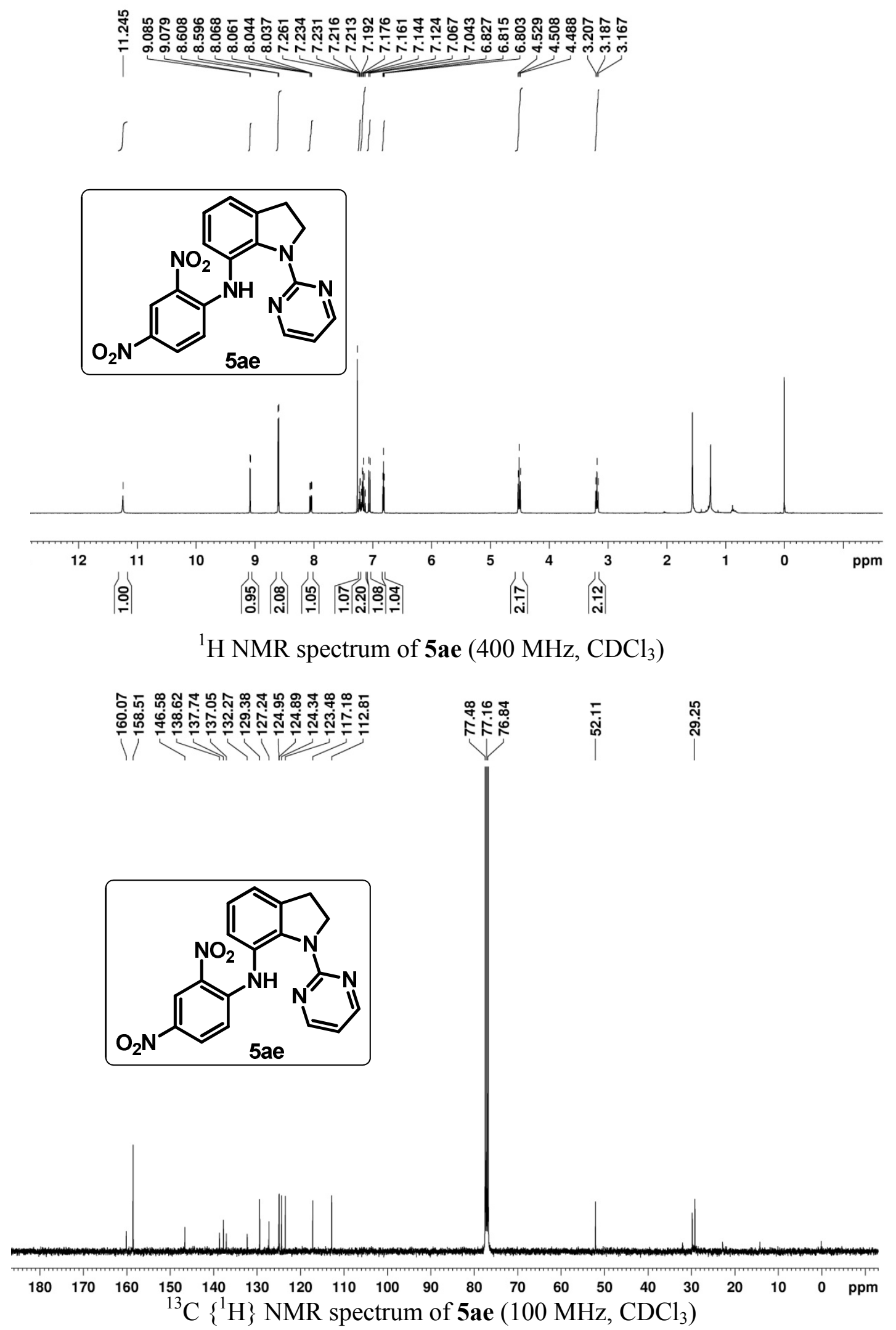

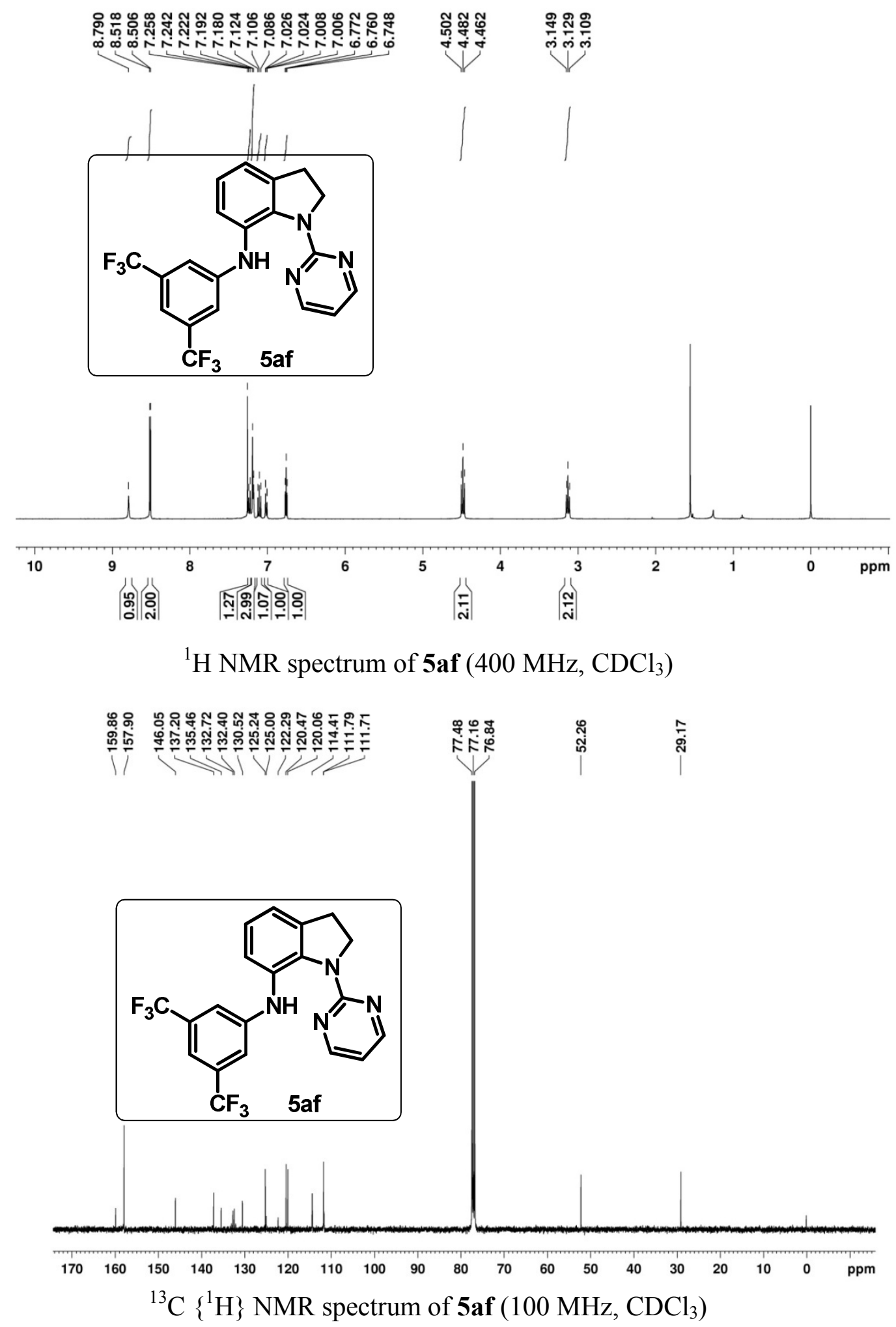

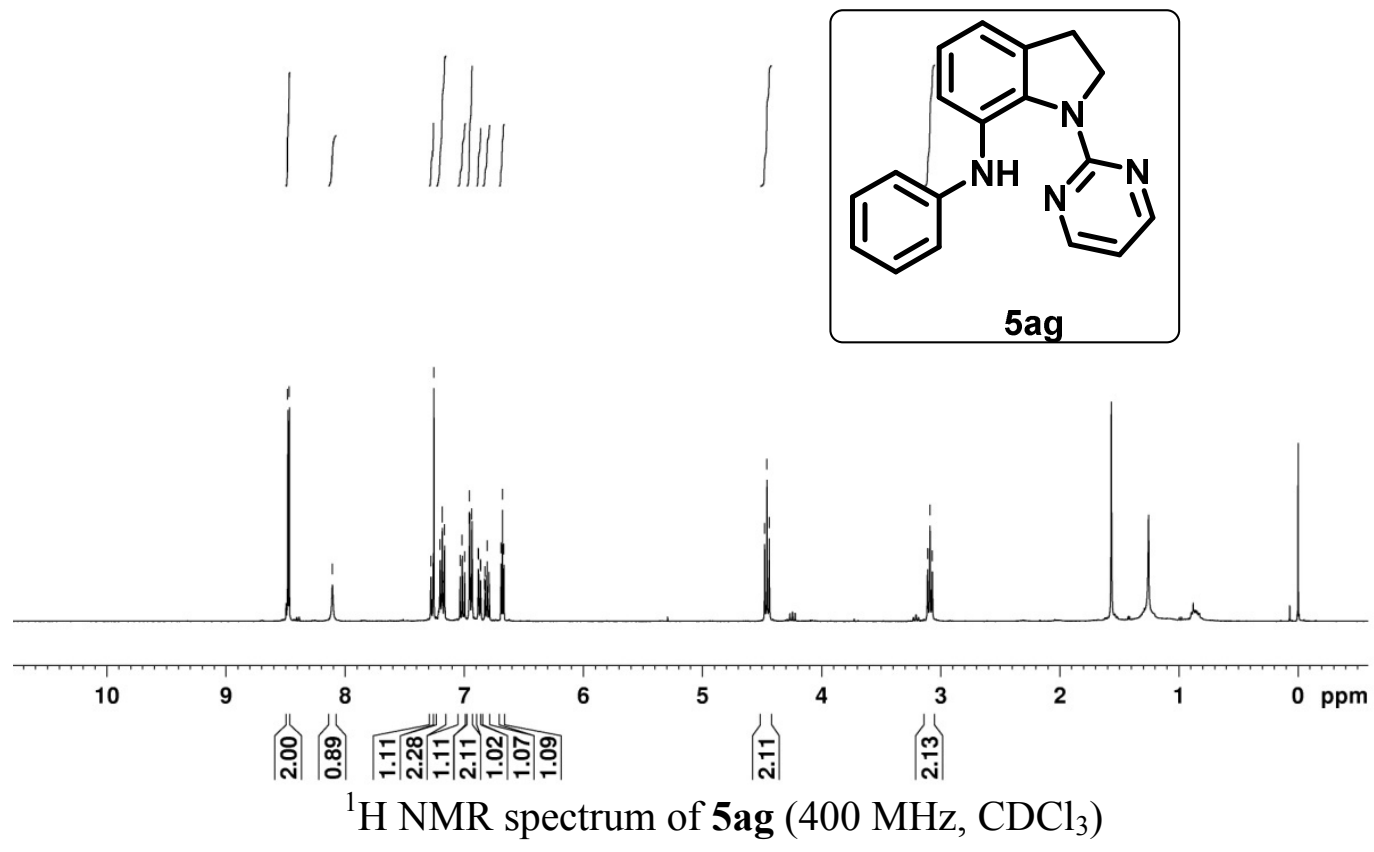

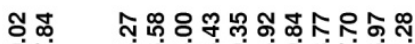

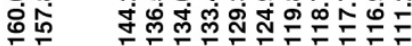
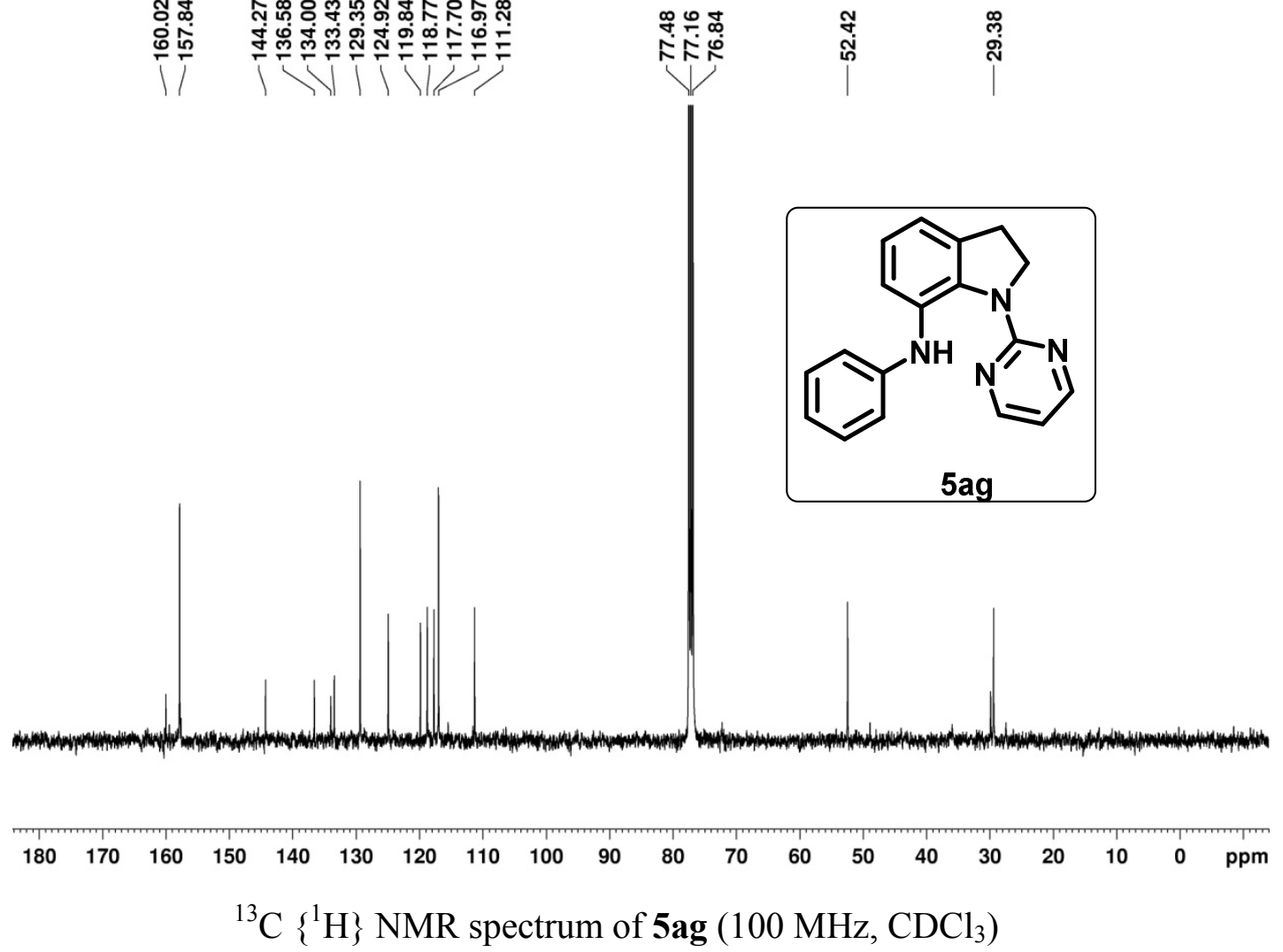

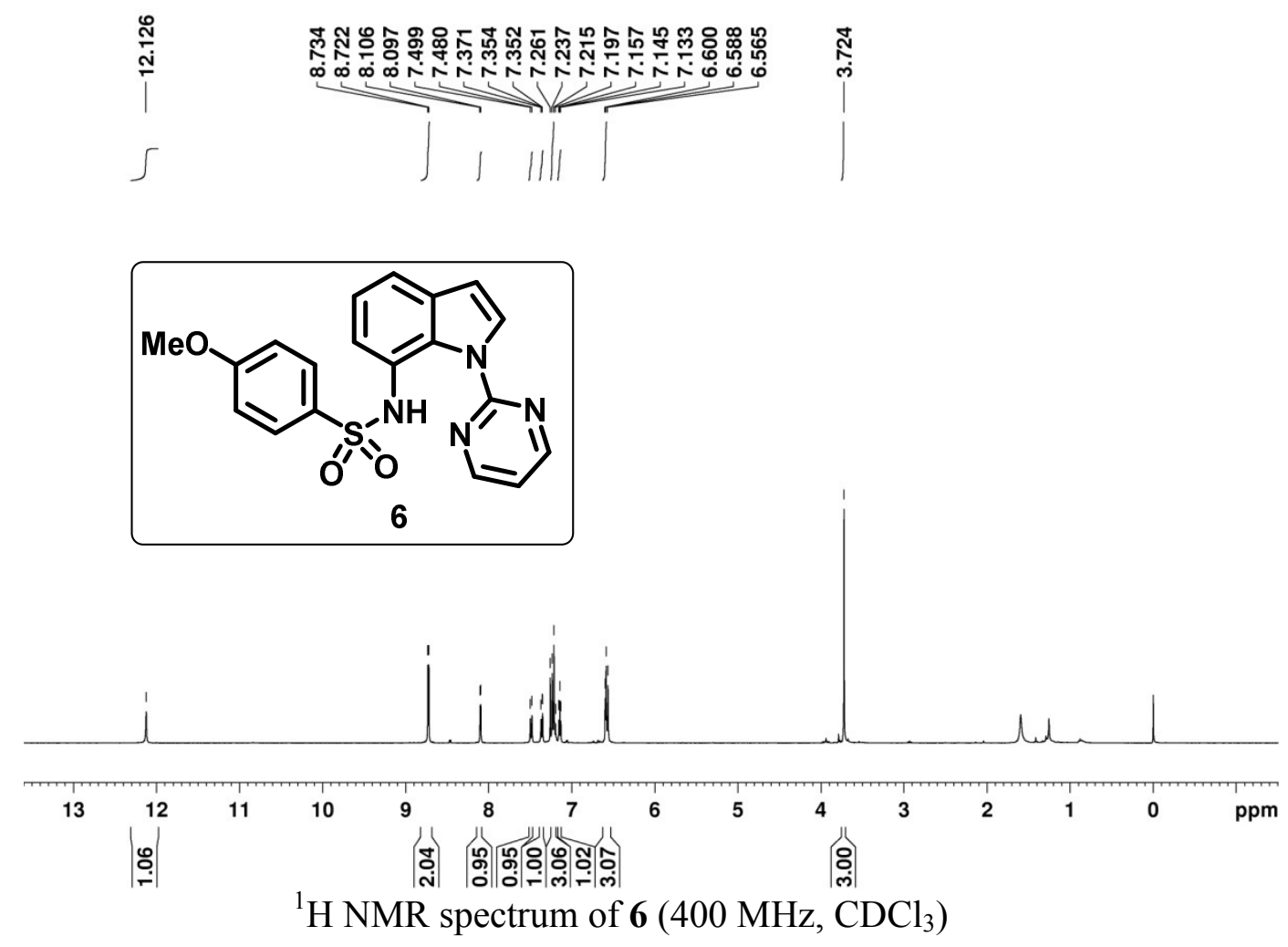

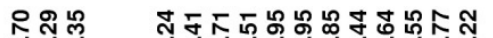
ง Ti
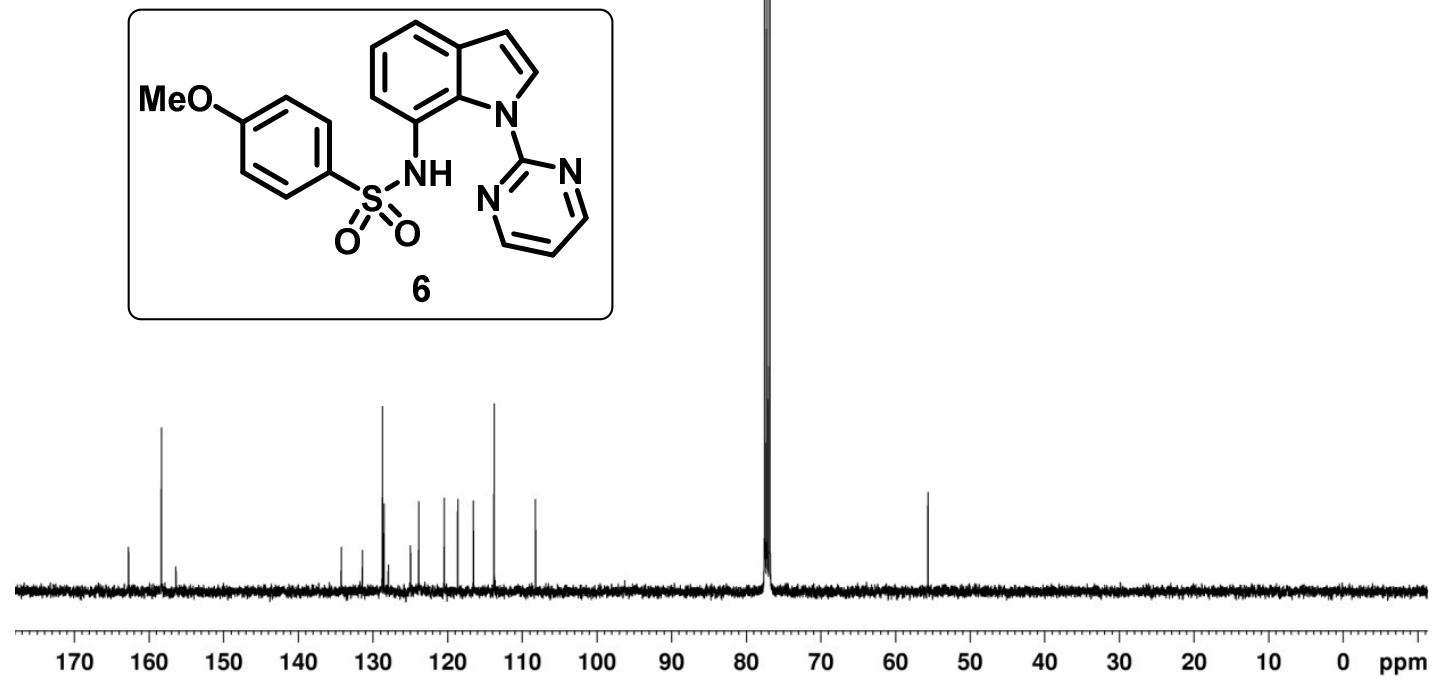

${ }^{13} \mathrm{C}\left\{{ }^{1} \mathrm{H}\right\}$ NMR spectrum of $6\left(100 \mathrm{MHz}, \mathrm{CDCl}_{3}\right)$ 


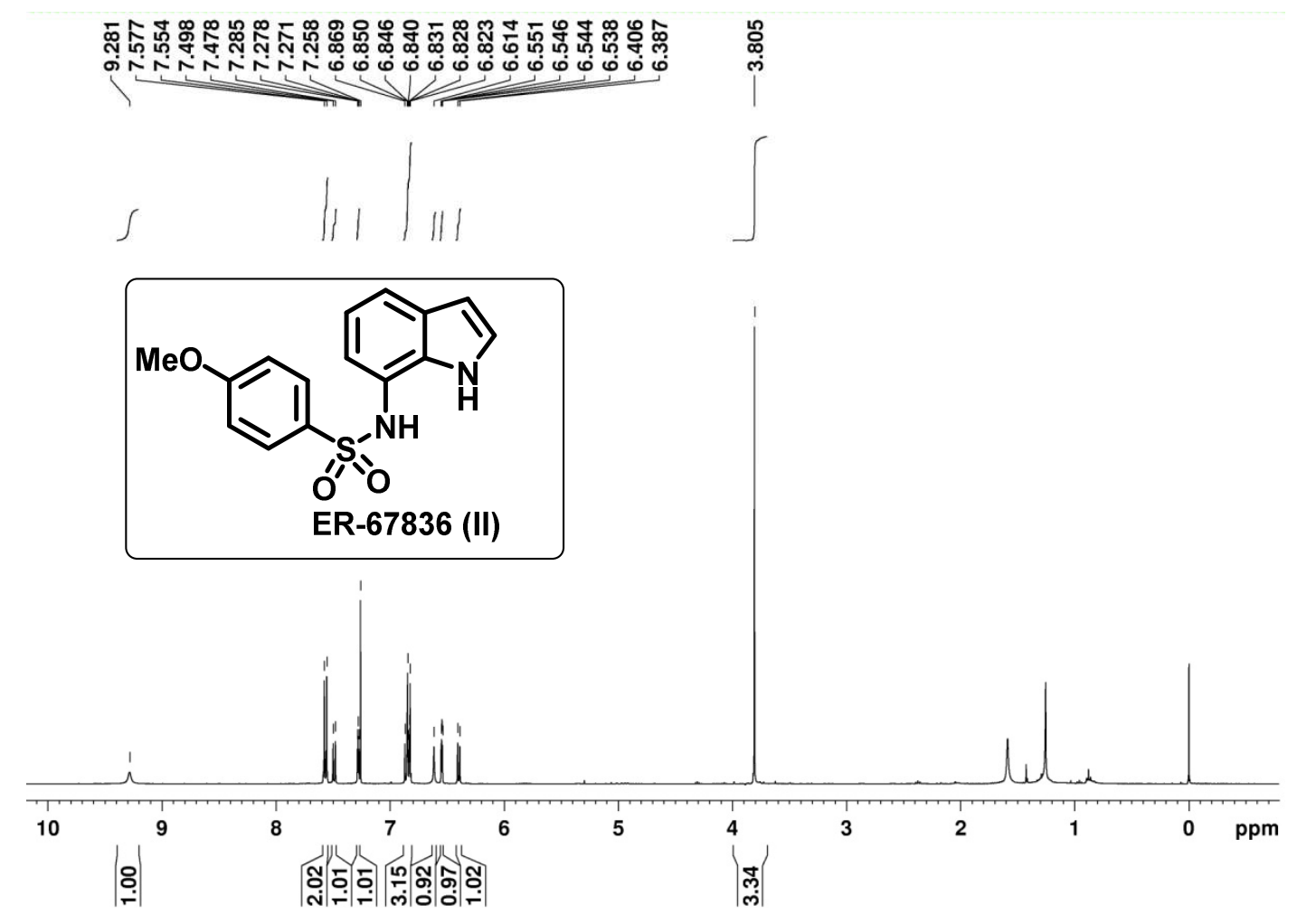

${ }^{1} \mathrm{H}$ NMR spectrum of ER-67836 (II) (400 MHz, $\mathrm{CDCl}_{3}$ )
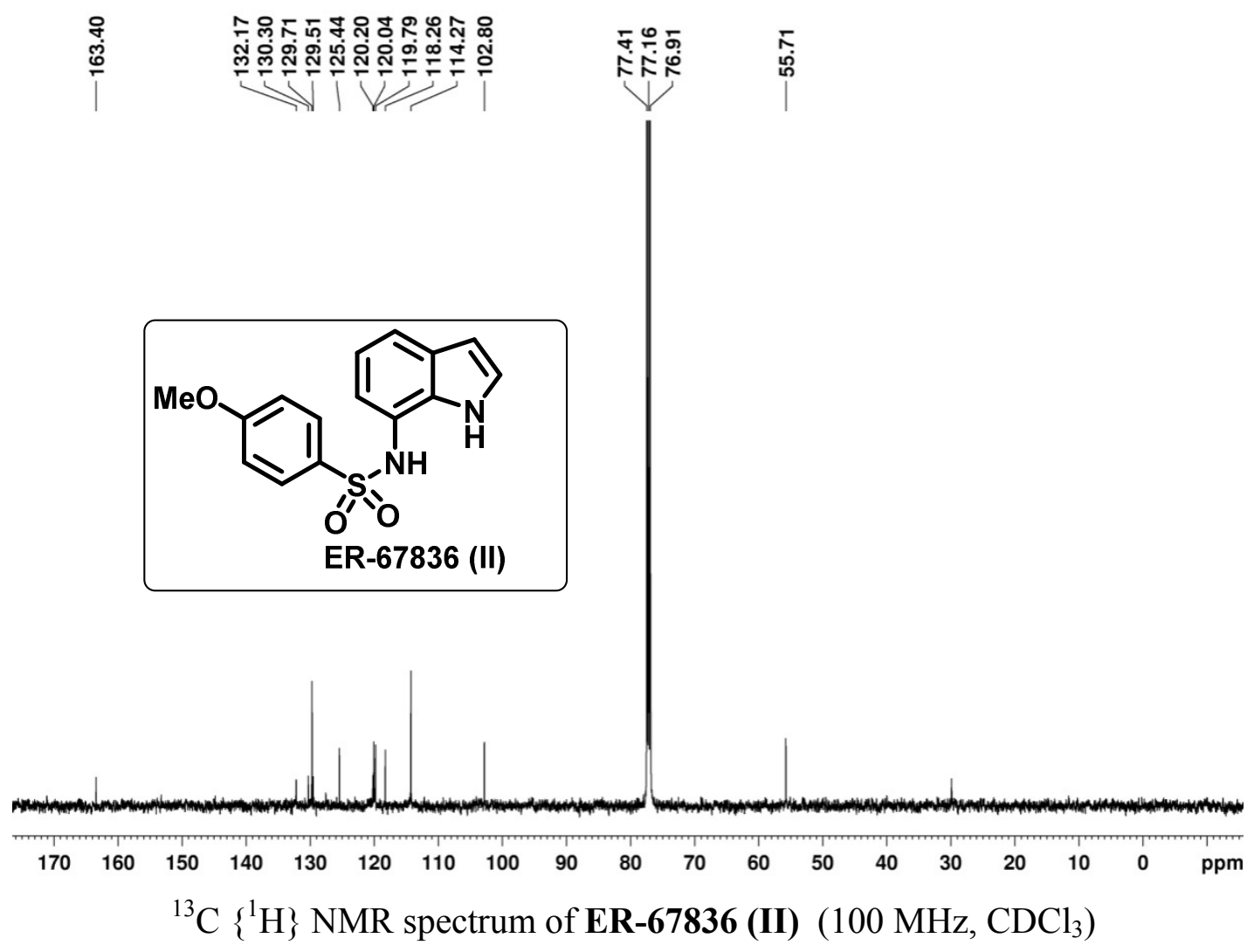